\title{
AN ANALYSIS OF SCHEMA THEORY AND LEARNING THEORY AS \\ EXPLANATIONS FOR VARIANCE IN ADOLESCENT ADJUSTMENT TO DIVORCE
}

NICHOLA MARIANNE WATSON

Thesis presented in fulfilment of the requirements for the degree of

Master of Arts (Psychology) at the

University of Stellenbosch

Supervisor: A P Greeff $\mathrm{PhD}$

March 2003 


\section{STATEMENT}

I, the undersigned, hereby declare that the work contained in this thesis consists of my own original work, and that I have not previously in its entirety or in part submitted it at any university for a degree.

Signature

Date 


\section{SUMMARY}

The primary aim of this study was to identify factors contributing to the adjustment of adolescents whose parents are divorced. Learning theory and schema theory were evaluated as possible explanations for the variance found in the adjustment of these adolescents. The secondary aim of the study was to research the possibility of attitude to divorce acting as a mediator between the parent-adolescent relationship and adolescent adjustment (a possibility suggested by schema theory). Self-report questionnaires were completed by first year Psychology and Economics students at Stellenbosch University. 293 students completed the questionnaires, but as only 39 of these students came from divorced families, 38 of the data sets from students with married parents were randomly selected for use in the study. Respondents completed Antonovsky's Life Orientation Questionnaire (measuring adjustment); Hudson's CAM and CAF questionnaires (measuring relationships with mother and father, respectively); and a set of questions measuring attitude to divorce; as well as a biographical questionnaire. The results showed only limited evidence for attitude to divorce acting as a mediator between the parent-adolescent relationship and adolescent adjustment. Schema theory is therefore not supported conclusively, although further research is recommended. Results did, however, support learning theory as an adequate explanation for the positive correlations found between parent-adolescent relationships and adolescent adjustment. Knowledge of the importance of learning theory in explaining adolescent adjustment can increase parents' awareness of their influence on their children's adjustment. This knowledge can also be used in the design of therapeutic programmes for families going through divorce. 


\section{OPSOMMING}

Die hoofdoelstelling van hierdie ondersoek was om faktore te indentifiseer wat bydra tot die aanpassing van adolessente wie se ouers geskei is. Leerteorie en skemateorie is geëvalueer as moontlike verklarings vir die variansie in die aanpassing van dié adolessente. 'n Sekondêre doel was om die moontlikheid te ondersoek dat die adolessent se houding teenoor egskeiding ' $\mathrm{n}$ rol kan speel in die ouer-adolessent verhouding en die aanpassing van die adolessent (dié moontlikheid volg uit skemateorie). Selfrapporteringsvraelyste is deur onderskeidelik eerstejaar studente in Sielkunde en Ekonomie aan die Universiteit van Stellenbosch voltooi. 293 studente het die vraelyste voltooi, maar omdat net 39 van hierdie studente uit geskeide gesinne gekom het, is 38 studente met getroude ouers in die ondersoek ingesluit. Studente het Antonovsky se Lewensorientasievraelys (wat aanpassing meet); Hudson se CAM en CAF-vraelyste (wat verhoudings met die ma en pa meet); en ' $n$ stel vrae wat houding teenoor egskeiding meet; sowel as ' $n$ biografiese vraelys voltooi. Beperkte bewys is gevind vir die moontlikheid dat houding teenoor egskeiding bemiddelend optree tussen die oueradolessent verhouding en die aanpassing van die adolessent. Skemateorie kon gevolglik nie bewys word nie, alhoewel verdere ondersoeke aanbeveel word. Die resultate ondersteun leerteorie as ' $\mathrm{n}$ goeie verduideliking vir die positiewe korrelasie wat bestaan tussen ouer-adolessent verhouding en die adolessent se aanpassing. Kennis van die belangrikheid van leerteorie as verduideliking vir die aanpassing van adolessente beklemtoon die belangrike invloed wat die ouers se aanpassing op hul kinders se aanpassing het. Die kennis kan ook gebruik word in die ontwerp van terapeutiese programme vir gesinne wat egskeiding beleef. 


\section{ACKNOWLEDGEMENTS}

I would like to express my gratitude and appreciation to:

Dr A.P. Greeff for his support, help and encouragement,

Dr M. Kidd for his guidance and work on the statistical analysis of the data,

Mrs H. Loxton and Mrs P. Horne for their assistance in accessing participants for this study,

Bertie Hanekom and Saboga Nunes for, respectively, granting permission to use the $\mathrm{CAM} / \mathrm{CAF}$ and SOC (Life Orientation Questionnaire) scales for the purposes of this study,

My father, Mr J.A. Watson, for the challenges, discussions and mutual support in our simultaneous writing of our theses,

My mother, Mrs C. Watson, for her emotional support and listening ear,

My brother, Damian, for his encouragement, and for proofreading my thesis and

My husband, Stephen, for his unerring confidence in me.

"With God all things are possible" - I know that without His help I would not have been able to complete this task! 


\section{CONTENTS}

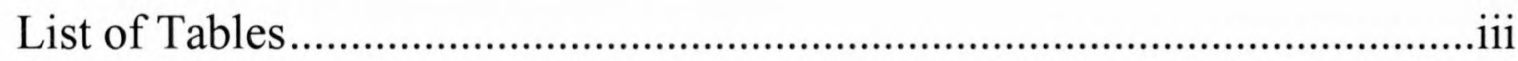

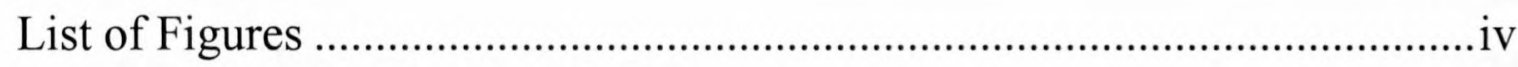

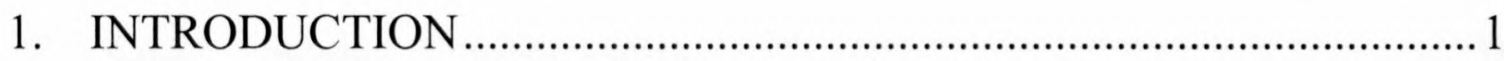

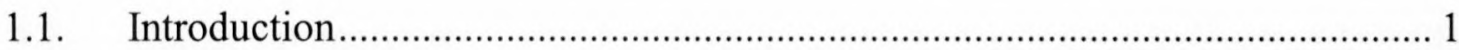

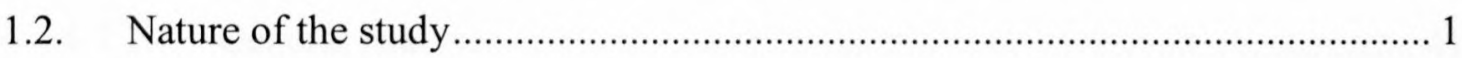

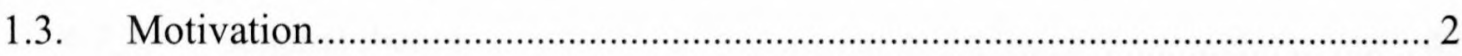

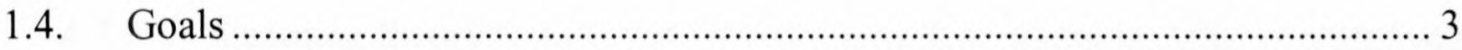

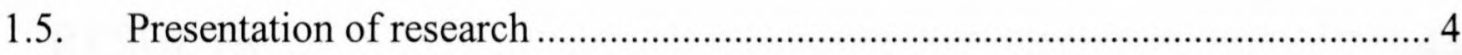

2. THEORETICAL BACKGROUND ….................................................. 5

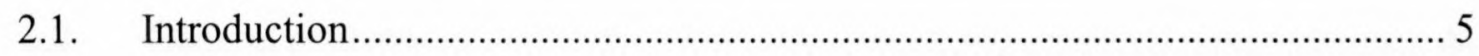

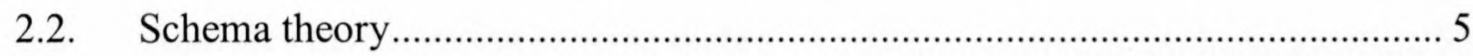

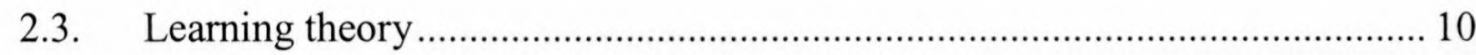

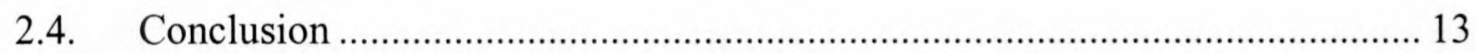

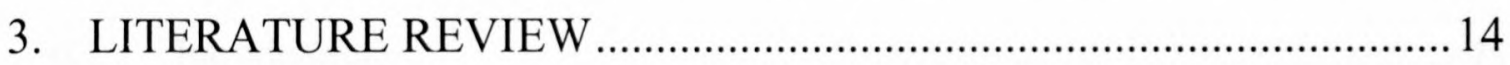

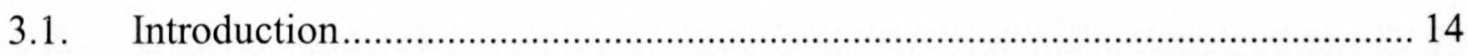

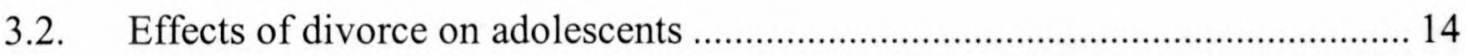

3.3. The importance of the parent-child relationship ............................................. 16

3.4. The role of attitudes and interpretations ...................................................... 18

3.5. The impact of time on children's adjustment to divorce .................................... 20

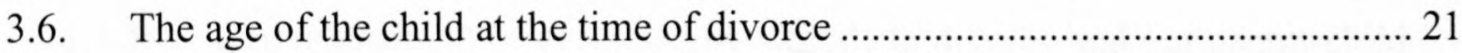

3.7. The impact of gender on adjustment............................................................ 22

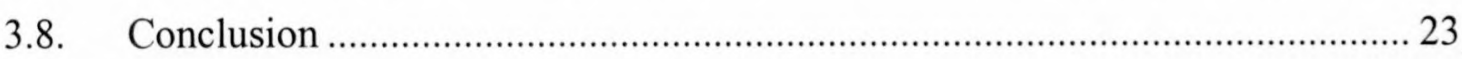

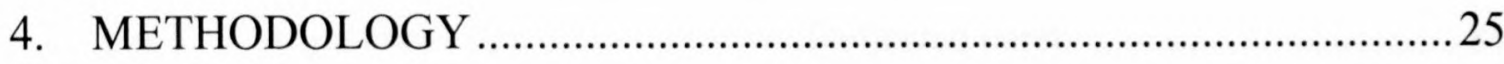

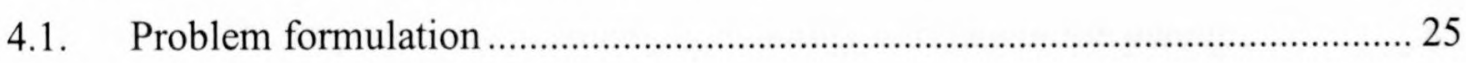

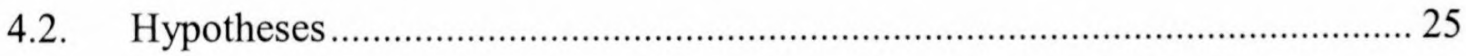

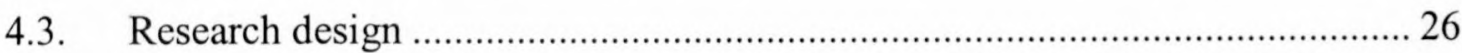

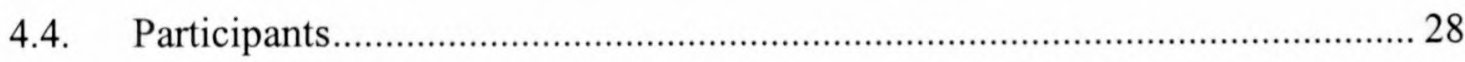

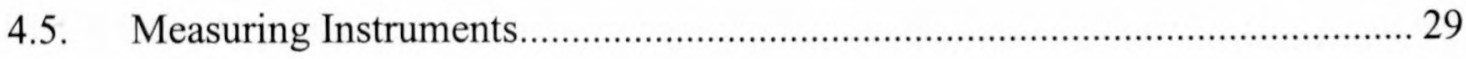


4.5.1. Child's attitude toward mother / father (CAM/CAF) (Hudson, 1982) ..... 30

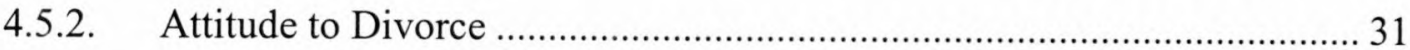

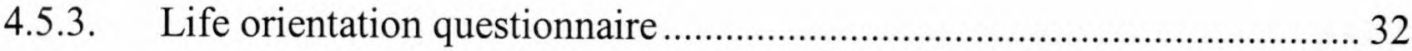

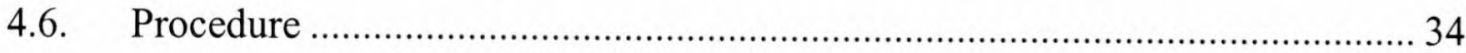

4.6.1. Practical Data Gathering ......................................................................... 34

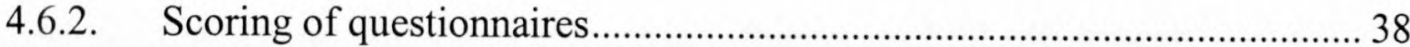

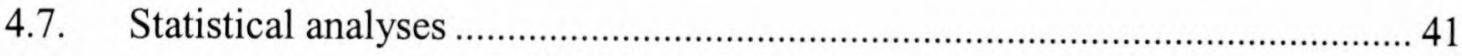

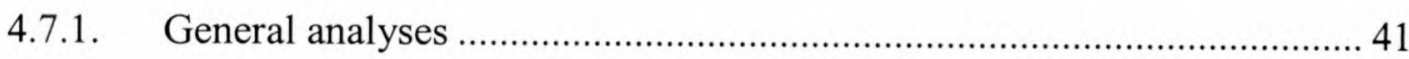

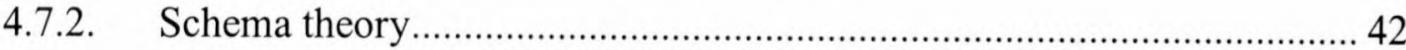

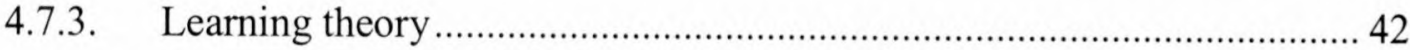

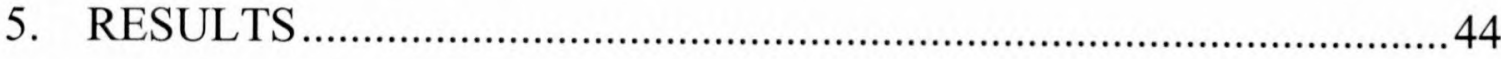

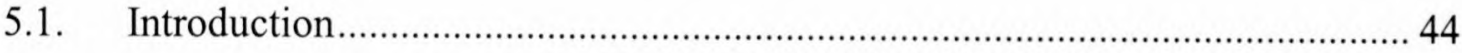

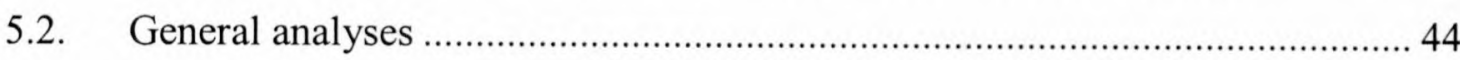

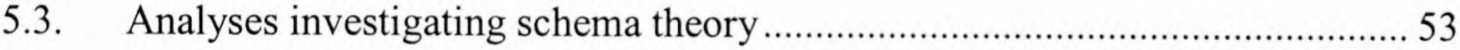

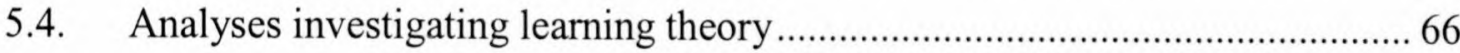

6. DISCUSSION AND CONCLUSIONS ......................................... 75

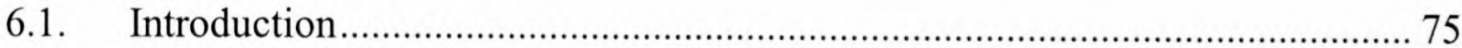

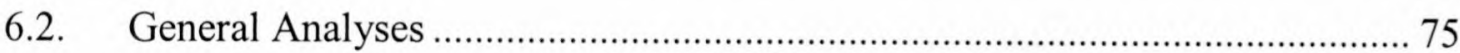

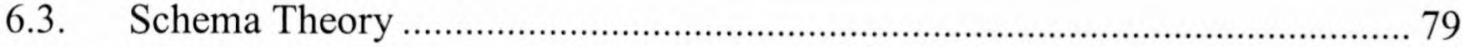

6.3.1. Is there a significant correlation between parent-child relationship (CAM / CAF scores) and attitude to divorce (ATD)? ........................................ 79

6.3.2. Is there a correlation between attitude to divorce and adjustment? .......... 82

6.3.3. Can adjustment be predicted by attitude to divorce and / or parent-child

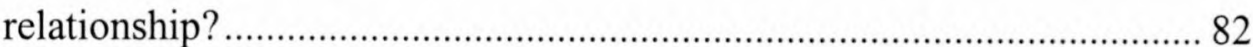

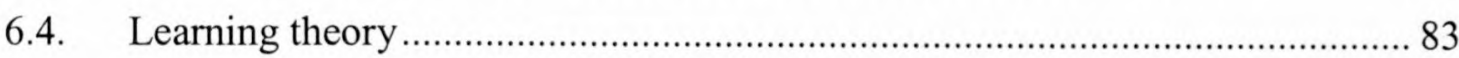

6.4.1. Adjustment of a child with a well-adjusted parent ................................. 84

6.4.2. The impact on adjustment of an ability to relate to the parent.................. 85

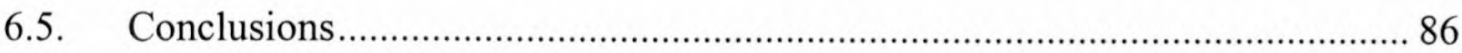

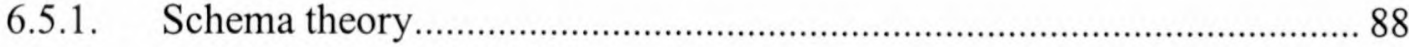

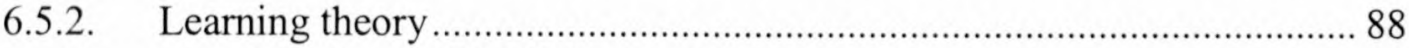

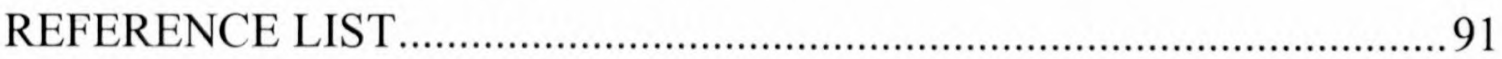




\section{List of Tables}

TABLE

PAGE

Table 5.1. Regression summary of the predictive validity of parent-child relationships (CAM) and attitude to divorce in influencing child adjustment (LOQ). 


\section{List of Figures}

FIGURE

PAGE

Figure 5.1. A comparison between LOQ (Life Orientation Questionnaire) scores of children from married families and those of children from divorced families.

Figure 5.2. A comparison between ATD (Attitude to Divorce) scores of children 46 from married families and those of children from divorced families.

Figure 5.3a. A comparison between LOQ (Life Orientation Questionnaire) scores of children based on the existence or absence of changes in their relationships with mothers.

Figure 5.3b. A comparison between LOQ (Life Orientation Questionnaire) scores of children based on the existence or absence of changes in their relationships with fathers.

Figure 5.4a. A comparison between ATD scores of children based on the existence or absence of changes in their relationships with their mothers. Figure 5.4b. A comparison between ATD scores of children based on the existence or absence of changes in their relationships with fathers.

Figure 5.5a. A comparison between ATD scores of children whose parents fought prior to divorce, and those whose parents were co-operative.

Figure 5.5b. A comparison between ATD scores of children whose parents fought after the divorce, and those whose parents were co-operative.

Figure 5.6. A comparison between ATD scores of children of families who have 53 experienced changed financial positions and those who have not.

Figure 5.7. The correlation between attitude to divorce and mother-child relationship (CAM) for divorced and married families. The lines are regression lines fitted through the data.

Figure 5.8. Correlation between attitude to divorce and parent-child relationship 55 where children do not feel able to relate to their mothers (for divorced and married families) 
Figure 5.9. Correlation between attitude to divorce and parent-child relationship 56 where children feel able to relate to their mothers (for divorced and married families).

Figure 5.10. The correlation between attitude to divorce and father-child relationship (CAF) for divorced and married families.

Figure 5.11. Correlation between attitude to divorce and parent-child

relationship where children do not feel able to relate to their fathers (for divorced and married families).

Figure 5.12. Correlation between attitude to divorce and parent-child relationship where children feel able to relate to their mothers (for divorced and married families).

Figure 5.13. The correlation between Life Orientation (LOQ) and attitude to divorce (ATD), for children from divorced and married families.

Figure 5.14. Least-square means diagram of groups with similar attitudes to divorce, based on adjustment and parental marital status.

Figure 5.15a. Comparison of mother-child relationships between children who are unable to relate to their mothers and children able to relate to their mothers. Figure 5.15b. Comparison of father-child relationships between children who are unable to relate to their fathers and children able to relate to their fathers. Figure 5.16. Comparison between attitudes to divorce of children, separated according to the nature of their relationships with the parent who had requested the divorce.

Figure 5.17. A comparison of the adjustment (LOQ) of children whose mothers had adjustment problems $(n=24)$ and those whose mothers did not $(n=18)$.

Figure 5.18. A comparison between adjustment of children with well-adjusted mothers who are able to relate to their mothers $(n=16)$, and those unable to relate to their mothers $(n=2)$.

Figure 5.19. A comparison between adjustment of children (with poorlyadjusted mothers) able to relate to their mothers $(n=20)$, and those unable to relate to their mothers $(n=4)$. 
Figure 5.20. A comparison of the adjustment (LOQ) of children whose fathers

had adjustment problems $(n=27)$ and those whose fathers did not $(n=8)$.

Figure 5.21. A comparison between adjustment of children with well-adjusted

fathers who are able to relate to their fathers $(n=4)$, and those unable to relate to their fathers $(n=4)$.

Figure 5.22. A comparison between adjustment of children (with poorly-

adjusted fathers) able to relate to their fathers $(n=15)$, and those unable to relate to their fathers $(\mathrm{n}=12)$.

Figure 5.23a. A comparison between attitudes to divorce of children whose

mothers experienced adjustment problems $(n=24)$ and those whose mothers did $\operatorname{not}(\mathrm{n}=18)$.

Figure 5.23b. A comparison between attitudes to divorce of children whose fathers experienced adjustment problems $(n=27)$ and those whose fathers did $\operatorname{not}(\mathrm{n}=8)$. 


\section{INTRODUCTION}

\subsection{INTRODUCTION}

The focus of the current study is on the adjustment of adolescent children of divorce. Adjustment is here defined in terms of one's general orientation to life: one's ability to cope with stress; to make sense of the world and to find purpose in life (Antonovsky, 1991).

\subsection{NATURE OF THE STUDY}

The aim of the study is to identify possible explanations for variance in the adjustment of adolescent children of divorce. Two possible explanations are postulated, and these will be discussed in more detail in chapter 3. Learning theory, in brief, suggests that the child's adjustment will be influenced by that of his parents. Antonovsky (1991) writes that the behaviour of people close to us tends to influence our adjustment. Schema theory (Janoff-Bulman, 1992), on the other hand, supplies a possible explanation for the oftnoted link between good parent-child relationships and good child adjustment (inter alia Harrist \& Ainslie, 1998).

A university study population was used in order to insure that differences in education did not confound results. Education was found to be a variable impacting adjustment in various studies (Brown, Portes \& Christensen, 1989; Grych \& Fincham, 1992).

A convenience sample was used for this study. Although random sampling was considered impractical, the exclusive use of psychology students as respondents was avoided. Mouton and Marais (1990) point to the extensive use of psychology students in psychological research, and postulate that this may introduce problematic biases in data collected. It was therefore decided to include a class of economics students, as well as one class of psychology students. Permission was obtained to use two such class groups of students at Stellenbosch University. These class groups were then approached and the students were asked to participate. Those willing to participate were then asked to complete various questionnaires (discussed in chapter 4). A cross-sectional research 
design was used: there was only one contact session with participants. The questionnaires completed in that contact session were then used as the source of data of the study. The questionnaire responses of the individual participants were studied, making individuals the focal point.

\subsection{Motivation}

There has been increasing social concern in recent years about the high divorce rate present in various countries (Kalter, 1990). For this reason, it is considered important to look at the possible effects that such a high divorce rate might have. It is evident that the more families experience divorce, the more people will be affected by this. It is particularly disturbing that many divorces involve families with children, and that living through one's parents' divorce would have some impact on these children (Kalter, 1990). The current study will then focus on the effect that divorce might have on the children.

Various studies have pointed, particularly, to the relative paucity of studies on the adjustment of adolescents following their parents' divorce (Amato, 1996; Kalter, 1990). It becomes evident that a large body of literature exists on divorce, but it is apparent that adolescents have been relatively neglected in this literature. Lengua, Wolchik and Braver (1995) point also to the importance of examining factors that might be conducive to positive adjustment of children of divorce. For this reason the current study will focus on adolescent children of divorce. Amato and Keith (1991) looked at the high risks that exist that adolescents will develop problems as a result of their parents' divorce. Such problems include having bad educations, which tend to lead to low job achievement and often to a felt lack of fulfilment. This research suggests again the necessity of a study of adolescent adjustment to divorce.

It can further be noted that, of those studies that do analyse adolescent adjustment to divorce, very few focus specifically on South African adolescents. In a Nexus (National Research Foundation) search for literature on this topic only two South African studies were found, both of which were masters' theses. As the context of the current study is South African, it is deemed necessary to take a closer look at this group of people in order to determine what can be done to improve their adjustment to an adverse 
occurrence such as divorce. Adolescents are the future businessmen, the future educators, the future leaders in society. They are also the parents of the future. If these people are poorly adjusted, this could have huge ramifications for society as a whole. Amato (1996) further writes on the intergenerational transmission of divorce. If learning theory is indeed found to play a role in children's adjustment, it seems essential that this cycle of problematic learned behaviour (such as poor conflict resolution and adjustment problems) be broken. If the current adolescents can be taught better coping skills to help in their dealing with conflict and general adjustment, this could help to break this cycle.

Schema theory and learning theory will be used to explain the adjustment of adolescent children of divorce. The relevance of these theories to adolescent post-divorce adjustment will be discussed, then statistically tested using the responses of South African adolescents. In this way, it will be possible to see whether these theories can explain the adjustment of South African adolescents following their parents' divorce.

Once the theories have been tested, and valid influences on children's adjustment have been established, this will help in designing interventions for the improvement of adolescent adjustment. Knowledge of the factors that contribute constructively to the adjustment of children of divorce can be used in therapy, and to help individual children to cope better with divorce. Programs can also be designed for single parent families to help them to adjust to divorce, based on the findings in this study.

\subsection{GoAlS}

The goal of the present study is to ascertain whether either (or both) of the theories considered (schema theory and learning theory) are able to explain the variance found in adjustment in the sample of adolescents used in this study. The premises on which the two theories are based will be expounded, following which each of these premises will be tested statistically using the data gathered from participants. The existence (or absence) of statistically significant findings will be taken to indicate whether or not the theories can be supported by the data gathered in this study. If it is found that one or other of the theories is supported by the data, this knowledge can be used by those working with divorced families. If it can be ascertained that either the parent-child relationship or the 
parents' adjustment has a positive impact on the child's adjustment, this knowledge can be used to help divorced parents, who can then help their children to better adjust to divorce. Programmes can be developed to enhance the functioning of single parent families, and to improve communication. One to one therapy could also make use of knowledge of factors that influence the positive adjustment of children of divorce, as these people could be counselled to improve their functioning.

\subsection{Presentation OF RESEARCH}

The second chapter consists of a review of available literature on divorce (with specific reference to adjustment). It looks not only at what has been found, but also points out some of the gaps that exist in the current literature. In the third chapter, the two theories being examined as possible explanations for adjustment in adolescent children of divorce are expounded. Following this, the methodology of the study is discussed. Here the hypotheses forming the basis of the study are laid out, and the questionnaires being used are discussed in more detail. In chapter five, the results found by the statistical analyses are reported. Finally, in chapter six, these results are discussed and conclusions are drawn based on the findings of the study. Possibilities for further research based on the current findings are also discussed, as are possible interventions. 


\section{THEORETICAL BACKGROUND}

\subsection{INTRODUCTION}

Psychology literature contains a plenitude of different theories attempting to explain different aspects of human behaviour. Two such theories have been selected (schema theory and learning theory), which are believed to be particularly relevant to the issues under discussion in this paper. The theories concerned are, to a large extent, fairly similar in their predictions, but diverge in their explanations of these predictions. It is hoped that an in-depth analysis of results obtained from the current research will support either of these theories.

Amato and Rogers (1999) studied the positive relationship between holding accepting attitudes to divorce and getting divorced as adults. They propose two possible explanations for this relationship: people with more favorable or accepting attitudes to divorce are likely to put less effort into their marriages than are people less accepting of divorce. This lack of effort decreases the quality of their relationships, resulting in a higher probability of divorce. The other possible explanation applies Festinger's cognitive dissonance theory, which states that holding attitudes that are contrary to one's behaviour results in dissonance, but that attitudes are easier to change than behaviour (Baron \& Byrne, 1997). The causality for the above effect, therefore, would work in the opposite direction: people divorcing would adopt more accepting attitudes of divorce in order that their attitudes be congruent with their behaviour. Amato and Rogers found more evidence for the former proposal, but point to the need for further research on this issue.

\subsection{SCHEMA THEORY}

Basic schema theory is discussed by Janoff-Bulman in his book, Shattered Assumptions (1992). The premise from which this theory is derived states that people have ways of organizing knowledge or information about any subject into categories. The subject may be a person, an idea, a thing, or even a social category. Such categories are known as "schemata", and are used to organize new information (Howard, 1987). They may exist at a very basic level (a schema might, for example, exist for the category "cow" and 
might include knowledge such as breeds of cows, features of cows, and so on), or may be far more abstract (for example, a schema may include an individual's assumptions about himself).

Any new information which is perceived must somehow be incorporated into the individual's cognitive world. This can pose a problem, should new information be contrary to the knowledge contained in the relevant schema. There then exists a choice of two cognitive processes, which may be followed to incorporate this information: assimilation or accommodation. Assimilation takes place when new information is changed, or interpreted in such a way as to fit the schema. For example, if an individual had a schema for dogs, and this schema included a belief that dogs were friendly animals (schema); and the individual was bitten by a dog (new information: an action that would usually be seen as somewhat unfriendly) that individual would find a way of interpreting the dog bite in such a way as to maintain his schema (dogs are friendly). He could, for example, assume that the dog had been trying to play with him, and had not been attacking him. Accommodation is, more or less, the converse process: here the schema is altered in order to fit the new information. To continue with the above example, having been bitten by a dog, the individual might adjust his dog schema to one that says that dogs are not always friendly.

Janoff-Bulman, in his studies of these processes, has concluded that people tend to be biased towards assimilation, rather than accommodation. That is, people find it cognitively easier to adjust new information to fit with their previous schemata (assimilation) than to change these schemata (accommodation). This is said to be because it is easier to notice, attend to and process information if it is related to an existing schema. He even proposes that people extract those features of their environments that confirm, or maintain their schematic views. Janoff-Bulman (1992) writes that cognitive processes are "theory-driven" rather than "data-driven" (p. 29). This means that even where people perceive data that appears to contradict their schemata, they attempt to maintain those schemata. Such that in the above example, the individual would try to maintain his "dogs are friendly" schema, even in the face of what might 
seem, to an outside observer, to be a fairly clear contradiction of that schema: being bitten by a dog.

Various findings suggest that this schema theory might be applicable to children of divorce, and their attitudes to divorce. Janoff-Bulman (1992) writes that children's early representations tend to be powerful, and that such early representations tend not to change much in later childhood or adolescent years. As parents are one of a young child's first experiences of the world, it would seem that the representations children have of their parents would be fairly powerful and well established. It follows, then, that the mental representation, or schema, of the parent would be unlikely to change too dramatically, even in the face of new information. Swartzman-Schatman and Schinke (1993) found support for this premise in their study of young adult children of divorce. According to their findings, young adults have a mature mental image of their parents, which is very difficult to alter.

Schwartz (1992) looked at children's perceptions and responses to parental divorce, with specific reference to the role of cognitive interpretations of divorce at different stages in child development. Adolescents are at a stage where they are able to contemplate alternatives, and therefore alternative ways of coping with divorce, which may benefit their ability to adjust to divorce. They are also, however, possessed of a rigid sense of right and wrong, particularly in early adolescence. This, according to Schwartz, may result in their attributing blame to one or other parent for the divorce, and being less accepting of it. Kalter (1990), in his book on children of divorce, points to a similar view: the strong sense of right and wrong typical of adolescence may result in the condemnation of parents who divorce. This may happen because of behaviour seen as wrong by the adolescent, such as an extra-marital affair, or may simply be a condemnation of the breach of the marital contract as a broken promise. Howard (1987) looks at how schemata are used to help the individual to comprehend such events and issues.

Continuing with schema theory, the case where a young adolescent boy has a positive relationship with his mother can be considered. His mental image (or schema) of his 
mother is one of a loving, caring, good person. Should his parents then divorce, he would be left with two options. He could interpret the divorce as unacceptable behaviour on the part of his mother, and accommodate his schema to see his mother as a good person who engages in unacceptable behaviour (change his schema to incorporate the new information). Alternatively, he could change his interpretation of the new information such that he would be able to maintain his established schema for his mother. In other words, he might assimilate the information by, for example, seeing divorce as an acceptable solution to terminating an unhappy marriage. Schema theory suggests, particularly given the established nature of the mother schema, that the latter would be the cognitively easier, and therefore the more likely, of the two options. Research by Burns and Dunlop (1999) on adolescent children of divorce appears to confirm this theory. They found that adolescents who perceive their parents as caring and understanding tend to experience fewer negative emotions relating to the divorce.

Conversely, should the same individual have a negative schema for his mother, seeing her as unloving and spiteful, he might interpret the same information (the fact of his mother having divorced his father) in an entirely different light. In order to maintain his negative mother schema, he might interpret her behaviour in divorcing his father as yet another bit of evidence of her unloving and spiteful nature, seeing divorce as unacceptable.

Schema theory, then, suggests that a child who has a positive relationship with his/her parent(s) would be inclined to hold more accepting attitudes toward divorce. This is explained by the natural preference exhibited by people for assimilating information into existing schemata, rather than trying to alter these schemata to fit with new information. This seems to be the case even when this new information appears to contradict the existing schemata. A child with negative, or unaccepting relationships with his/her parent(s) would tend, according to this theory, to hold less accepting attitudes towards divorce. 
The first deduction which will be made from this theory is, then, that children with positive relationships with one or both parent(s) would, overall, hold more accepting attitudes to divorce than would children with negative parent-child relationships.

Janoff-Bulman (1992) looks at the impact of trauma on the worldviews and assumptions held by individuals. These basic assumptions are seen to be important for the adjustment of individuals. One of the more negative impacts of trauma, according to the author, is the way in which it may force changes in basic worldviews. People tend to trust in the benevolence of the self, that of other people, and that of their future prospects. Divorce, as a traumatic experience, may challenge all of these basic assumptions:

- Children may show some degree of self-blame for their parents' divorce (Burns \& Dunlop, 1999), challenging their trust in the benevolence of the self;

- Divorce is believed to affect adolescents, in particular, because of the breakdown of interpersonal trust that this represents, challenging their beliefs in the benevolence of other people (Franklin, Janoff-Bulman \& Roberts, 1990);

- Much of the literature on divorce tends to focus on the negative, rather than positive, consequences for the children (Amato \& Keith, 1991a), challenging the beliefs held by these children of having good future prospects.

It would appear, from schema theory, that the way in which the divorce experience is integrated into existing schemata would also influence the extent to which these basic assumptions are affected by the divorce. A child with a good relationship with his/her parent(s) would, as detailed above, be more likely to see the divorce as acceptable, and even to interpret it as a good thing (an end to an unpleasant situation, for example). With such an interpretation,

- The child would be less likely to blame him / herself for the divorce, as it would not be a "bad" thing requiring blame;

- The breakdown of interpersonal trust might be interpreted otherwise, by, for example, seeing the divorce in terms of an optimal solution to a bad situation; 
- Seeing the divorce as an acceptable option would probably lead the child towards a more positive outlook on his/her future. Perhaps the decrease in conflict around the home, or the ability to spend good times with each parent separately, would be emphasized by the child.

The child would, with this more positive outlook, be able to maintain both his schema of his parent as a good person, and his basic assumptions about life, intact. The second deduction from schema theory is, then, that a more accepting attitude to divorce would enable more positive interpretations of the divorce experience on the levels of all three basic assumptions. As the maintenance of these assumptions is beneficial to adjustment, it follows that a positive attitude to divorce would enable better adjustment. The theory deduced from schema theory now stands as follows: a good parent-child relationship would result in a more accepting attitude to divorce in children whose parents divorce. This accepting attitude to divorce would facilitate the maintenance of optimistic basic assumptions, which would enable the child to adjust better to the divorce experience.

The literature on divorce (detailed in chapter 3) points to the importance of a good parent-child relationship in child adjustment to divorce. The role of schemata and interpretations, and of the child's consequent attitude to divorce, do not appear to have been given as much attention. These areas will be examined (parent-child relationship, attitude to divorce, and adjustment) and the links between them will be investigated, in order to evaluate the theory expounded above. As this study refers specifically to adolescents, schema theory and the role of children's interpretations of the divorce experience would seem to be particularly relevant. Schwartz (1992) emphasizes the role of cognitive interpretations in adolescent adjustment, referring specifically to the ability of adolescents to contemplate different alternatives. This adds credence to the relevance of schema theory in explaining the adjustment of this age group.

\subsection{LEARNING THEORY}

Learning theory refers to the learning of behaviour by modeling, or imitation. Children, for example, are found to learn aggressive behaviour by witnessing adult models engaging in such behaviour, and copying this behaviour. In the same way, children who 
have witnessed good communication between their parents (as models) are found to be more likely to develop good social skills, than are those who are not modeled such adaptive behaviour (Linker, Stolberg \& Green, 1999). These authors found, however, that a good parent-child relationship was also required for this transfer of communication skills. It seems possible, then, that some kind of motivation might be necessary for this modeling to take place. A child with a poor relationship with his parents might be less inclined to imitate their behaviour.

Learning theory, nonetheless, suggests that children would learn from their parents' behaviour. This learning would result in the children's imitating their parents' behavioural responses to divorce. Therefore, parents who have positive attitudes to divorce and behave in adaptive ways, signifying good adjustment, would have children who are accepting of their situation and well adjusted. Likewise parents demonstrating adjustment problems and negative attitudes to divorce would be likely to have children with similarly negative attitudes and problems.

Indeed research appears to exist to back up such a proposal: Various studies have found links between parents' post-divorce adjustment and that of their children (Kalter, 1990; Lengua, Wolchik \& Braver, 1995). These studies show that well-adjusted parents tend to have well-adjusted children; while poorly adjusted parents tend to have poorly adjusted children. Amato (1996) conducted a longitudinal study looking at the intergenerational transmission of divorce (children whose parents are divorced appear to have a higher likelihood of themselves being divorced than do children from intact homes). This study proposes that this effect may exist as a result of the fact that children from divorced families might model their parents' solutions to marital problems. Their parents divorced when their marriage had problems, so the children, if they experience similar problems, would follow a similar course, and get divorced. While this argument appears to make sense, it should be mentioned that Amato also found a fairly high divorce rate among children who had lived through unhappy marriages that had remained intact. In other words, finding themselves in a similar situation to that of their parents, these children had not modeled their parents' behaviour (staying together in spite of unhappiness), but had divorced. 
However, in another study of children of divorce, Booth and Edwards (1989) report slightly different findings. They found that children were likely to adopt attitudes to divorce reflecting their parents' behaviour: children who had lived through divorce were more accepting of divorce (as this was the behaviour their parents had exhibited), while those whose parents had stayed together despite conflict felt that this was important (this being the behaviour exhibited by their parents). Booth and Edwards lend further support to learning theory in their finding that this adoption of parents' attitudes took place only when the children concerned perceived their parents as models. Again, caution needs to be exercised in interpreting these results: as Booth and Edwards' study looked only at attitudes, their study was not able to show whether these attitudes were ever translated into behaviour.

It is hypothesized, in the current study, that a good parent-child relationship is a good reflection of good adjustment in the parent. Stolberg, Complair, Currier and Wells (1987) found that parents' resolution of their divorce-related problems (that is, their adjustment to the divorce) impacts on the ability of parents to attend to their children's needs. This suggests that well-adjusted parents are more able to cultivate good relationships with their children. It seems also, from Stolberg et al's reference to parents' resolution of divorce-related problems, that these parents would have worked through the fact of their divorce, and developed an accepting attitude towards it.

Looking at the current study, then, from a learning theory perspective, good parent-child relationships appear to reflect good parent adjustment. To pick up on the findings of Booth and Edwards (discussed above): in order for children to imitate their parents' views or behaviours relating to divorce, children must see their parents as models. It stands to reason that a child having a good relationship with his/her parent would be more likely to see that parent as a model than would a child lacking such a relationship. This suggests that a good parent-child relationship would also predict a greater likelihood of that the child might model the parent's behaviour. It has further been established that well-adjusted parents would be more likely to hold accepting attitudes to divorce (Stolberg et al., 1987). 
Therefore, a good parent-child relationship ought, according to the above, to predict good parent adjustment and positive parent attitude to divorce, which would, in turn, according to learning theory, predict good child adjustment and positive child attitude to divorce, by modeling. A poor parent-child relationship, illustrative of poorer parent adjustment, and probably of a less accepting parental attitude to divorce might be less useful in predicting outcomes for the child. In a poor parent-child relationship, the child might not see the parent as a model, and might therefore be less inclined to imitate the behaviour of that parent. Should that parent be the only available model for the child, that parent's adjustment might nonetheless serve as a predictor of child's adjustment.

These relationships will be examined in more detail in the current study. Again measures will be used for parent-child relationship, the child's attitude to divorce and the child's adjustment. The child will be asked to report on parental adjustment in order to ascertain whether correlations do exist between parental adjustment and the parent-child relationship.

\subsection{Conclusion}

A detailed look at the three facets of child response to divorce will be taken in this study. Analyses will attempt to ascertain whether either, or both, of schema theory and learning theory are able to explain much, or at least some, of the variance in children's adjustment. As both of the theories discussed predict similar directions for results, it may be difficult to see which of the theories is in fact in operation. Schema theory puts forward child attitude to divorce as a mediating factor: moderating, or enhancing the effect of the parent-child relationship on post-divorce adjustment. Learning theory, however, says that both children's attitudes and children's adjustment are modeling responses to parents' attitudes and adjustment; responses which exist because of a good parent-child relationship.

If, then, it were possible to establish statistically that attitude to divorce did indeed mediate between parent-child relationship and adjustment, this would point to the role of schema theory in explaining this link. If, on the other hand, such a mediating role were not found to exist, this might suggest learning theory as a more credible explanation. 


\section{LITERATURE REVIEW}

\subsection{INTRODUCTION}

With the increase in divorce rates in recent years, coping with adjustment to divorce has become the focus of much research. In particular, attention has been given to children of divorce. It is, however, apparent that relatively little research exists concerning the adjustment of late adolescent children to divorce (Kalter, 1990). Those who have given attention to this age group have pointed to the importance of further studies in this regard (Amato, 1996; Kalter, 1990; Lengua et al., 1995).

Researchers have examined numerous aspects of child adjustment to divorce, but an in depth examination of all of these aspects is not necessary in this study. Consistent with the goals of this study, then, specific aspects of adjustment discussed in various research projects, will be examined. Firstly, the effects that divorce has on adolescents will be looked at. In the current study this age group is the focal point, and therefore the importance of studying this age group must be ascertained. The parent-child relationship will be evaluated in terms of its effect on child adjustment.

Following this, the role of attitudes and interpretations in children's adjustment to divorce, will be studied in order to determine the importance of these factors. The impacts of time since divorce, age at divorce and gender are also looked at, as these were factors pointed to in various studies as some which may require further analysis and discussion.

\subsection{EFFECTS OF DIVORCE ON ADOLESCENTS}

Barker, Brinkman and Deardorff (1995) in looking at a divorce adjustment programme, discuss some of the consequences and effects parental divorce may have on adolescents. They mention difficulty in breaking away from the family; having to take on adult responsibilities before they are ready; and feelings of powerlessness as some such effects. It is evident from various studies that adolescents are a group that ought not be neglected in their adjustment to divorce (Amato, 1996; Kalter, 1990; Lengua et al., 1995). 
Carstens and Spangenberg (1997) reasoned that adolescents and young adults are at a stage where they are seeking meaning and structure in life, and are therefore vulnerable to negative (or positive) influences. Portes, Lehman and Brown (1999), in their study of children of divorce aged 5 to 16 , observed that adolescents are more aware of parental problems, and more concerned about the possible long-term consequences that divorce might have for themselves and their families. Amato and Keith (1991), in a metaanalysis of the effects of divorce on adults, found that divorce might have more long-term consequences for adolescents or adults than it does for younger children.

Dankowski (2001) looks at adolescents' responses to divorce, and points to the stage of development in which adolescents find themselves. Adolescents need, according to Erikson, to solve the crisis of identity versus role confusion (Louw, 1991). Roles are redefined at this stage in life; and in order for the adolescent to accomplish this redefinition of roles, he/she needs safe attachments. If the attachment figure (that is, the parent) were unavailable to help the adolescent (as would be the case should the parent be struggling with divorce issues), this would result in immense stress for the adolescent (Dankowski, 2001). Frost and Pakiz (1990) found, in their 10 year longitudinal study of children of divorce, that adolescent girls might have female self-esteem and heterosexual adjustment issues arising from parental divorce that may only surface at this developmental stage.

After the adolescent has formed his/her identity, the next crisis which must be mastered is that of intimacy versus isolation. According to Louw (1991) this intimacy is essential for forming marital relationships. Franklin et al. (1990) studied the impact of parental divorce on the assumptions (or beliefs) children may maintain about themselves and the world around them. They found that children of divorce tend to have less trust in their own chances of marital success than do children from intact families. They suggest that the developmental stage of intimacy versus isolation tends to reactivate the divorce experience for adolescents, because of the need to master this developmental crisis.

Another problem that is specific to adolescents in having to deal with parental divorce is discussed by Dankowski (2001). He found that divorced parents might cling to their 
adolescent children (negatively impacting their ability to form their own identities) in order to avoid dealing with their own problems. Pryor (1999) studied young adults of age 18 and up with divorced parents. He observed that such people often have to "parent" their own parents, or mediate between their parents. The parents are not available to help or advise their children, resulting in feelings of vulnerability in the children. SwartzmanSchatman and Schinke (1993) reported similar findings. Divorcing parents with adolescent children tend to be less supportive as they expect their children to be mature enough to deal with the divorce alone. These parents also tend to be more reliant on their children for support.

It seems, then, that while adolescents experience adjustment problems with divorce, as do younger children, adolescents tend to receive less support and help in dealing with divorce. This group also has a unique set of developmental challenges to master, for which it would seem that more, rather than less, support is needed.

\subsection{THE IMPORTANCE OF THE PARENT-CHILD RELATIONSHIP}

Numerous studies of the effects of divorce on children of various ages point to the importance of the parent-child relationship. Tschann, Johnston, Kline and Wallerstein (1989) studied adolescents aged between 12 and 18, and found that better parent-child relationships helped predict better adjustment of children. They also underline the importance of consistent discipline and supportive parenting in child adjustment. Amato and Keith (1991) found, in a meta-analysis of the effects of divorce on children, that a good relationship with the mother (not the father) was related to fairly high levels of well-being. Kline, Johnston and Tschann (1991) reported similar findings in their study of the post-divorce adjustment of children aged 2 to 18 . Two years after the divorce, the child's relationship with the mother (but not with the father) was found to be a good predictor of the child's adjustment.

Amato's (1996) study of divorce, however, points to the importance of close relationships with either one or both parents in improving social skills and emotional security of children; Simons, Whitbeck, Beaman and Conger (1994) look at both parents playing a role in different aspects of child adjustment. They found both parents to impact on 
externalizing behaviour in boys and girls, but only the mother to influence internalizing behaviour in boys. Grych and Fincham (1992), evaluated various intervention efforts for children of divorce, and found that consistent parenting was a good source of stability and support for children. Warm and accepting relationships were especially beneficial to children, and it was the interventions that focused on parenting that were found to be most helpful.

Harrist and Ainslie (1998) found that marital discord had fewer negative effects on aggression and withdrawal in younger children where a good parent-child relationship existed. Linker et al. (1999) also found consistent parenting, in conjunction with good inter-parental communication to be beneficial in child adjustment and in the learning of social skills. Tschann et al. (1989) further found that conflict between parents may influence parents and children negatively. Petersen and Zill (1986) and Amato (1996) found that close parent-child relationships were able to decrease the effects of conflict or discord on children. Petersen and Zill also found, however, that high conflict homes were less likely to exhibit positive parent-child relationships than were low conflict homes. Numerous other studies have pointed to the negative effects of conflict on children (Amato \& Keith, 1991; Davies \& Cummings, 1994) and to the buffering effect a good parent-child relationship can have on such conflict (Forehand et al., 1991; Kline et al., 1991). Booth and Edwards (1990) even propose that staying in an unhappy marriage has more negative effects on children than does divorce, because of the prolonged exposure to conflict that children would experience in the former.

With specific reference to adolescents, Dankowski (2001) looks at the importance of open communication between parent and child in phases of transition in the family life cycle. It seems that adolescents' forming their own identities or leaving home could well be included in such transitions, pointing to the particular importance of a good parentchild relationship at this stage. Pryor (1999) also looks at the importance of the parentadolescent relationship for the transition stage in life represented by late adolescence. The converse of this is highlighted by Kalter (1990), who points to the danger of an overly close parent-child relationship in adolescence. He says that this could have a 
negative effect on the adolescent's ability to separate from the parent and form his/her own identity.

Antonovsky (1991) discusses the parent-child relationship in terms of the passing on of beliefs from parent to child. He mentions specifically beliefs pertaining to locus of control: parents with an internal locus of control (which is generally seen to be a more adaptive outlook) would tend to pass this outlook on to their children. Parents with a less adaptive external locus of control would do likewise, usually having children with similar external loci of control. He goes on to suggest that the behaviour of those close to us often has an impact on our adjustment. This again points to the importance of the parentchild relationship in child adjustment, as it cannot be denied that a parent is someone fairly close. Parent behaviour, then, seems to affect the adjustment of the child, be it positively or negatively.

It seems from the above that the parent-child relationship plays a vital role in child adjustment to divorce, whatever the age of the child. This is a factor that will receive further attention in this study.

\subsection{THE ROLE OF ATTITUDES AND INTERPRETATIONS}

Amato (1996) found that children of divorce who hold more accepting attitudes to divorce are more likely to themselves get divorced in later life than are children not holding such attitudes.

Pryor (1999), examining young adults whose parents separated when they were 18 years of age or older, found that those whose parents had marriages involving high conflict levels were more likely to hold accepting or positive views of separation and divorce; while those whose parents had divorced despite having relatively low conflict marriages tended to hold less accepting or negative views of divorce. Another study looking at the intergenerational transmission of divorce in adult children of divorced families draws a similar distinction: Booth and Edwards (1990) found that living through divorce tended to lead to relatively accepting attitudes towards divorce in the children, but that this was only the case if the children saw their parents as models. On the other hand, they also 
found that children who had lived through a marriage where the parents had "stuck it out" despite marital problems tended to see such perseverance as important, and therefore to be less accepting of divorce. This study also points to the role which religious affiliation often plays in influencing attitudes to divorce: People holding strong religious beliefs tend to be less accepting of divorce than those not holding such beliefs.

In a study looking at changes in attitudes to divorce in recent decades, Amato and Booth (1991) look at the role which experience with divorce might play in these changes. They found that, in children who had lived through a divorce, the divorce, as well as the marital and family unhappiness which usually preceded this, were associated with the holding of more liberal and accepting attitudes to divorce.

Harrist and Ainslie (1998) look at the ways in which children's abilities to understand and interpret events could mediate the effect which conflict and/or divorce has on them. Where it is possible to place a positive interpretation on a situation, this will tend to lessen the negative effect that the situation has on the child. As older children and adolescents have more advanced cognitive development, it would seem, then, that the influence of divorce would be different from that experienced by younger children. Harrist and Ainslie (1998) also look at how conflict in their parents' marriage may disrupt the cognitive attributions of young children. Lengua et al. (1995) examine the effect of post-divorce variables on children who have lived through divorce. They, too, find that the interpretation of the family situation and of the divorce may differ between children. They observe the role that children's interpretations can play in their adjustment to divorce. Fincham (1994) writes that it is possible to alter the way in which children experience conflict in a marriage, by changing their appraisals, or interpretations, of that conflict.

Franklin et al. (1990) studied a group of college (university) students from divorced and intact families, to examine the role which divorce plays in redefining children's assumptions about the world, themselves and other people. They theorize that traumatic life events tend to influence people's assumptions, and divorce is seen as such a traumatic event. They found that while broader assumptions are not, on the whole, too seriously 
affected, children of divorce may show less trust of others in general as they have witnessed the breakdown of trust in their parents' relationship. They also found that children of divorced families tend to be more pessimistic about their own chances of having successful marriage relationships.

\subsection{THE IMPACT OF TIME ON CHILDREN'S ADJUSTMENT TO DIVORCE}

Various studies have asked whether the effects of divorce on children tend to increase, diminish, or remain constant with the passage of time after divorce. Different studies have found fairly diverse results in response to this question, so it seems that no real conclusions can be drawn on this issue.

Burns and Dunlop (1999) conducted a 10 year longitudinal study of adolescent children of divorce. They found that some feelings about divorce persisted, even years after the divorce. These feelings included relief at the end of a conflictual family life, and often anger at one parent who was deemed to be in the wrong. Other feelings, particularly those of shock and upset, decreased with the passage of time. Simons et al. (1991), however, in their study of divorced women and their adolescent children, found that the impact of the parents' behaviour on their children showed no significant change, either for better or for worse, with time since divorce. Allison and Furstenberg (1989) in their longitudinal study of children and young adolescents, also found evidence of fairly stable effects of divorce with the passage of time. They found that effects tended to be negative and prolonged, and propose that this is because divorce itself is usually only the beginning of a child's exposure to an adverse situation of single parenting, less financial stability and other such changes. The stable negative effects of divorce are therefore attributed less to the divorce itself, than to this ongoing adverse life situation.

Other studies were more optimistic about decreases in the deleterious effects of divorce with time. Amato and Keith (1991), in their meta-analysis on adult children of divorce, found that these effects do indeed tend to decrease. They do, however, comment that in such a meta-analysis it is possible that the effect of passage of time since the divorce could be confounded with two interrelated factors: the age of the affected person, and, perhaps more importantly, a cohort effect. Because Amato and Keith studied adults 
ranging from under 20 to over 40 years of age, it is possible that the increasing acceptability of divorce in more recent years, and not only the time since the divorce, helped to influence these results. Frost and Pakiz (1990) were also more optimistic about the time variable. They found, in a study of 15-year-old children of divorce and their adjustment, that those whose parents had divorced more recently tended to exhibit more negative effects on their adjustment than did those whose parents had been divorced for longer periods of time. It seems, then, that the effects of divorce might become less as time since divorce increases. They do, however, caution that it is possible, especially for female children of divorce, that some divorce related issues might surface years after the divorce, having been put aside until they become developmentally relevant. Such issues include female self-esteem and heterosexual adjustment, which would tend to surface during adolescence.

\subsection{THE AGE OF THE CHILD AT THE TIME OF DIVORCE}

Much of the available literature on children of divorce looks at younger children of divorce, to the point of neglecting adolescents (Amato \& Keith, 1991a; Kalter, 1990; Kalter \& Rembar, 1981). This suggests that this younger age group is considered to be more seriously affected. As with time since divorce, there do, however, exist contrary findings on this issue. Glenn and Kramer (1985) found no evidence to suggest that the negative effects of divorce on children are any less if the child is older. This was, however, a study of children of divorce aged 16 to adult, and it is possible that differences in impact of divorce by age might exist between younger children and adolescents, for example, rather than between 16 year olds and adults.

A study of children aged from 5 to 16 (Portes et al., 1999), on the other hand, found some evidence that older children or adolescents might suffer more long-term effects of divorce than do younger children. A second study, examining factors which put children at risk for experiencing problems resulting from their parents' divorce (Brown et al., 1989), also concluded that older children tend to experience more problems later on in life, related to their parents' divorce. Adolescents were also found to be more consciously troubled by the divorce, perhaps because of their more advanced cognitive development. 
Kalter and Rembar (1981) studied problems and emotional disturbance in children of divorce. Their study encompassed children aged from 7 to 17 . They found that both age and gender may play a role in the type of emotional disturbance exhibited by children, but that neither of these factors had any impact on the severity of the disturbance. In other words, it cannot be said, according to this study, that any one age group is more, or less, seriously affected by parental divorce. Again, these results should perhaps be treated with some caution, as the sample used for this study was taken from children who were referred for counseling because of problems with adjustment. As numerous writers caution, such clinical samples may present different results to those found in more random samples (Amato \& Keith, 1991; Block, Block \& Gjerde, 1988).

Where the child's age is concerned, one can look either at the age of the child at the time of the divorce, or at the current age of a child whose parents are divorced. Different researchers have studied these two aspects. In the current study, the current age of the adolescent is used, regardless of the age at which his / her parents divorced.

\subsection{THE IMPACT OF GENDER ON ADJUSTMENT}

As was the case with the impact of time and of age on post-divorce adjustment, different studies present different answers to this question. Kalter and Rembar (1981) found that while the impact of divorce on boys and girls may differ qualitatively, it does not differ quantitatively, that is, boys and girls suffer a similar quantity of adverse effects on their adjustment. Allison and Furstenberg (1989), looking at the effects of divorce on various measures of well-being in children and young adolescents, found no differences according to gender in the extent of negative effects suffered because of parental divorce.

Glenn and Kramer (1985), cited above, found that girls tend to suffer more negative effects resulting from the divorce than do boys; while Block et al. (1988) describe boys who have lived through their parents' divorce as being more aggressive and impulsive than are girls in the same situation. The latter comes from a 10 year longitudinal study tracing families from before dissolution to later, when some families remained intact and others were dissolved. 


\subsection{CONCLUSION}

In the literature examined, various facets of divorce and adolescent adjustment showed a need for further examination. Firstly, it was evident that adolescents, being a group relatively neglected in research in terms of their adjustment to parental divorce, are indeed in need of attention. Some studies suggest that this group might experience more negative effects resulting from divorce than would younger children; an effect made more problematic by parents' tendencies to assume that children of this group are mature enough to cope, not only with the fact of their parents' divorce, but also with the responsibility of being a source of support for their parents.

The parent-child relationship certainly appears to be of great importance in the adjustment children exhibit to the trauma of their parents' divorce. Studies of various age groups have found this relationship to act as a kind of buffer in the midst of stress experienced by children, decreasing the negative impact of divorce. It is, however, cautioned that too close relationships with parent(s) may become problematic in adolescence. The exact mechanism of the good parent relationship as a buffer to adjustment problems is not, however, detailed, and this study would examine one possible mechanism for this effect.

The role of attitudes and interpretations of the divorce experience cannot go unnoticed. Different studies find different effects of parental divorce on children's attitudes to divorce. Again reasons for these different effects are not always clear, and would seem to require further attention. The role of children's appraisals, or interpretations of what is going on around them is also pointed to as a factor influencing adjustment. It would seem, then, that the attitude a child holds to divorce (taken as a kind of appraisal of the divorce experience) would impact on that child's adjustment to divorce in his/her family. This, as well as the reasons for different attitudes being held to divorce, will be further examined in the current study.

The literature examined shows many contradictions in the findings concerning time since divorce, age of children at divorce, and gender of children. These are all seen in some studies to play a role in the extent to which divorce affects a child; other studies find 
them to be less important, or indeed to exert no appreciable influence. The current study will, then, attempt to draw its own conclusions, taking into account the results of similar studies. Should it be deemed necessary, these variables might require controlling. 


\section{METHODOLOGY}

\subsection{PROBLEM FORMULATION}

The study will focus on late adolescents (age 17 to 22) from both divorced and married families. This group has been relatively neglected in research in terms of their reactions to divorce. An effort was made to better understand which factors contribute to positive adjustment to divorce in adolescents. In order to accomplish this, various factors were examined: the relationship between adolescents and their parents; the adjustment of the adolescents; and their attitudes to divorce. Biographical details and other aspects of the family life of these adolescents, such as their parents' marital status, their felt ability to relate to their parents, their perceptions of their parents' adjustment; and which parent requested the divorce; were also determined. The research strategy was then to attempt to determine in what ways these factors are interrelated, in order to explain the adjustment of adolescents.

The research question, then, can be stated as follows:

\section{What factors can be identified as contributors to the adjustment in adolescents whose parents are divorced?}

The above factors (child's relationship with parents, child's attitude to divorce, parent's adjustment) will be examined in order to see whether any of these contribute in any way to the adjustment of adolescents. It seems important to try to ascertain such links, given the disturbingly high rates of divorce with which adolescents of today are faced.

\subsection{HYPOTHESES}

Given the problem stated above, it becomes necessary to propose some possible answers to this problem. The study will then attempt to ascertain statistically whether any of these answers might indeed appear to provide a plausible solution. Based on available literature, the following hypotheses are proposed:

1. The parent-child relationship will be positively related to the child's adjustment, whether or not the parents are divorced. If the parents are divorced, the child's 
post divorce adjustment will be positively linked to his/her relationship with his/her parents.

2. The above-mentioned correlation will be weaker if the child holds condemning attitudes to divorce than if the child's attitude to divorce is accepting, that is to say, the child's attitude to divorce will act as a mediating variable in the above relationship.

3. If the parent is well adjusted after a divorce, this will have a positive relationship with the child's adjustment, provided that the child feels he/she is able to relate to the parent in question. Similarly if the parent has adjustment problems, a child who feels able to relate to that parent will also exhibit problematic adjustment.

4. Children from divorced homes are more likely to be accepting of divorce, if those children have positive relationships with their parent(s), than are children from intact families.

\subsection{RESEARCH DESIGN}

A cross-sectional survey research design was used. It was decided to use questionnaires as the method of data collection. These questionnaires rely on self-report, which is, by nature, subjective. Grotevant and Carlson (1989) found, however, that self-report instruments are best used for assessing attitudes, beliefs and perceptions. Given the focus of the present study, it would seem that such a method would then be most appropriate.

Mouton and Marais (1990) discuss the concept of validity of research, pointing out that while it is never possible to control for all possible threats to validity, efforts should be made to minimize "nuisance variables" that might get in the way of the validity of the research. They emphasize the importance of eliminating such problems at the design phase of a research project in order to maximize the validity of the project. The steps taken to eliminate threats to validity will be discussed later on.

The unit of analysis in this study is the individual. The study will focus on individual adolescents and their perceptions of their relationships with their parents, their adjustment, and their attitudes to divorce. 
These individuals will be divided into subgroups based on different variables. The structure of the study will be such that an individual could fit into more than one subgroup, depending on which of the hypotheses is being tested. So, for example, an individual may have divorced parents, but may also feel that she is not able to relate to her mother, putting her into a subgroup for hypothesis 3. Hypothesis 2, however, looks not at the ability to relate to parents, but rather at whether the child is accepting or condemning of divorce. If the same individual held a condemning attitude to divorce, this would put her into a different subgroup for this analysis.

The subgroups to be analyzed will include: divorced parents and married parents; able to relate to parent(s) and unable to relate to parent(s); well adjusted parent(s) and parent(s) with adjustment problems; improved, deteriorated or unchanged parent-child relationship after divorce; amicably divorced parents and parents divorced with much fighting; families where a parent with whom the child has a good relationship requested the divorce, and families where a parent with whom the child does not have a good relationship requested the divorce. However, not all of the analyses will be looking exclusively at between group comparisons: some will be looking for the existence of correlations between different variables (for example, between Child's Attitude toward Mother (CAM total score) and Attitude to Divorce (total score for questionnaire).

In order to test the hypotheses outlined above, strengths of correlation between two variables are evaluated for different subgroups. Following this, these strengths of correlation can be compared in order to ascertain whether the variable on which the subgroups are separated, has an impact on the relationship between the two variables for which the correlation is being calculated. Attempts will also be made to ascertain statistically whether any of the three main variables predict one another, and further whether there is a mediating variable in such a relationship. These analyses will be discussed in more detail under "statistics".

The three main variables to be evaluated will be measured using established measuring instruments (detailed below). These measuring instruments have been previously researched and have been found to have acceptable reliabilities and validities (Amato \& 
Rogers, 1999; Grotevant \& Carlson, 1989; Petrie \& Brook, 1992). Other variables are measured simply by means of direct questioning. For example, where changes in the relationship between the child and the parent after divorce are being assessed, the individual is asked whether or not this relationship changed, and if it did, in what way it changed. It is assumed, for those variables where direct questioning is used, that the individual would be able to report accurately on these variables.

\subsection{Participants}

A convenience sample was used in the current study. Psychology and Economics lecturers of first year students at the University of Stellenbosch were asked to cooperate in the study by allowing the researcher 20 minutes of lecture time. The psychology department was chosen for various reasons: as the research is in this field, these lecturers were assumed to be open to participation in a study that might serve to further research in their field. They were also expected to have an interest in psychology, and in psychological research. It was then hoped that these students would be motivated to participate in such a study. However, Mouton and Marais (1990) point to a problematic trend in psychological research: they have found that close to 90 percent of psychological research uses samples composed exclusively of psychology students. This sampling bias would inevitably result in biases in research findings. It was for this reason that it was decided to also approach the Economics department of the University of Stellenbosch. It was believed that by avoiding the exclusive use of psychology students, some of the biases that such a sample might introduce could be avoided.

First year students were asked to participate in the study, as it was believed that the average age of these students would fall into the age group being studied. By asking students to state their age in the biographical questionnaire, it was possible to exclude any students not falling in the required age group. It was believed that by using a university sample, any educational differences that might influence aspects of children's postdivorce adjustment could be avoided.

However, as Mouton and Marais (1990) pointed out, the external validity of a questionnaire (and similarly of a study) is dependent on the extent to which that 
questionnaire (or the results of that study) can be generalized to the population being studied. A university student sample may not be representative of 17 to 22 year olds in South Africa. It clearly represents a limited section of the population. For practical reasons, it was decided, nonetheless, to limit the present study to a student sample. Should it be found that this study yields significant findings, this may pave the way for further research in this field using a broader sample, more representative of all South African adolescents.

\subsection{MEASURING INSTRUMENTS}

It was decided to use existing questionnaires to operationalise the main variables being examined:

- Hudson's "Child's Attitude Toward Mother (/Father)" questionnaire (Hudson, 1982) was used to measure the relationship with each parent.

- Antonovsky's (1979) “Life Orientation Questionnaire” was used to assess child adjustment.

- A set of questions used by various researchers (Amato \& Rogers, 1999; Booth \& Edwards, 1989) was used to measure attitude to divorce.

Other factors being examined were questioned directly under the heading of "Biographical information". This included questions about the child's upbringing, the felt ability to relate to parents, the parent who had requested the divorce, family circumstances before and after the divorce (including any changes in financial position and in relationships with the child following the divorce), frequency of contact with parents at the current time and immediately following the divorce, the child's perception of the parents' adjustment to the divorce, as well as information about gender, living arrangement, age, religion and so on (see Appendix 1).

Mouton and Marais (1990) refer to the danger of using retrospective data in measuring changes (including changes in attitudes and behaviour) over time. It is believed that people's memories tend to be fairly inaccurate, especially when emotional content is involved (divorce would be an emotional experience, and would probably involve 
memory distortions). For this reason, reliance on retrospective information was avoided wherever possible in the biographical questionnaire.

\subsubsection{Child's attitude toward mother / father (CAM/CAF) (Hudson, 1982)}

Hudson (1982) refers to these scales as a child-focused instrument to assess relationship problems between parents and child from the point of view of the child. These scales have been found to be suitable for use with adolescents and adult children (Grotevant \& Carlson, 1989) and were therefore believed to be appropriate to the current investigation. The questionnaires consist of 25 statements pertaining to the relationship with each parent. Respondents have to answer on a 7-point Likert-type scale, where options range from "rarely" to "most of the time". Some items are reverse scored (a score of 7 is then allocated where a response with an explicit score of 1 is chosen, and vice versa). These items are numbers $2,3,8,12,14,15,16,21$ and 24 . Once reverse scored items have been reversed, the total score is summed. The total score will then range from 25 to 175 . A higher score is indicative of more problems in the relationship between parent and child. Scores can be converted to a score from ranging from 0 to 100 . On this scale, Hudson suggests that a score of 30 would be a good cut-off point, above which one could assume that clinical problems exist in the parent-child relationship (Hudson, 1982). It is, however, emphasized by Hudson (1982) that this is an approximate cut-off, and that this score should not be used in isolation to determine the existence or absence of problems.

In the current study it was decided to work with raw scores instead of converting the scores to the scale from 1 to 100 . This was decided because of the ambiguity of the cutoff point and, more importantly, because of the desire to work with between-subject comparisons. It was believed that by using raw scores with a wider range, more betweensubject variability would be maintained, and that, in this way, more accurate comparisons could be drawn.

Grotevant and Carlson (1989) found alpha values of between .93 and .97 for both the CAM and CAF scales, indicating high reliabilities for these scales. They also found strong validity for these questionnaires. The questionnaires are clear, easy and quick to 
administer, rendering them suitable for a large group such as that used in the current study. However, Grotevant and Carlson (1989) point out that these questionnaires are, as is the case with many self-report questionnaires, susceptible to socially desirable answering. The questions are explicit in what they are measuring, and it is therefore easy to either answer these questions in such a way as to imply that one's relationship with the parent concerned is either very healthy or malfunctional. The nature of the questions is such that giving socially desirable (or undesirable) answers does not require any knowledge of psychology or of the questionnaire itself. Hudson (1982), however, argues that explaining the need for accurate information, as well as the futility for all concerned of giving false responses, should solve this problem. He also suggests looking for inconsistencies with scores on other tests, should the researcher suspect that answers are not a true reflection of the relationship. Such inconsistencies would suggest the giving of dishonest responses. In order to lessen participants' tendency to give socially desirable answers, participants were assured of anonymity. This will be discussed at greater length later on in this chapter.

These scales are culturally transferable, meaning that the existence of different cultural groups in the sample should not confound the analysis of results (Hudson, 1982). It was also found that the scales are not usually mood dependent (Hudson, 1982). Hudson further cautions that scales should be analyzed as complete scores, and that individual items cannot be analyzed independently.

\subsubsection{Attitude to Divorce}

A 6-item questionnaire has been used in various studies to measure attitude to divorce (Amato \& Rogers, 1999; Booth \& Edwards, 1989). Again a Likert-type scale is used where statements are rated from 1 to 4 by respondents. These statements concern whether or not divorce is seen as an acceptable solution to marital problems. Possible responses range from "strongly agree" to "strongly disagree". Again, some items are reverse scored (items 2, 3 and 6). The total score will then range from 6 to 24. A low score indicates a negative, or condemning attitude to divorce; while a high score indicates a positive, or accepting attitude to divorce. 
Amato and Rogers (1999) have used this questionnaire in their studies of divorce, and have found it to possess reliabilities (alpha) ranging from .63 to .67. Grotevant and Carlson (1989) argue that reliabilities between .5 and .6 are quite acceptable for research purposes, meaning that these questions should give a reliable indication of attitude to divorce.

Again the self-report nature of this questionnaire is beneficial in that it lends itself to use in large groups, but carries the disadvantage that it is easy to respond in a socially desirable way. As was the case with the CAM and CAF questionnaires, questions are fairly explicit in what they are measuring, so it is easy to answer in such a way as to express a very positive or very negative attitude to divorce. By keeping answers anonymous, the desire to answer in this way should be lessened.

\subsubsection{Life orientation questionnaire}

In order to get a measure of adjustment, it was decided to use the Life Orientation Questionnaire developed by Antonovsky (1979) measuring "sense of coherence" (SOC). Antonovsky (1979) defines SOC as

a global orientation that expresses the extent to which one has a pervasive, enduring, though dynamic, feeling of confidence that one's internal and external environments are predictable and that there is a high probability that things will work as well as can reasonably be expected (p. 132).

The concept includes three dimensions, described by Petrie and Brook (1992) as follows:

- Meaningfulness: life has purpose and life tasks are a good investment of energy and commitment

- Manageability: seeing oneself as having resources to cope with problems or demands in life

- Comprehensibility: seeing the world as making sense 
Flannery and Flannery (1990) describe SOC as an orientation that will enable an individual to select the best coping strategy for a situation. It is therefore deemed to be a good measure of adjustment.

Frenz, Carey and Jorgensen (1993) said that one's SOC could change either as a result of significant changes in one's environment, or could change temporarily due to major stresses. It was also found that divorce and remarriage are both periods when a reorganization of one's environment takes place, and that such reorganizations would influence the self and the SOC (Antonovsky, 1991). It seems, then, that the SOC concept links well with the focus of the current study, and therefore that the Life Orientation Questionnaire would be an appropriate instrument to use in assessing the adjustment of the individual.

The questionnaire consists of 29 statements to which answers range from scoring 1 to 7 on a Likert-type scale. Items 1, 4, 5, 6, 7, 11, 13, 14, 16, 20, 23, 25 and 27 are reverse scored. Once reverse scores have been taken into account, the scores are added together, giving a total score ranging from 29 to 203. The higher the score, the stronger the SOC of the individual (or the better the adjustment of that individual). Eleven items measure comprehensibility, ten measure manageability and eight measure meaningfulness. Frenz et al. (1993), however, suggest that because of high intercorrelations between factors, it is possible that the scale in fact only measures one global factor. For this reason, in the current study, these subscale scores were not used. Only the total SOC score was used for the purpose of analysis.

Because the questionnaire measures generalized beliefs about the self and the world, which are in turn seen to shape the individual's appraisal of situations (Antonovsky, 1991), this questionnaire seems to fit well with schema theory (discussed under theoretical orientation). Antonovsky and Sagy (1986) theorized that the nature of one's relationships with one's parents would influence one's development of a SOC. They were not able to establish whether this was in fact the case, as their study found that little variance in the SOC could be explained by relationships with parents. However, Antonovsky (1991) found that one learns one's SOC through one's experiences with 
one's parents. A secondary goal of this study is then to see whether any such links can be found with the nature of the parent-child relationship (as measured on the CAM / CAF).

The questionnaire has a high reliability, with alpha-coefficients ranging from .84 to .93 , as well as good validity (Petrie \& Brook, 1992). Frenz et al. (1993) assessed this questionnaire using undergraduate students (a sample similar to the one being used in the present study) and found alpha reliabilities of .92 and alpha values of .93 for internal consistency. This suggests that this questionnaire should provide a reliable measure for the current study. They also found that the SOC was able to discriminate between patients and non-patients in known groups, suggesting the existence of good discriminative validity.

Frenz et al. (1993) also point to the vulnerability of this questionnaire to socially desirable answering. Again, it is easy to predict what is being measured in each question, and therefore to answer so as to seem well adjusted, or alternatively, so as to seem to have many adjustment problems. Again, anonymous participation should lessen this problem.

\subsection{Procedure}

\subsubsection{Practical Data Gathering}

In order to use a student sample from the University of Stellenbosch, it was first necessary to approach the registrar for student affairs, to obtain permission to use students in a research project. This permission having been granted, the heads of department for Psychology and Economics were approached in order to obtain their permission to use lecture time in their departments for this research. It was explained to them that a once off contact time of 20 minutes would be needed in order to explain to the students the reasons for requesting their participation, and the way in which questionnaires would need to be answered, and to give them an opportunity to complete the questionnaires. It was also explained that the research would hope to benefit this group of students in some way, should it result in findings that might assist children from 
divorced families to better adjust to the divorce. For this reason, the participation of students in the research would be worthwhile.

After the heads of department had agreed in principle to the survey being conducted, the lecturers involved with first year students at the relevant time were approached with the above motivation. Both lecturers agreed to participate. The Economics lecture attended by the researcher was one in which role-call was to be taken (this had been made known to the students in advance). This meant that all students in that economics class ought to have been present at the lecture, avoiding any biases due to less well-adjusted (or better adjusted) students' being less likely to attend classes. The psychology lecture attended was one ear-marked by the lecturer concerned as that with the best attendance (it was found by this lecturer that early morning and late afternoon classes tended to have lower attendance, as the students grouped in these classes tended to remove themselves from these groups in order to attend lectures deemed to be at more reasonable times). Here again, then, it was hoped that biases involving those less likely to attend class would be less problematic.

Hudson (1982) points out that people tend to be rather wary of psychological testing of any kind, and that it is essential, for this reason, that the researcher show confidence in the merit of any tests or questionnaires that he or she might be using. When explaining to the students what it was that would be asked of them, the researcher explained the basic principles of the questionnaires, and why it would benefit the current research to have them completed. It was attempted to do this as broadly as possible, while at the same time being as open as possible about the research. Students interested in knowing more about the research were invited to speak with the researcher after filling in their questionnaires (or before filling in their questionnaires, should this be deemed necessary). Students were also invited to use a pseudonym on their questionnaires should they wish to know the results from the questionnaires that they had completed. It was hoped that in providing this facility, students would feel that the researcher was treating them with openness and respect. They might then be more inclined to reciprocate this open respect by filling in questionnaires honestly and accurately. 
Mouton and Marais (1990) discuss the way in which subjects of research tend to modify their behaviour because of their awareness of being studied. This behaviour modification could take the form of trying to look good (resulting in socially desirable responses), or could involve a deliberate mis-informing, to suggest that the respondent has many problems. They see this behaviour modification as the single largest threat to validity in research. It is therefore essential that participants be convinced not to change their behaviour (or in this case, not to change the way they report on their behaviour). Hudson (1982) also points to the importance of approaching explicitly the issue of socially desirable answering. It is his suggestion that one discuss the ease with which socially desirable answers can be identified by the respondent, and further that one discuss the right of the respondent not to disclose information. It should then be suggested that, should the individual not feel comfortable with disclosing this information, he should feel free not to complete the questionnaire. Indeed the voluntary nature of the students' participation in this study was an issue that was strongly emphasized both by the researcher and by the University. It was made clear from the start that the researcher was merely requesting the co-operation of the students present, and that they should in no way feel obliged to participate. Further, should they at any point wish to discontinue their participation for any reason, that they would be free to do so. The researcher made every effort to emphasize that student participation would be most appreciated, but that participation where people were not prepared to give honest answers to questions asked would not be helpful at all. The issue of socially desirable answering was explicitly broached, and students were strongly requested not to participate unless they intended to answer all questions as honestly as they could. It was emphasized that making oneself look good would not be of any benefit to anyone. Given the anonymous nature of the questionnaires, it was easy for the researcher to point out to participants that no-one would ever be able to link the scores of the questionnaires they had completed with them. There again the futility of giving socially desirable answers was made clear.

Mouton and Marais (1990) also discuss other threats to validity that need to be addressed in research. These will be briefly described. Following this, an explanation will be given of how each threat was dealt with in the current study: 
- The motivation of participants: Mouton and Marais believe that this is influenced by interest in the study, and by the extent to which the study is perceived as threatening. It was hoped that by briefly explaining the questionnaires and the nature of the study to participants, those participants would become interested in the study. By offering reports-back to those interested, the researcher hoped to gain co-operation. Effort was made to present the study and the role of the participant in as friendly and non-threatening a way as possible. Furthermore, it was hoped that by conducting the study in a familiar environment, anonymously, and with a large group of familiar people, that this would not be seen as threatening. The voluntary nature of participation should also make this research less threatening.

- Invasion of privacy is a perception that ought to be avoided in participants if one wishes to glean valid data. If people feel that their privacy is being invaded, they are less likely to give valid responses. While the nature of some of the questions was fairly personal, it was hoped that by keeping participation voluntary, in conjunction with the anonymous completion of the questionnaires, people would not feel compromised in their rights to privacy.

- Association of researcher with a respected body: Mouton and Marais have also found that research participants tend, in general, to take research more seriously where the researcher is deemed to be associated with a respected body. It was hoped that by presenting the researcher as a post-graduate student of Stellenbosch University, that this problem would be adequately dealt with. It was believed that students who had chosen Stellenbosch University as a suitable institution to complete their studies would see this university as a body worthy of respect.

- Researcher as an "outsider": Research participants tend to be less accepting and less co-operative if the researcher is someone who is seen as an "outsider". Here again, the association with Stellenbosch University proved useful in this study. The researcher was able to present herself as a fellow student at Stellenbosch University, hoping that this would result in the co-operation of the students. Indeed, this appeared to be successful, as in the two classes approached for data, all of the students present volunteered to participate in the research! 


\subsubsection{Scoring of questionnaires}

A total of 293 questionnaires were completed by the students. When this data was sorted into those respondents who had divorced parents $(n=42$, of which 3 did not complete all the questionnaires) and those whose parents were still married $(n=251)$, it was found that an overwhelming majority came from intact families. It was decided to work with more similar numbers of respondents from divorced and married backgrounds. Numbers from 1 to 251 were assigned to each set of questionnaires. This was done in order to enable random decisions on which respondents to exclude from the analysis; as well as to enable respondents' answers to be checked up on, should irregularities arise later on in the analysis. For those from divorced families, all responses were used. Where families were intact, a random number table (Howell, 1995) was used to decide on which 38 participants' questionnaires to use in the analysis.

For the biographical questionnaire, it was decided to convert answers to numbers. This was made possible by the fact that all questions (except age, which is by nature numerical) were answered by ticking a box. This means that there were a limited number of possible answers to each question. For example, question 6 asked how many times the respondent had seen his/her mother in the last year. Possible answers given were "daily" (allocated a score of "6"); "few times a week"(allocated a score of "5"); "weekly" (allocated a score of "4"); "monthly" (allocated a score of “3”); "few times a year" (allocated a score of "2"); and "never" (allocated a score of "1"). The numerical values allocated to answers of other questions can be found in Appendix 3. This use of numbers instead of what tended often to be fairly long-winded verbal answers, made it easier to enter data into an Excel data file, and also facilitated the analysis of the data.

Each question was given a title. These titles were then entered as the top row of the Excel sheet. For example, question 17 of the biographical questionnaire asked whether the family's financial position had deteriorated after the divorce (that is, whether they had had to move to a less expensive neighbourhood, to a smaller house, etc). In the Excel sheet, this question was titled "finances". This was done in order to facilitate easy 
interpretation of the data in the Excel file for analysis. Individual questions in the Child's Attitude to Mother (CAM), Child's Attitude to Father (CAF), Life Orientation Questionnaire (LOQ) and Attitude to Divorce (ATD) questionnaires were simply labeled CAM1, CAF2, etc. The nature of these questions did not need to be explicit in their titles, as it is cautioned by those who compiled these questionnaires that individual questions cannot be used on their own to draw conclusions. The only score that would be used in analyses of these questionnaires would be the total score, labeled "CAM total", "CAF total", "LOQ total" and "ATD total" respectively.

Calculating the total score for the CAM, CAF, LOQ and ATD required the use of formulae. A simple sum of scores would not yield an accurate answer, as these questionnaires all contain items needing to be reverse-scored. In order to reverse-score an item in a questionnaire where answers range from $1-7$ (as is the case in the CAM, $\mathrm{CAF}$ and LOQ), the raw score obtained for the reverse-scored question needs to be subtracted from 8. This score was then added into the total score. For the ATD questionnaire, reverse-scored items have their raw score subtracted from 5 , as answers range from $1-4$ on this questionnaire.

Some questionnaires had answers that had been left out. It is impossible to tell whether this took place by accident, or whether respondents had found the questions concerned too threatening, and had therefore abstained from answering them. Hudson (1982) states that the CAM and CAF questionnaires would provide valid estimates of the relationship provided that no more than 5 items had been left out. Only two respondents had left out more than 5 items, but these people had also left out the entire LOQ and ATD questionnaires. It was assumed that they had chosen not to continue with their responses, and their responses were discarded, as they were incomplete. As both of these respondents were from divorced families, it was impossible to simply replace this data with questionnaires from other respondents. For the LOQ, which consists of 4 more items than did the CAM and CAF, it was decided to follow Hudson's rule-of-thumb, and to exclude from the analysis only questionnaires where more than 5 answers had been left out. This was not the case for any of the respondents (except for the two mentioned above). The ATD questionnaire proved more problematic in deciding when to consider 
responses too few to be valid. Only 1 respondent had left out answers on this questionnaire, so it was decided to estimate answers for this respondent based on the answers that had been completed. A note was made of his/her questionnaire number (105), so that his/her responses could be discarded, should any irregularities arise elsewhere in the analysis.

Where information had been left out, a method had to be decided on for scoring the questionnaire. Hudson (1982) suggests a method to be used when working with scores from 1 to 100 , but this had to be modified as the current study used raw scores rather than converted scores (discussed previously under Measuring Instruments). Simply leaving out the score for an unanswered question would obviously result in an inaccurate total score (the computer would have allocated either " 0 " or " 8 " depending on whether it had been a reverse-scored item or not). For this reason, it was decided to calculate an average score, based on the questions that had been answered. For example, suppose respondent 33 (who has a raw score, as calculated based on the formula, of 115) had left out questions 8 and 10 on the CAM. Question 8 is reverse-scored, so the computer would have added " 8 " to the total score. Question 10 uses ordinary scoring, so " 0 " would have been added. Subject 265 had only answered 23 of the 25 questions, meaning his total possible score would be $161(23 \times 7)$. However, he has had 8 points added to his score by the computer. It is then necessary to subtract these 8 points from his total score, before converting this score. Subtracting 8 from 115 leaves him with a score of 107 . However, as this is a score out of 161 , it cannot, at this point, be compared to the scores of other respondents, as those scores are all out of 175 (25 x 7). The next step, then, will be to convert this score to a score out of 175 . Dividing 107 by 161 , then multiplying the resulting score by 175 , will do this. This respondent's score will now be 116.3 , which can be rounded down to 116 . This score can then be compared to those of other respondents in any analyses being conducted. A similar procedure was used for scores on other questionnaires. All that needed to be changed was the base numbers. It was also essential to check whether reverse scored items had been left out. Where this was the case, it was necessary to subtract 8 (or 5 on the ATD questionnaire) from the total before converting the score. 


\subsection{Statistical ANALYSES}

The data obtained from the questionnaires was entered into an Excel spreadsheet. Excel was chosen as this programme can be used in interaction with Statistica (StatSoft, 2003), the statistical package used to analyze the data. Excel is also a user-friendly programme that facilitates the scoring of questionnaires.

The various analyses performed will be discussed in more detail in chapter 5 . These analyses were divided into three sections: general analyses, analyses investigating the role of schema theory, and analyses investigating the role of learning theory.

\subsubsection{General analyses}

The following analyses were conducted in order to investigate the interrelationship between various factors suggested by previous research to be of importance in divorce:

- Life Orientation Questionnaire (LOQ) scores of children from married families were compared to those of children from divorced families, using t-tests and leastsquare means diagrams;

- Attitude to Divorce (ATD) scores of children from married families were compared to those of children from divorced families, using t-tests and leastsquare means diagrams;

- LOQ scores were compared for children from divorced families who had either improved, deteriorated or unchanged relationships with their mothers and / or fathers after the divorce. This was done using analysis of variance (ANOVA);

- ATD scores were compared for children from divorced families who had either improved, deteriorated or unchanged relationships with their mothers and / or fathers after the divorce. This was done using ANOVA;

- ATD scores were compared for children where pre-divorce circumstances had involved a lot of fighting to those where these circumstances were friendly and co-operative. ANOVA was again used;

- ATD scores were compared for children where post-divorce circumstances had involved a lot of fighting to those where these circumstances were friendly and co-operative. Again ANOVA was used; 
- ATD scores were compared for children whose financial position had deteriorated following divorce to those whose financial situation had not changed. Here, too, ANOVA was used.

\subsubsection{Schema theory}

In order to investigate whether schema theory provides an acceptable explanation of the results, the following would need to be ascertained:

- In divorced families, there should be a positive correlation between the parentchild relationship (measured on the Child's Attitude to Mother (CAM) and Father (CAF) scales) and the child's attitude to divorce (ATD). This was done using Pearson correlation, and presented as a scatter plot;

- A positive relationship should exist between the child's attitude to divorce, and the child's adjustment (measured using the LOQ) in divorced families. Again, Pearson correlation was used to analyse this;

- Both CAM / CAF and ATD should predict variance in LOQ scores, that is, relationship with parents and attitude to divorce should predict the child's adjustment. Regression analyses were used;

- ATD should indicate greater acceptance of divorce where the child feels able to relate to the parent who requested the divorce. ANOVA was used here.

\subsubsection{Learning theory}

Here again, in order to ascertain the relevance of learning theory as an explanation for the results found, the following questions must be answered:

- Is a child whose parent(s) did not experience adjustment problems following divorce better adjusted than one whose parent experienced adjustment problems? Significant differences were sought between these children in their LOQ scores using ANOVA, and presented using least-square means diagrams.

- Is this effect more pronounced where the child is able to relate to the parent concerned? Again, a series of ANOVA's and Mann-Whitney U-tests (non- 
parametric) were used to determine whether the child's ability to relate to his/her parent influenced his/her adjustment. 


\section{RESULTS}

\subsection{INTRODUCTION}

Various analyses were conducted on the data in this study. These analyses are separated into three sections. The first section includes general analyses, which present the role of biographical factors (divorce, changes in relationship with parent, circumstances preceding divorce, circumstances following divorce, changes in financial position following divorce). Next, analyses pertaining to schema theory are presented (the existence of correlations between the parent-child relationship (measured on CAM / $\mathrm{CAF}$ ), the attitude to divorce (ATD) and the adjustment of the child (measured on the Life Orientation Questionnaire (LOQ) is investigated here). Finally, analyses pertaining to learning theory are presented. Here the study attempts to establish whether the parent's adjustment is related to the child's adjustment (measured on the LOQ).

\subsection{GENERAL ANALYSES}

In Figure 5.1 below, the existence of possible differences between the adjustment of children from married families and that of children from divorced families was investigated. 


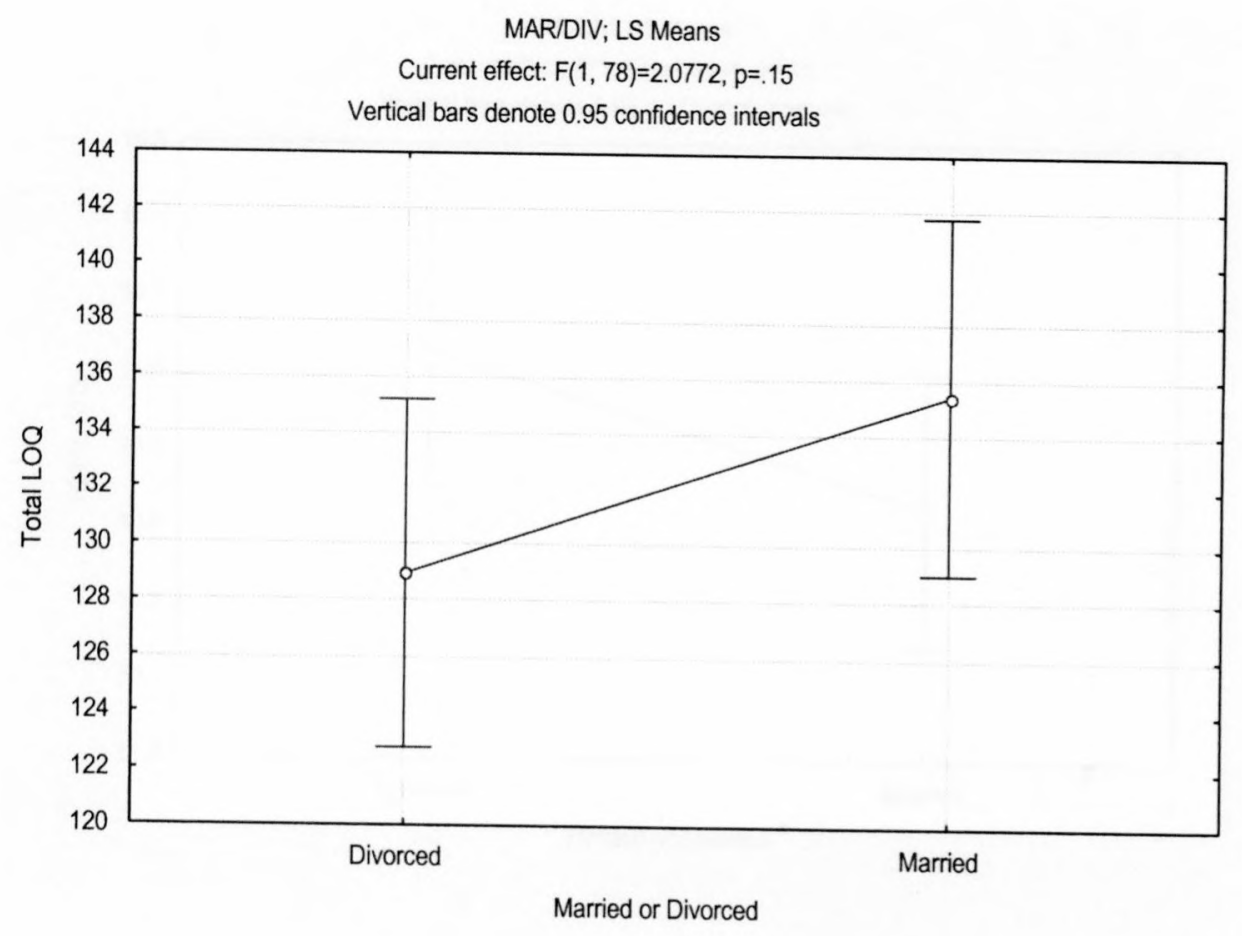

Figure 5.1. A comparison between LOQ (Life Orientation Questionnaire) scores of children from married families and those of children from divorced families.

As can be seen in Figure 5.1, children from married families $(n=38)$ did tend to have higher LOQ scores than did children from divorced families $(n=39)$. This was, however, not a significant difference $(p=.15)$.

In Figure 5.2, the existence of possible differences between the attitudes to divorce of children from married families and those of children from divorced families was analyzed. 


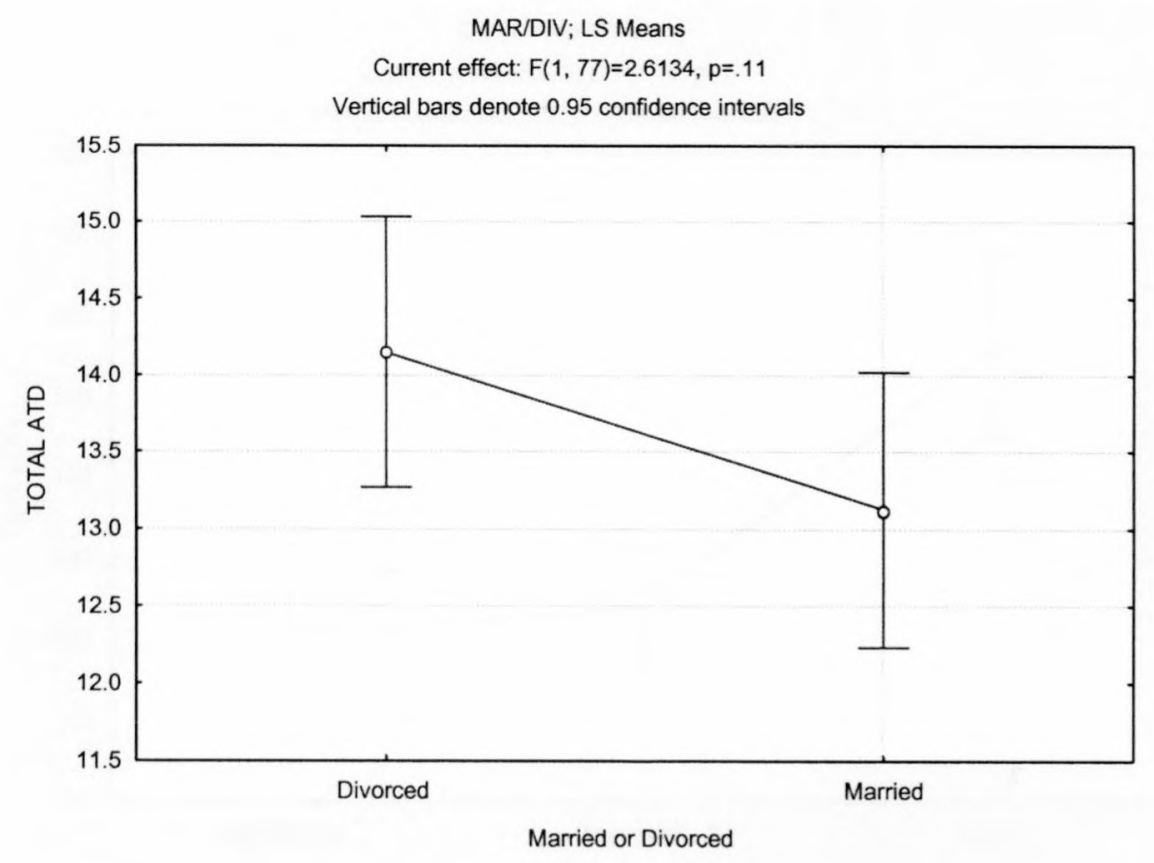

Figure 5.2. A comparison between ATD (Attitude to Divorce) scores of children from married families and those of children from divorced families.

While there was a trend where children from married families tended to have lower ATD scores than did children from divorced families, this trend only approached significance $(p=.11)$. As can be seen in Figure 5.2, there is quite a bit of overlap between the 95\% confidence intervals of these two groups, suggesting that they are not entirely different.

In Figure 5.3a, adjustment of children is compared between children whose relationships with their mothers improved, deteriorated or stayed the same following divorce. 


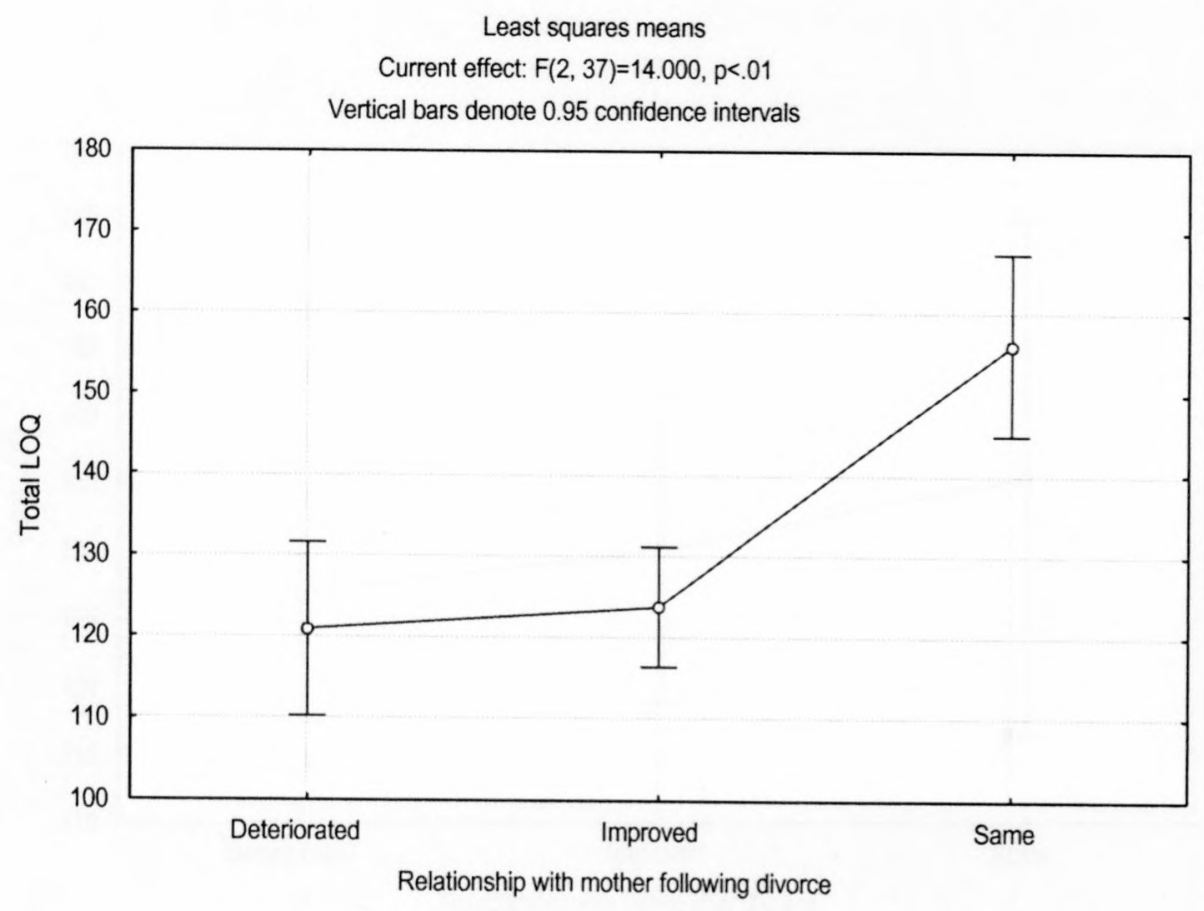

Figure 5.3a. A comparison between LOQ (Life Orientation Questionnaire) scores of children based on the existence or absence of changes in their relationships with mothers.

In Figure 5.3b, adjustment of children is compared between children whose relationships with their fathers improved, deteriorated or stayed the same following divorce. 


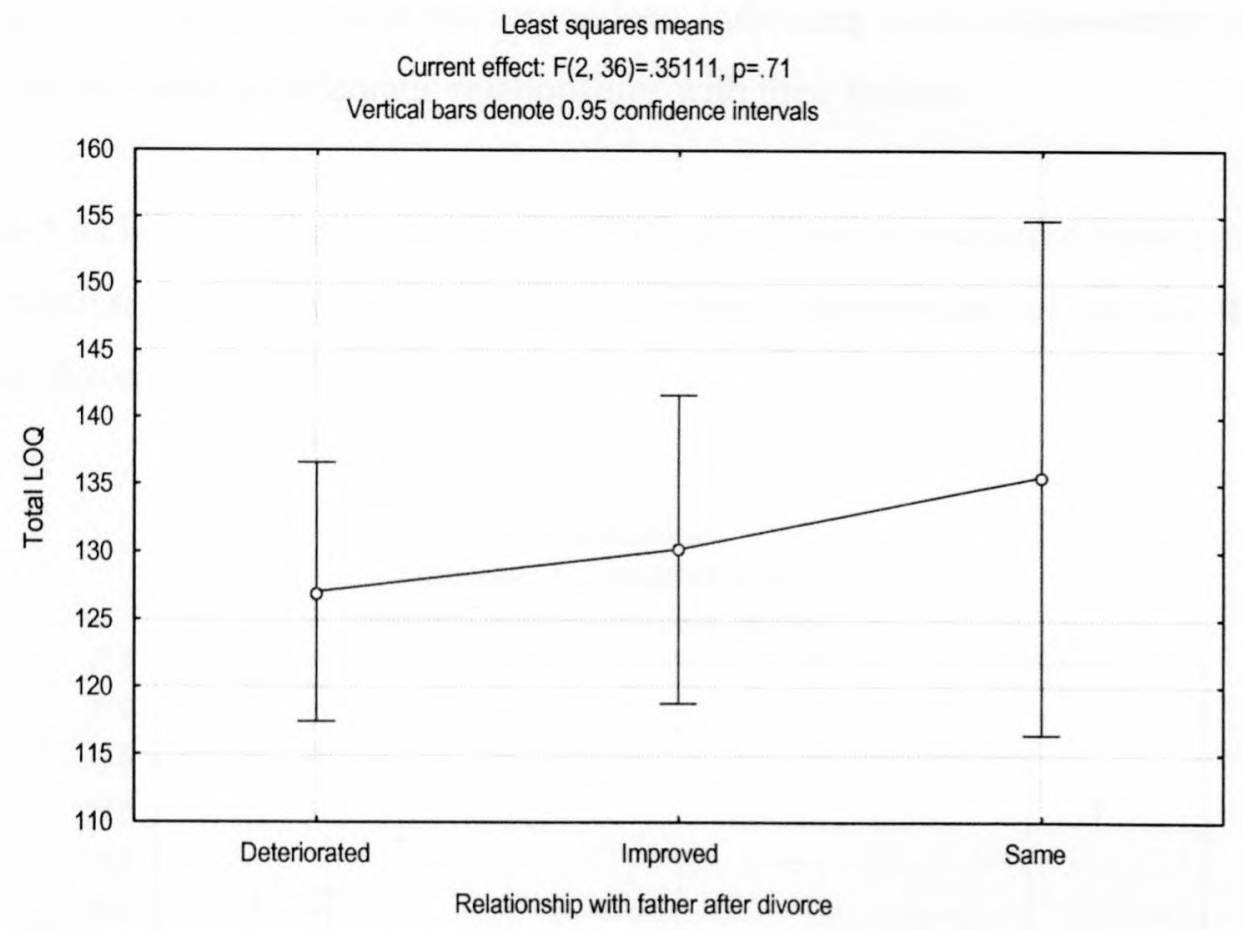

Figure 5.3b. A comparison between LOQ (Life Orientation Questionnaire) scores of children based on the existence or absence of changes in their relationships with fathers.

Where the relationship with the mother was concerned (Figure 5.3a), a relationship that had remained the same after the divorce was related to a significantly higher average LOQ score than where the relationship had improved or deteriorated $(p<.01)$. It would seem that there is something to be said for stability in the mother-child relationship. However, closer analysis of the data indicates that all of those respondents who had indicated stable relationships with their mothers also indicated positive relationships with their mothers. None of the respondents indicated stable problematic relationships with their mothers.

Where the relationship with the father was concerned (Figure 5.3b) the trend was not significant - here the mean LOQ scores in the three groups evaluated (relationship improved, deteriorated and stayed the same) were very similar, and much overlap can be seen in the $95 \%$ confidence intervals, suggesting no significant differences between these 
groups $(p=.71)$. Here some of the respondents indicating stable relationships with their fathers also indicated problematic relationships with their fathers.

In Figure 5.4a below, attitude to divorce (ATD) of children is compared between children whose relationships with their mothers improved, deteriorated or stayed the same following divorce.

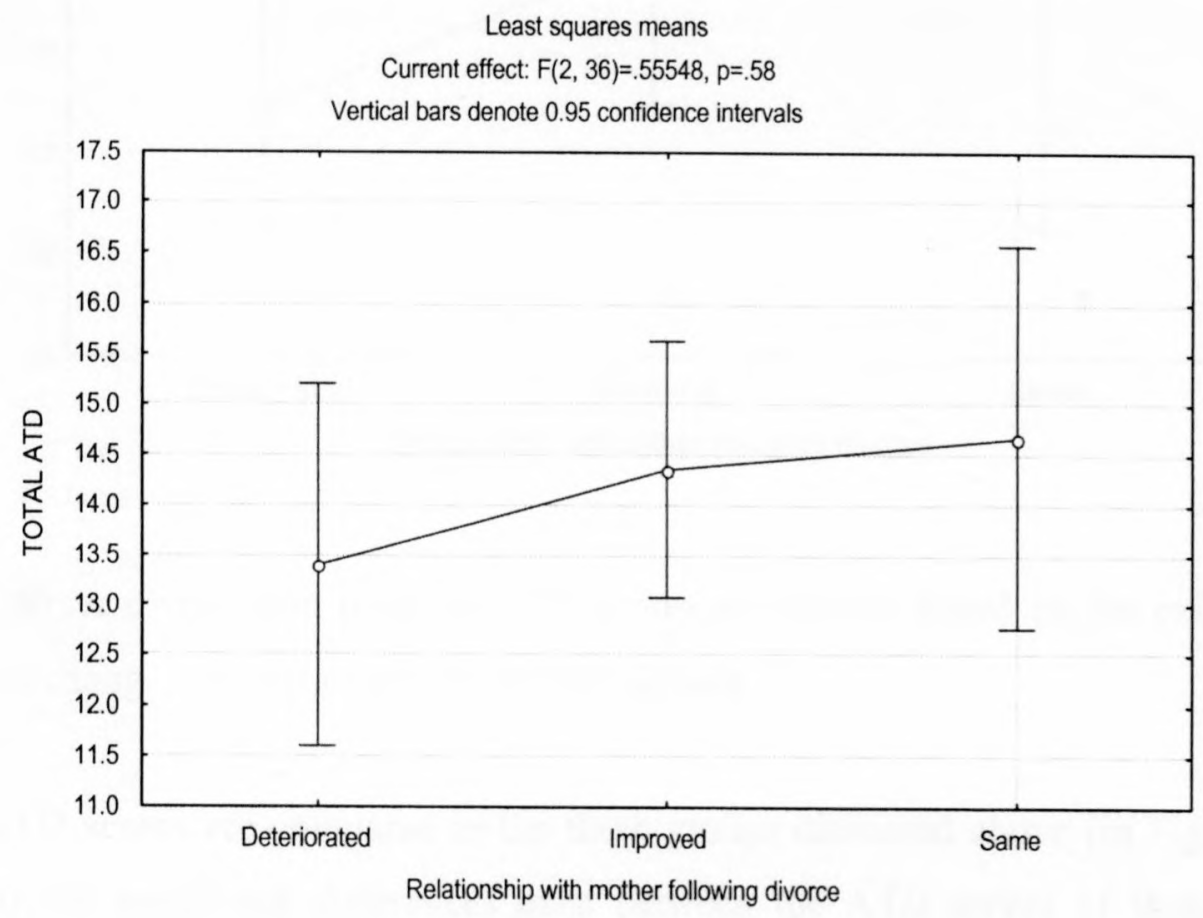

Figure 5.4a. A comparison between ATD scores of children based on the existence or absence of changes in their relationships with their mothers.

In Figure 5.4b, attitude to divorce (ATD) of children is compared between children whose relationships with their fathers improved, deteriorated or stayed the same following divorce. 


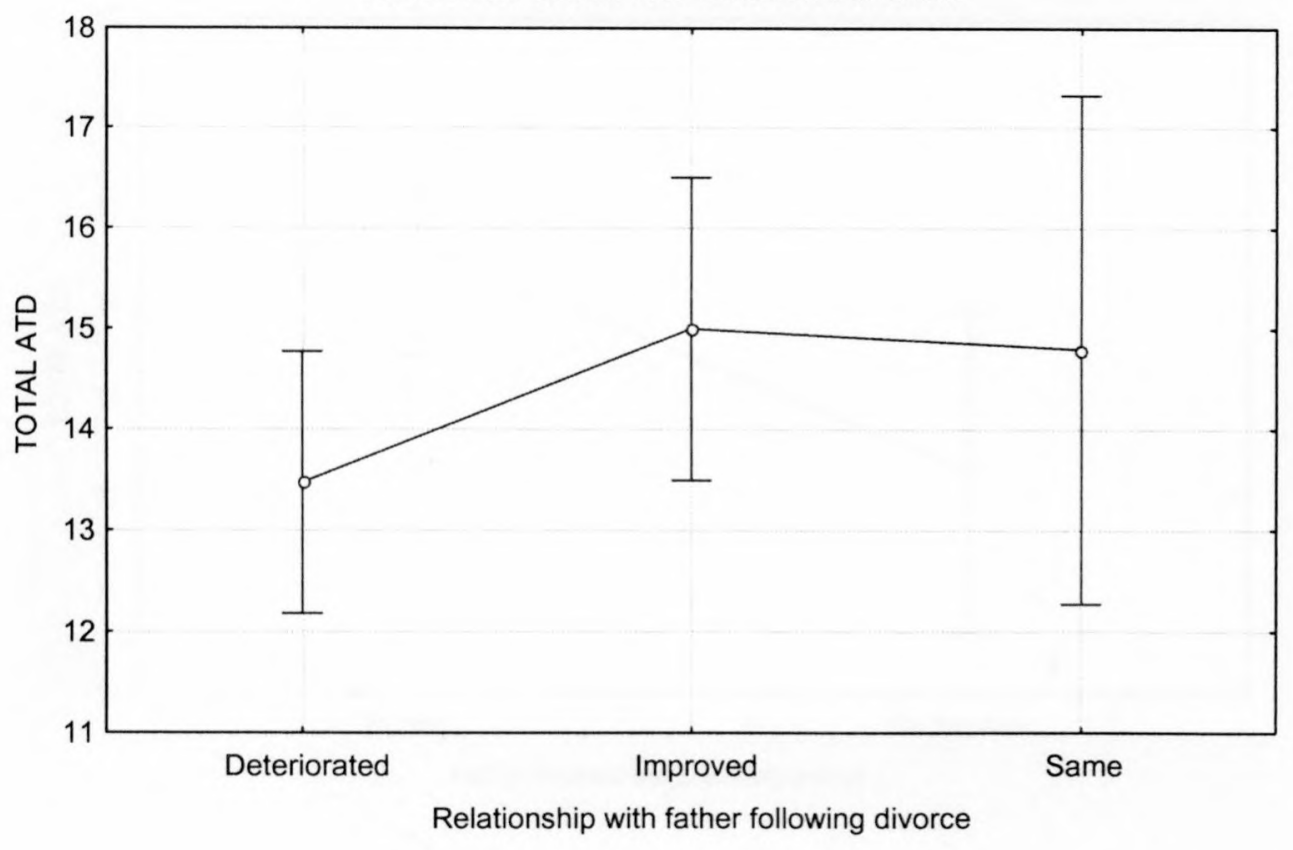

Figure 5.4b. A comparison between ATD scores of children based on the existence or absence of changes in their relationships with fathers.

Where ATD scores are compared in the three groups discussed above (in Figures 5.3a and 5.3b), no significant differences exist between the ATD scores of these groups, whether it be the relationship with the mother or the relationship with the father that is being examined (for mother, $\mathrm{p}=.58$; for father, $\mathrm{p}=.28$ ).

In Figure 5.5a, attitude to divorce (ATD) is compared for children based on the home circumstances that preceded their parents' divorce. Those whose parents fought a lot (fighting) are compared to those whose parents were more friendly and co-operative (cooperative). 


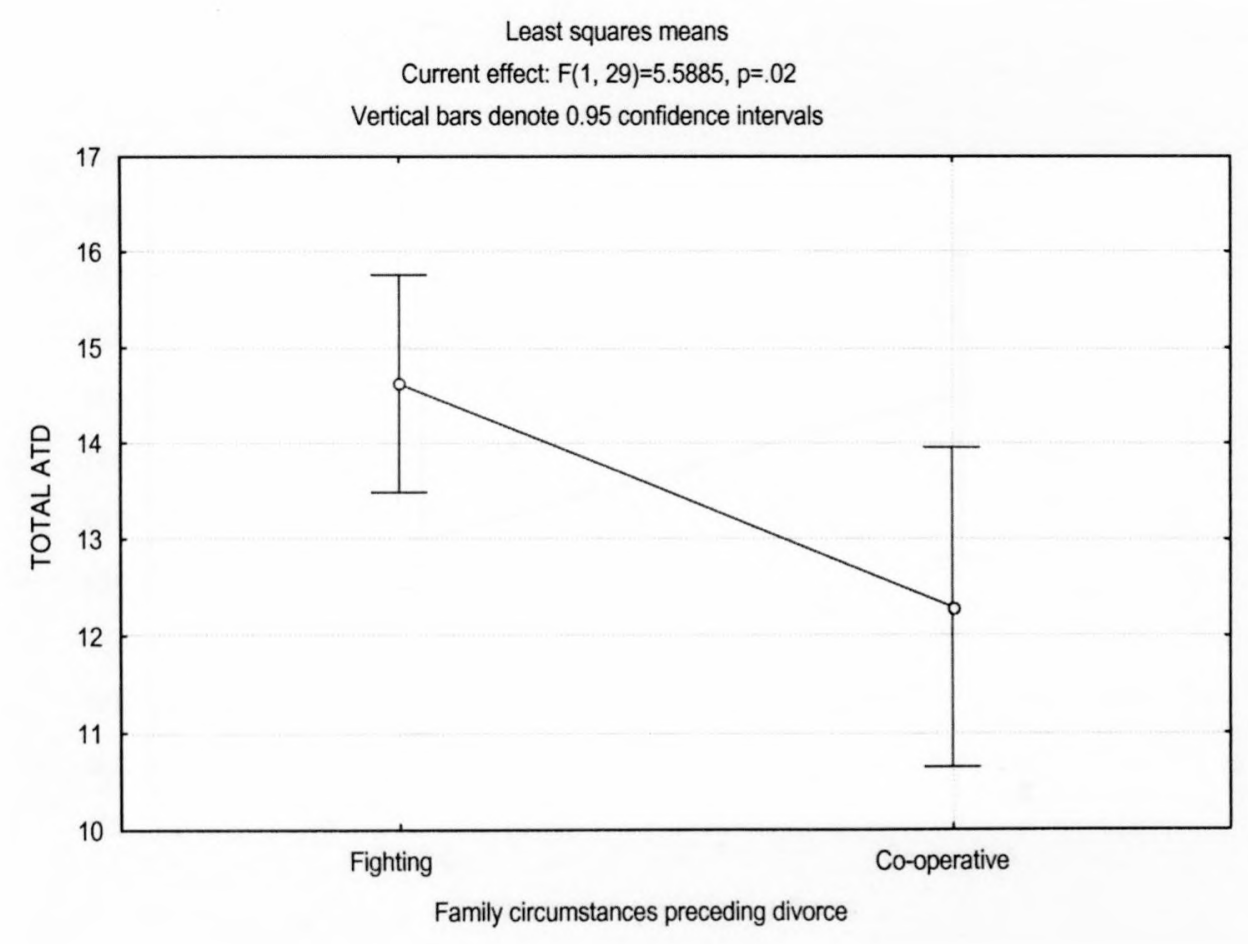

Figure 5.5a. A comparison between ATD scores of children whose parents fought prior to divorce, and those whose parents were co-operative.

It is evident that average ATD scores are significantly higher where the circumstances preceding the divorce involved a lot of fighting, than where these circumstances were fairly friendly and co-operative $(\mathrm{p}=.02)$.

In Figure 5.5b, attitude to divorce (ATD) is compared for children based on the home circumstances that followed their parents' divorce. Those whose parents fought a lot (fighting) are compared to those whose parents were more friendly and co-operative (cooperative). 


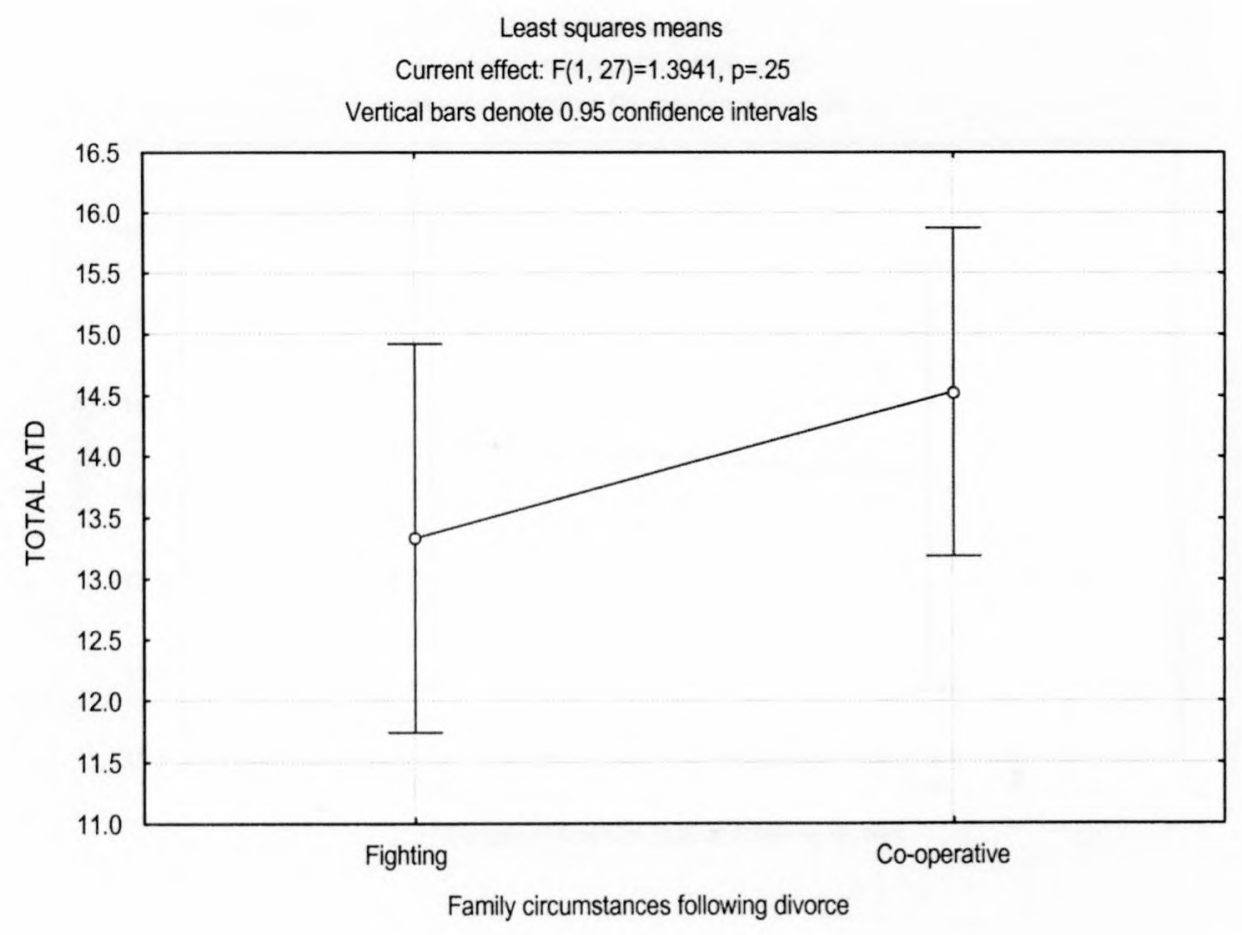

Figure 5.5b. A comparison between ATD scores of children whose parents fought after the divorce, and those whose parents were co-operative.

Where circumstances following the divorce are considered, attitude to divorce (ATD) does not appear to be significantly different whether circumstances involved cooperation, or whether much fighting was involved $(p=.25)$. It is interesting, though, that while prior to the divorce, fighting tended to predict higher ATD scores, after the divorce, the trend is for fighting to be associated with slightly lower ATD scores than those associated with co-operation.

In Figure 5.6, changes in the financial position of the family following divorce, and the relationship between such changes and the child's attitude to divorce (ATD) are analyzed. 


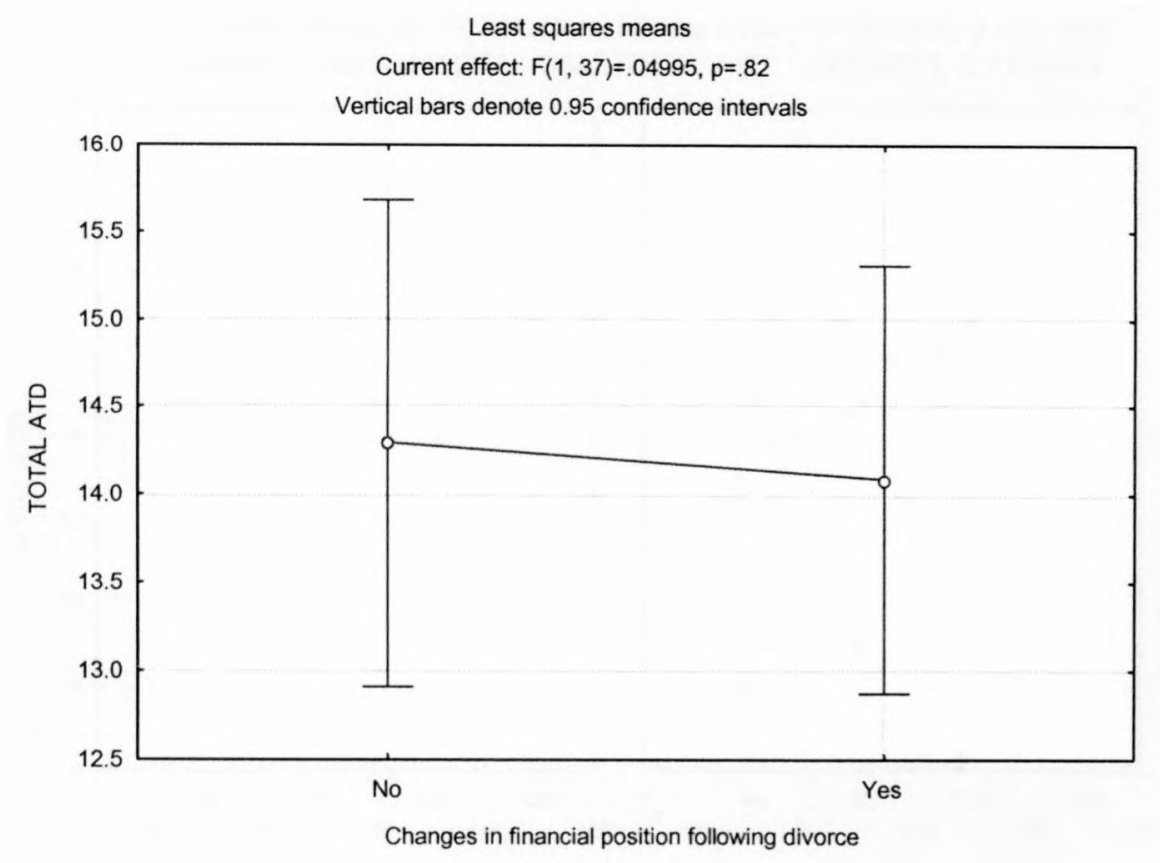

Figure 5.6. A comparison between ATD scores of children of families who have experienced changed financial positions and those who have not.

Changes in the family's financial position following the divorce do not appear to have any impact on ATD scores. The question asked was simply whether or not the financial position changed after the divorce, so there was no measure of the extent of changes. However, it can be seen in Figure 5.6 that the mean ATD scores fall within .5 points of one another. No significant differences existed between these 2 groups $(p=.82)$.

\subsection{ANALYSES INVESTIGATING SCHEMA THEORY}

In Figure 5.7 below, the correlation between child's attitude to divorce (ATD) and child's relationship with mother (CAM) is looked at for intact and divorced families separately. 


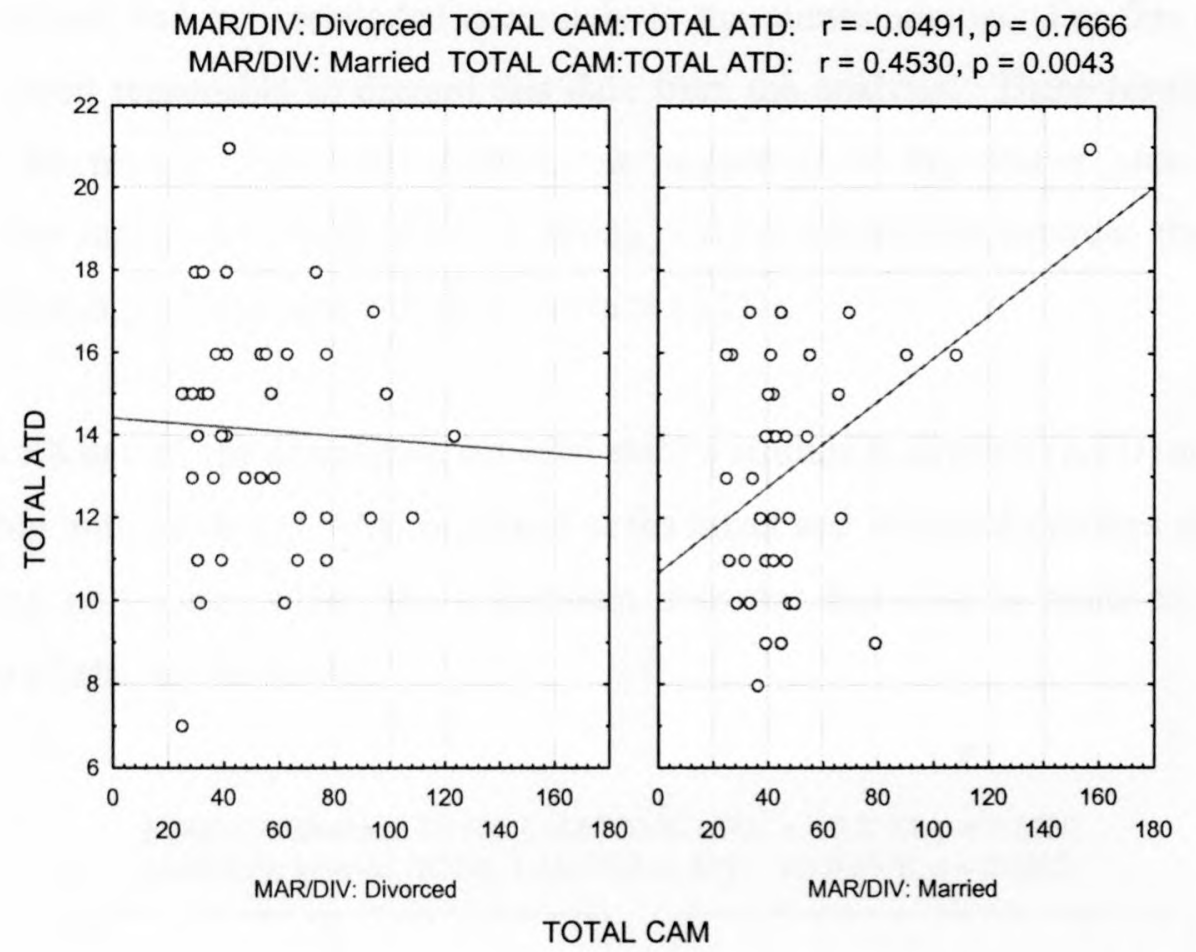

Figure 5.7. The correlation between attitude to divorce and mother-child relationship (CAM) for divorced and married families. The lines are regression lines fitted through the data.

It can be seen from the above graphs that there is a significant positive relationship $(\mathrm{r}=$ $.45, \mathrm{p}<.01$ ) between attitude to divorce (ATD) and mother-child relationship (CAM) in children of married families, but that this relationship is not significant, and is in fact slightly negative $(r=-.05, p=.77)$ where children of divorced families are concerned.

It is, however, apparent that, for the married group, one of the data points being analysed might be unduly influencing the data. This point can be seen in the top right hand corner of the "married" graph (Figure 5.7). It was identified as case 72, and because of its influence, it was decided to repeat this analysis without case 72 . After case 72 was removed, the slope of the regression line decreased, and the correlation dropped to $.22 \mathrm{p}$ $=.20$ ). Assuming, then, that case 72 was not valid, the null hypothesis (that no significant relationship exists between CAM and ATD) could not be rejected. However, case 72 was reviewed, and the data reported by this respondent gave no reason to suspect 
that this person had not responded accurately to the questionnaires. For this reason, it does not seem reasonable to discard this data from the analysis. These results should, however, be treated with some caution, as inspection of the scatter plot does not immediately suggest the existence of a strong positive correlation between the motherchild relationship (CAM) and attitude to divorce (ATD).

In Figure 5.8 below, the correlation between child's attitude to divorce (ATD) and child's relationship with mother (CAM) is looked at for intact and divorced families separately, considering only cases where the respondent does not feel able to relate to his / her mother as a behavioural model.

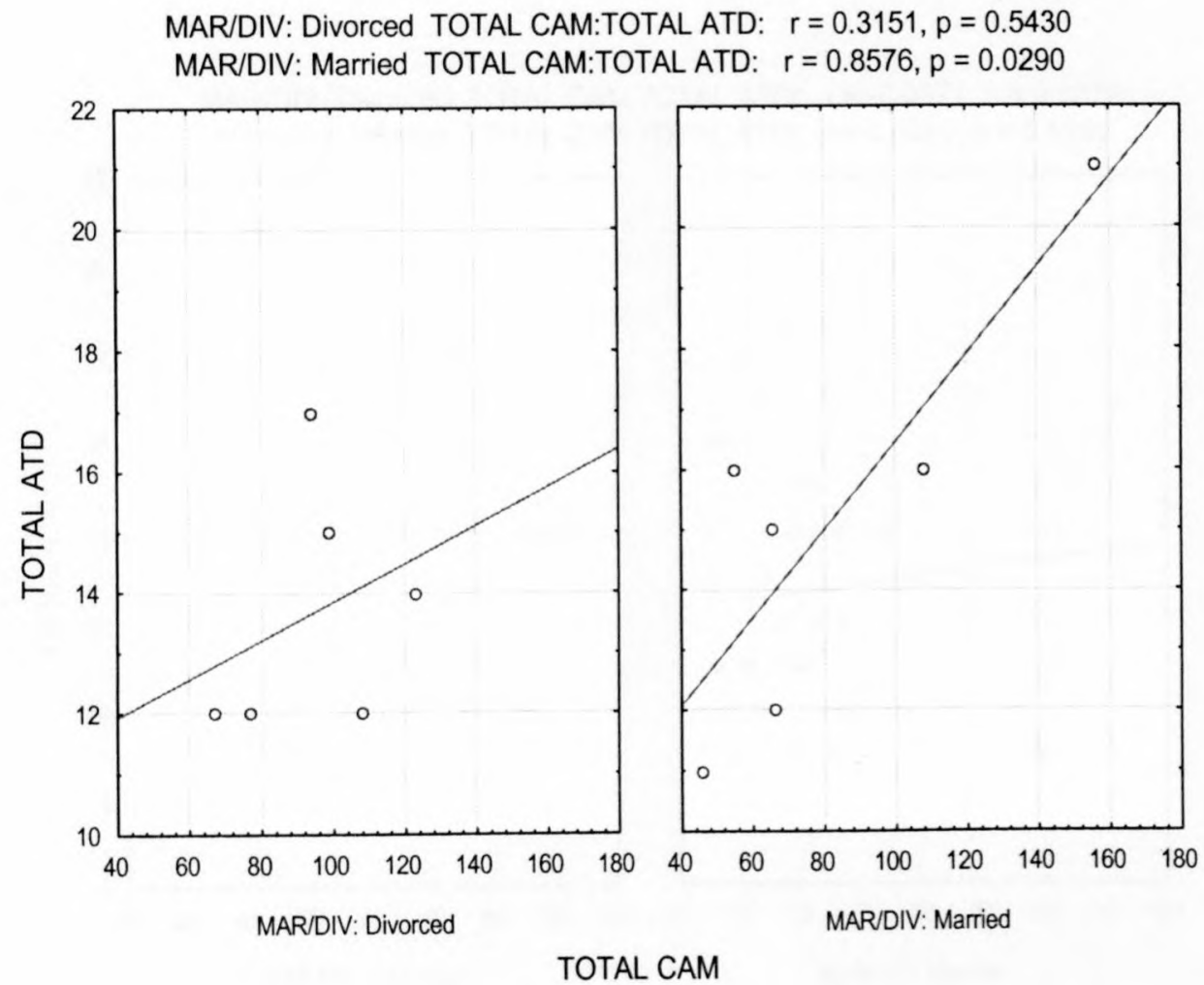

Figure 5.8. Correlation between attitude to divorce and parent-child relationship where children do not feel able to relate to their mothers (for divorced and married families). 
It appears from the above figure that correlations are stronger between mother-child relationship (CAM) and attitude to divorce (ATD) for children from both married and divorced families, where these children do not feel able to relate to their mothers. The extent of this correlation is still not significant in divorced families $(r=.32, p=.54)$. It is, however, significant in married families $(\mathrm{r}=.86, \mathrm{p}=.03)$. However, as can be seen in Figure 5.8, there are only 6 cases in each of these data sets.

In Figure 5.9 below, the correlation between child's attitude to divorce (ATD) and child's relationship with mother (CAM) is looked at for intact and divorced families separately, considering only cases where the child was able to relate to his/her mother as a behavioural model.

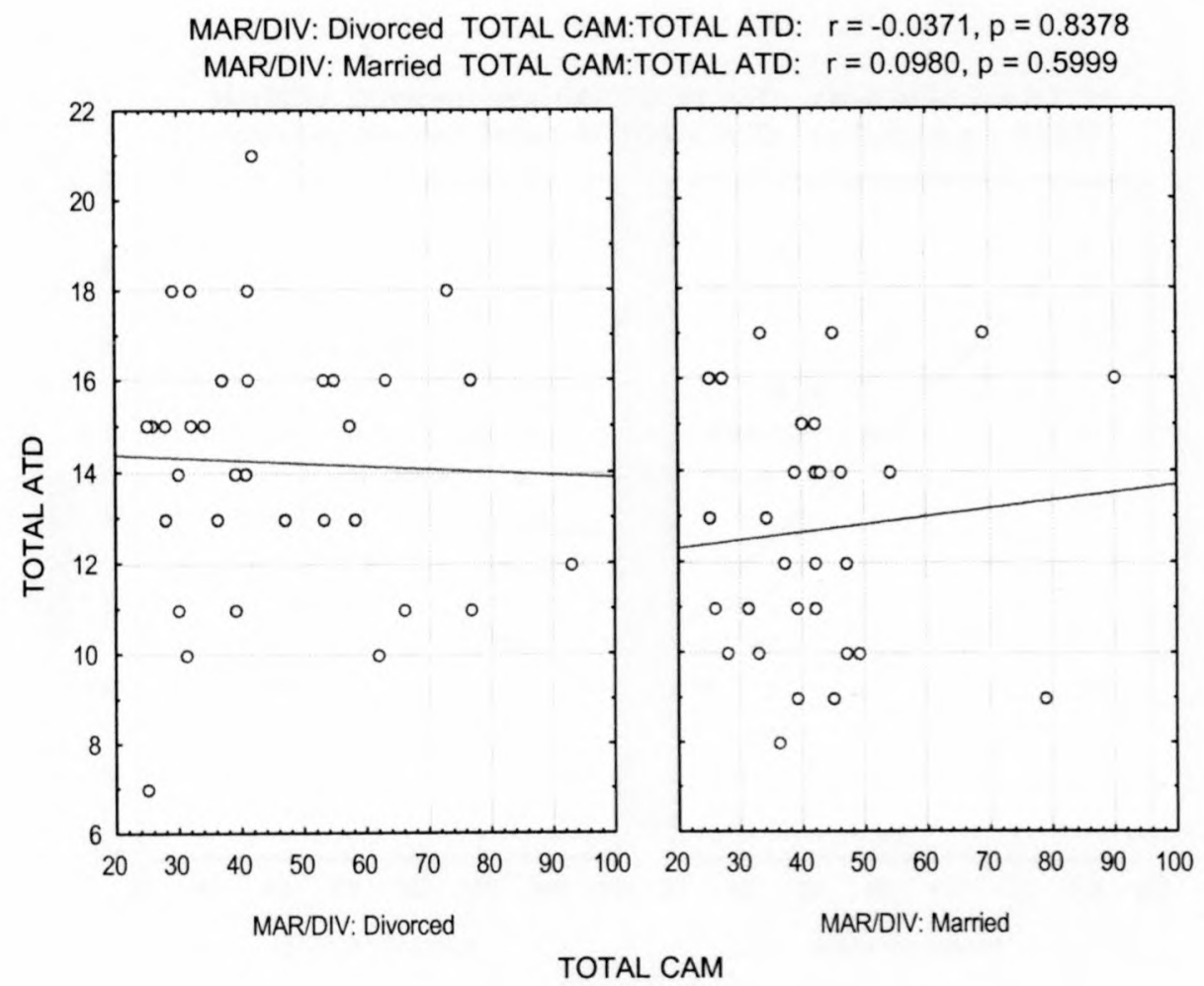

Figure 5.9. Correlation between attitude to divorce and parent-child relationship where children feel able to relate to their mothers (for divorced and married families). 
It is evident in these graphs that, when those participants who did not feel able to relate to their mothers were excluded from the data, the significance of the relationship between mother-child relationship (CAM) and attitude to divorce (ATD) dropped (see Figure 5.7). Neither of the 2 groups presented in Figure 5.9 showed a significant correlation.

In Figures 5.10 to 5.12, the analyses conducted in Figures 5.7 to 5.9 were repeated, this time using Child's Attitude to Father (CAF) instead of Child's Attitude to Mother (CAM).

In Figure 5.10 below, the correlation between child's attitude to divorce (ATD) and child's relationship with father (CAF) is looked at for divorced and intact families separately.

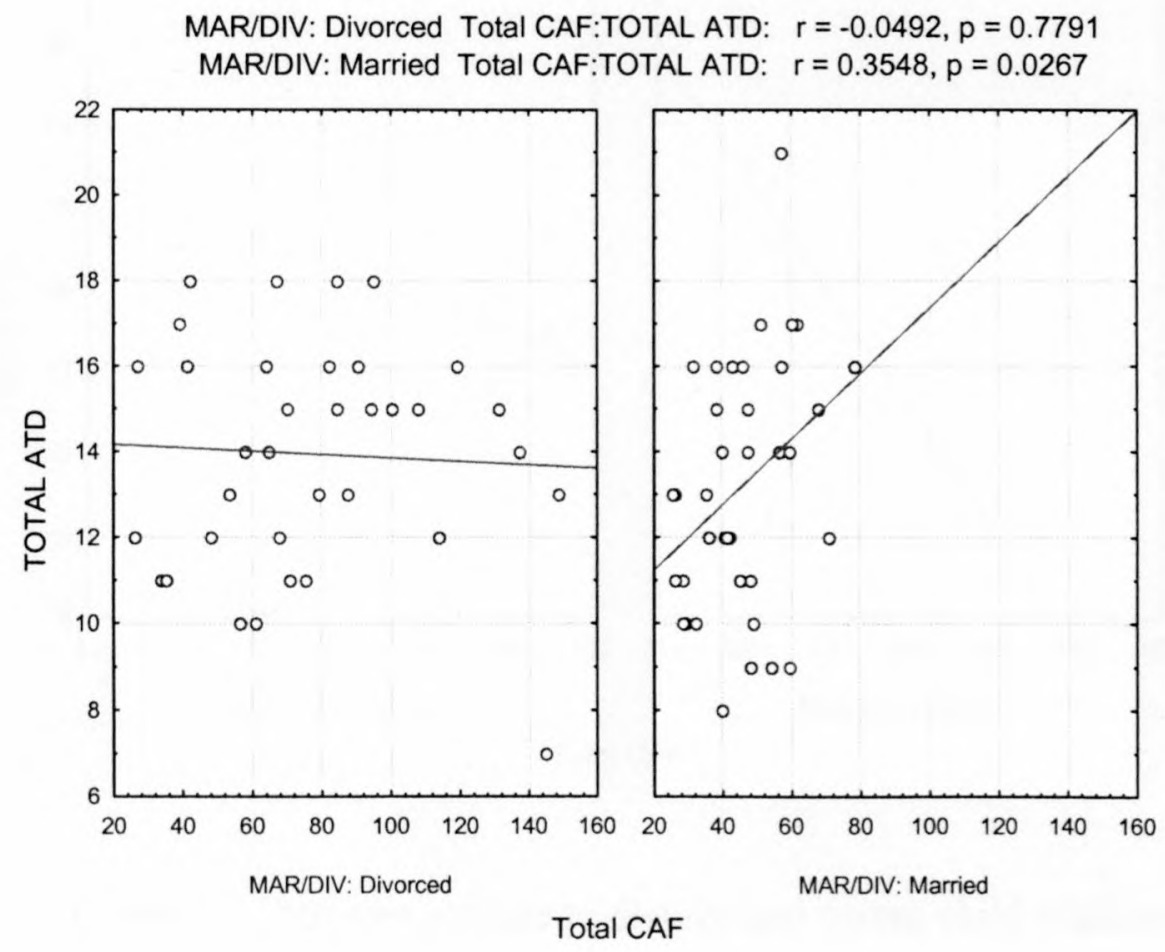

Figure 5.10. The correlation between attitude to divorce and father-child relationship (CAF) for divorced and married families. 
It follows from Figure 5.10, that the relationship between father-child relationship (CAF) and attitude to divorce (ATD) is significantly positive $(r=.35, p=.03)$ where the respondents' parents are still married, but that this relationship is non-significant $(\mathrm{r}=$ $.05, \mathrm{p}=.78)$ where the parents are divorced.

In Figure 5.11 below, the correlation between child's attitude to divorce (ATD) and child's relationship with father (CAF) is looked at for divorced and intact families separately, considering only cases where the respondent does not feel able to relate to his / her father as a behavioural model.

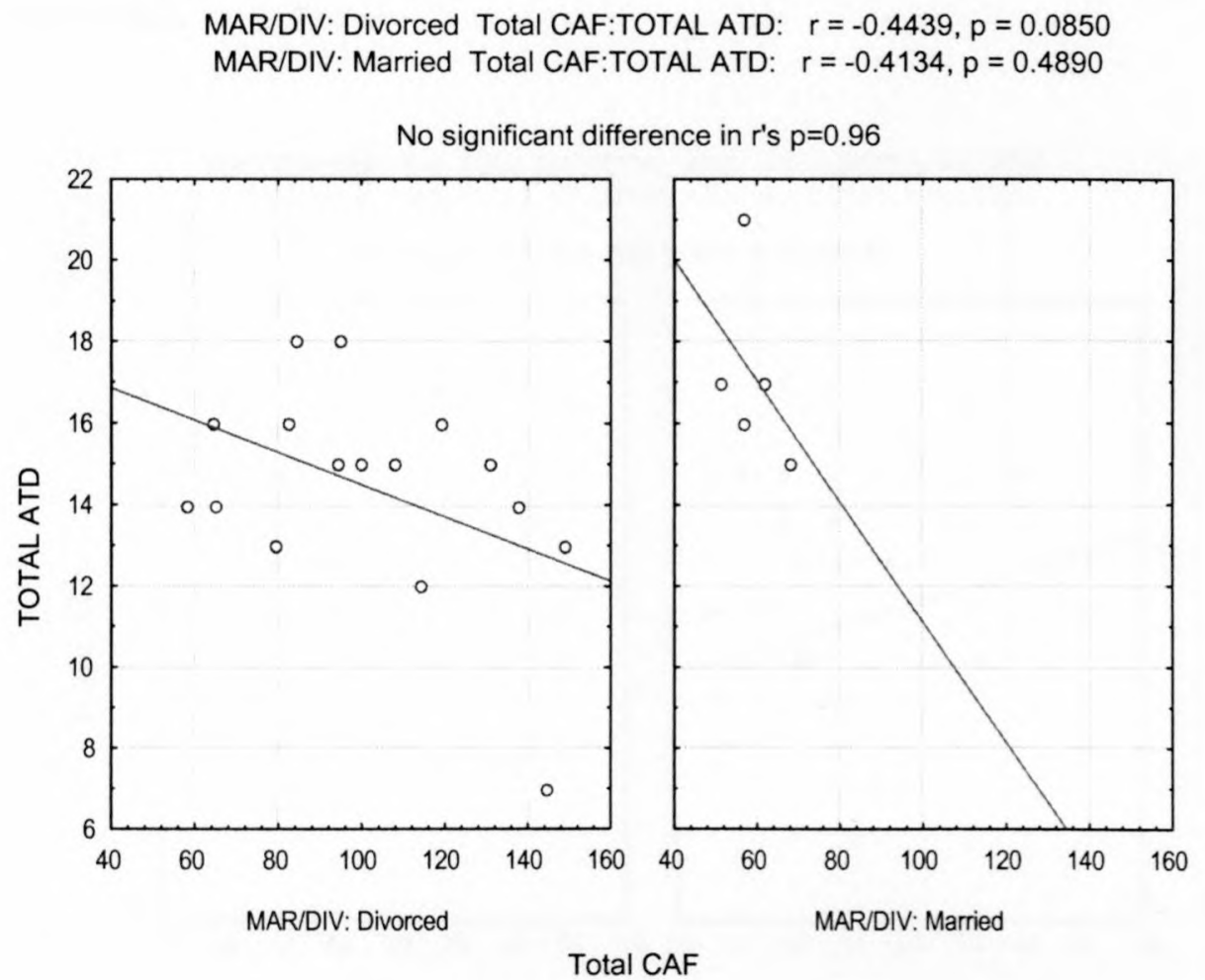

Figure 5.11. Correlation between attitude to divorce and parent-child relationship where children do not feel able to relate to their fathers (for divorced and married families)

In Figure 5.11 it is interesting to note that the correlations between attitude to divorce (ATD) and father-child relationship CAF are negative in both married $(n=5)$ and divorced $(n=16)$ groups, where respondents do not feel able to relate to their fathers. In the divorced group this correlation approaches significance $(r=-.44, p=.09)$, while in 
the married group it is negative, but non-significant $(r=-.41, \mathrm{p} .49)$. Cases 25 (divorced) and 72 (married) appeared to be outliers, so the analysis was repeated excluding these 2 cases. After this, both correlations remained negative, but not significant (divorced: $r=-$ $.24, \mathrm{p}>.05$; married: $\mathrm{r}=-.70, \mathrm{p}>.05$ ). As mentioned before with case 72 , re-inspection of the data gave no reason to suspect that these cases should be invalid. However, there were not sufficient cases in the married sample for meaningful deductions to be made.

In Figure 5.12, the correlation between child's attitude to divorce (ATD) and child's relationship with father (CAF) is looked at for intact and divorced families separately, considering only cases where the child was able to relate to his / her father as a behavioural model.

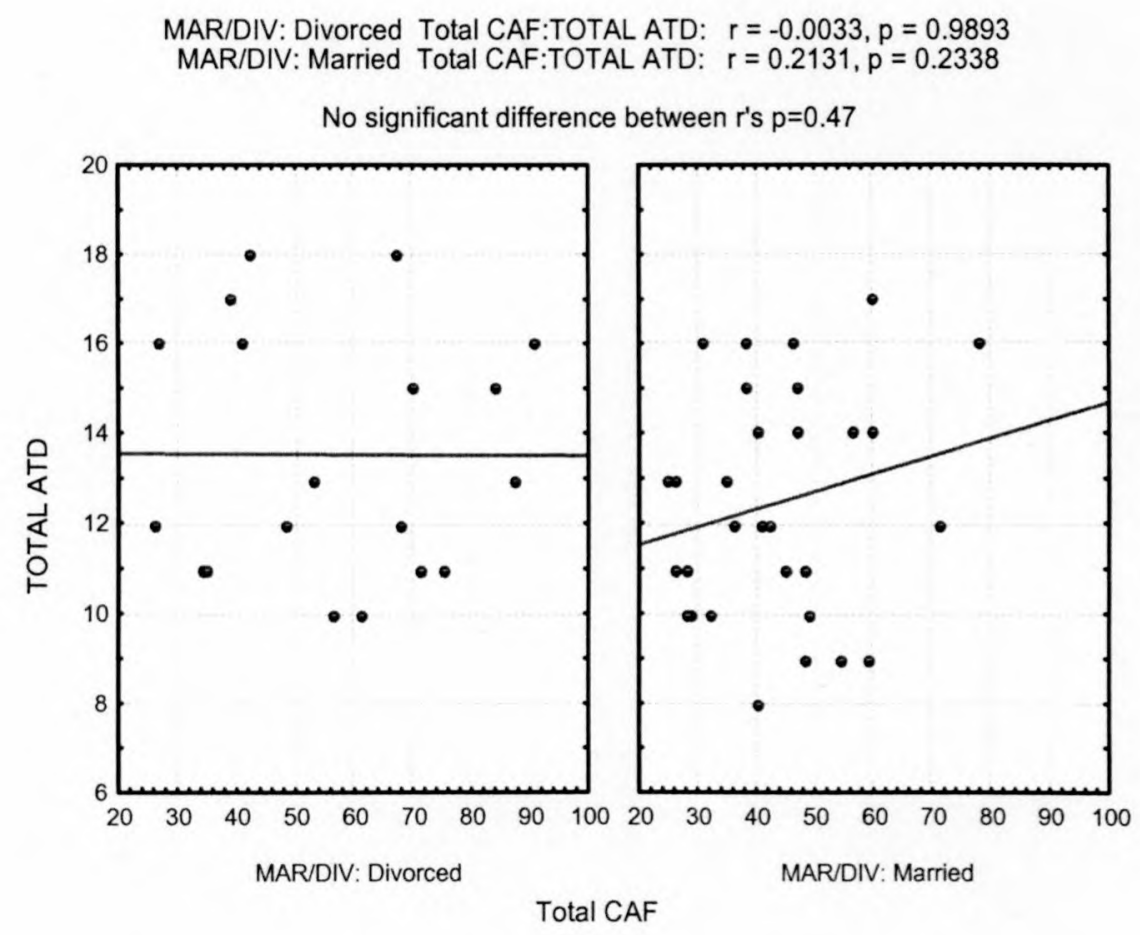

Figure 5.12. Correlation between attitude to divorce and parent-child relationship where children feel able to relate to their fathers (for divorced and married families).

As was the case with mother-child relationship (CAM) and attitude to divorce (ATD) (Figures 5.7-5.9), it is apparent in these cases where respondents felt that they were able to relate to their fathers, that any relationship that might exist between father-child 
relationship (CAF) and ATD (see Figure 5.10) was not significant when those cases where respondents felt unable to relate to their fathers had been excluded. Here the correlations for both groups were not significant.

In Figure 5.13, the correlation between child's adjustment and child's attitude to divorce is shown. Again, this analysis was conducted separately for divorced and married families.

MAR/DIV: Divorced Total LOQ:TOTAL ATD: $r=0.1679, p=0.3005$

MAR/DIV: Married Total LOQ:TOTAL ATD: $r=-0.1318, p=0.4240$

No significant difference between $r$ 's, $p=0.19$

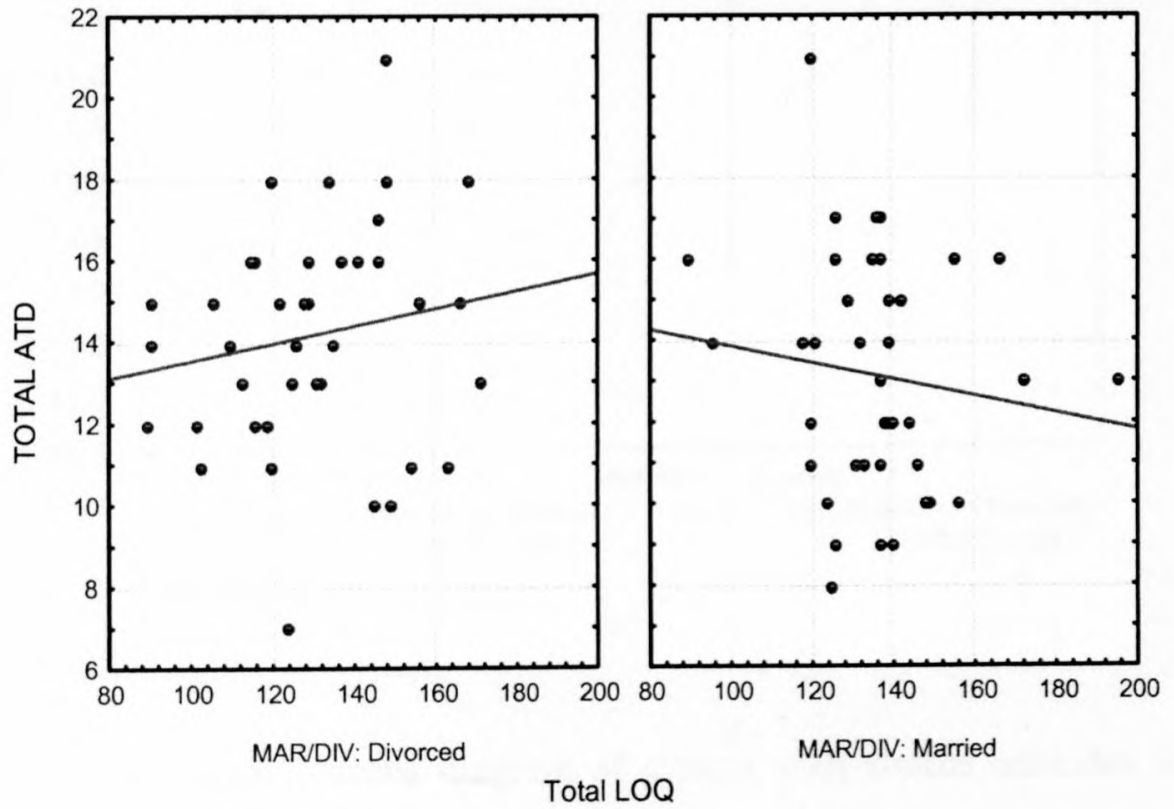

Figure 5.13. The correlation between Life Orientation (LOQ) and attitude to divorce (ATD), for children from divorced and married families.

Despite the existence of slight trends in opposite directions for the children from divorced and married families, no significant correlations were found to exist here. 
Figure 5.14 illustrates the groups of responses, separated according to adjustment (LOQ) and whether parents are married or divorced, that show similar attitudes to divorce. Groups were automatically separated according to their ATD scores, using regression trees analysis (see Appendix 2).

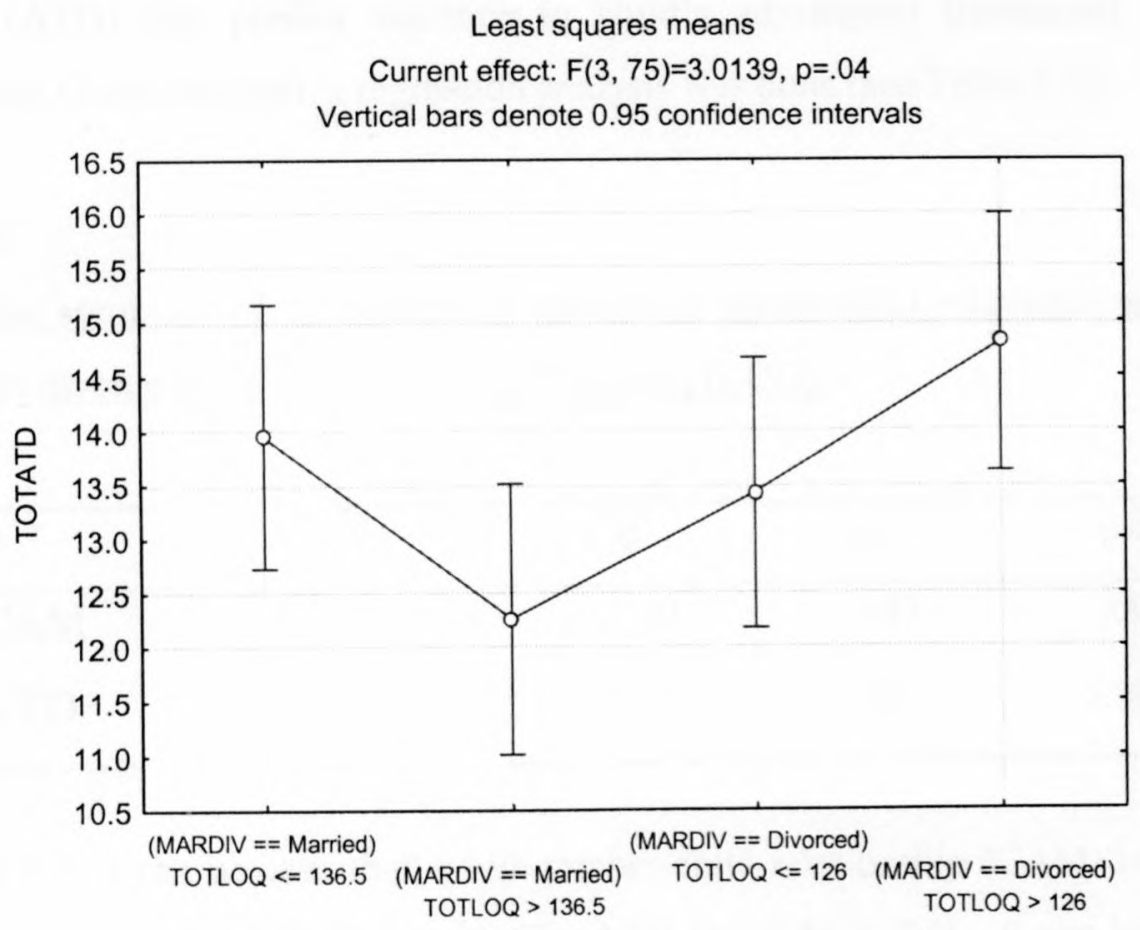

Figure 5.14. Least-square means diagram of groups with similar attitudes to divorce, based on adjustment and parental marital status.

The groups found to differ in their attitudes to divorce were (from left to right, as seen in Figure 5.14) less well-adjusted children (low LOQ scores) with married parents; welladjusted children (high LOQ scores) with married parents; less well-adjusted children (low LOQ scores) with divorced parents; and well-adjusted children (high LOQ scores) with married parents.

It appears from Figure 5.14 that there is a lot of overlap in confidence intervals between the divorced and married groups where LOQ is lower (for divorced, LOQ $<=126$ and for married, LOQ $<=136$ ). It cannot really be said, then, that these groups are significantly 
different. However, where LOQ is higher (for divorced, LOQ $>126$ and for married, LOQ > 136), there is no overlap in the $95 \%$ confidence intervals, suggesting that these groups are indeed significantly different.

In order to determine whether mother-child relationship (CAM) and child's attitude to divorce (ATD) can predict variance in child's adjustment (measured on the Life Orientation Questionnaire), a regression analysis was done (see Table 5.1).

Table 5.1

$\underline{\text { Regression summary of the predictive validity of parent-child relationships (CAM) and }}$ attitude to divorce in influencing child adjustment (LOQ).

\begin{tabular}{llll}
\hline Variable & $\underline{\mathrm{B}}$ & $\beta$ & $\mathrm{p}$-level \\
\hline Total CAM & -.40 & -.47 & .003 \\
Total ATD & 1.16 & .15 & .31 \\
\hline
\end{tabular}

In Table 5.1, it can be seen that, while mother-child relationship (CAM) is a significant predictor of adjustment (LOQ) $(\mathrm{p}<.05)$, ATD is not $(\mathrm{p}>.05)$. It can be seen that as CAM increases, LOQ tends to decrease.

In Figure 5.15a, Child's attitude toward mother (CAM) scores were compared for children (from divorced and married families) who felt able to relate to their mothers as role models, and children who did not feel able to relate to their mothers. 


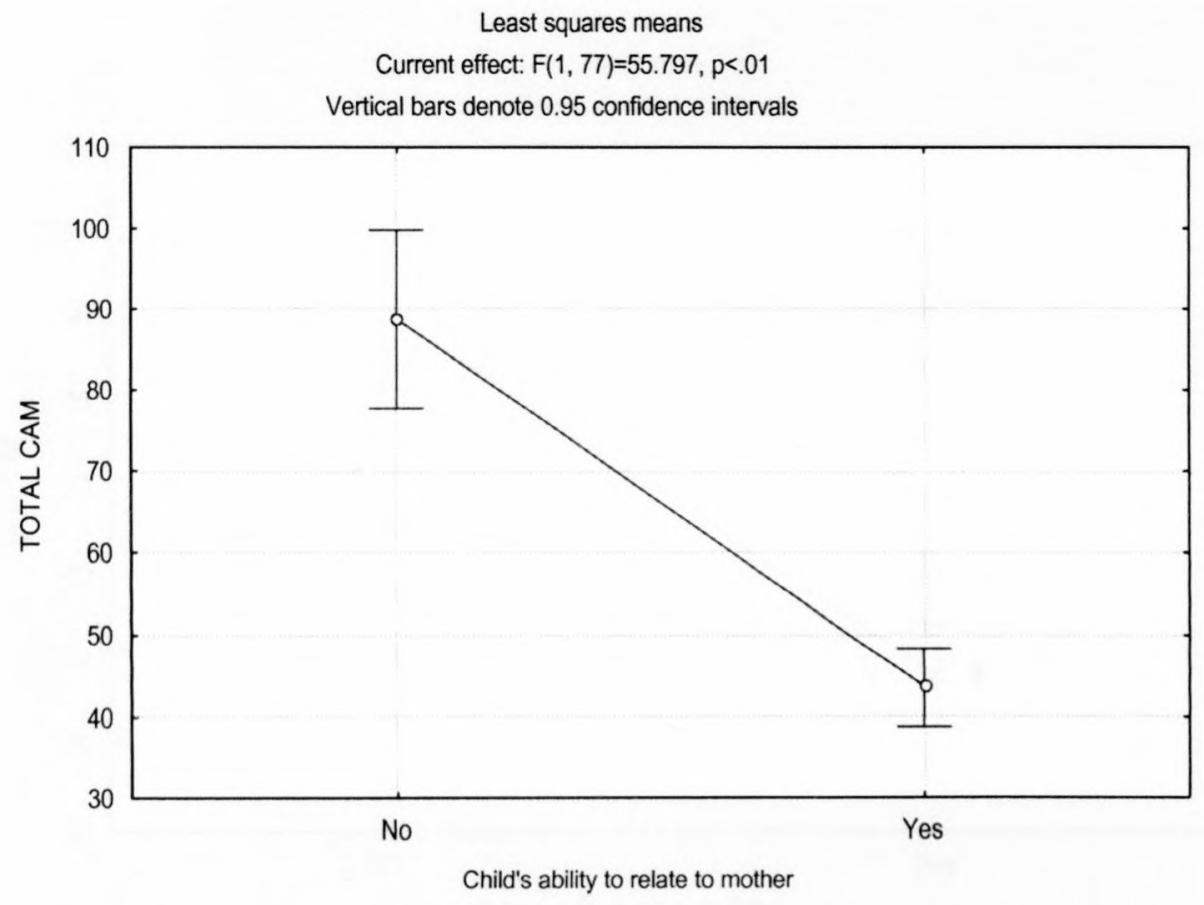

Figure 5.15a. Comparison of mother-child relationships between children who are unable to relate to their mothers and children able to relate to their mothers.

As can be seen from Figure 5.15a, there is a significant difference between the two groups $(\mathrm{p}<.01)$. It is clear that people who are able to relate to their mothers have significantly lower CAM scores than those who are not able to relate to their mothers.

In Figure 5.15b, child's attitude toward father (CAF) scores were compared for children (from both married and divorced families) who felt able to relate to their fathers as role models, and children who did not feel able to relate to their fathers. 


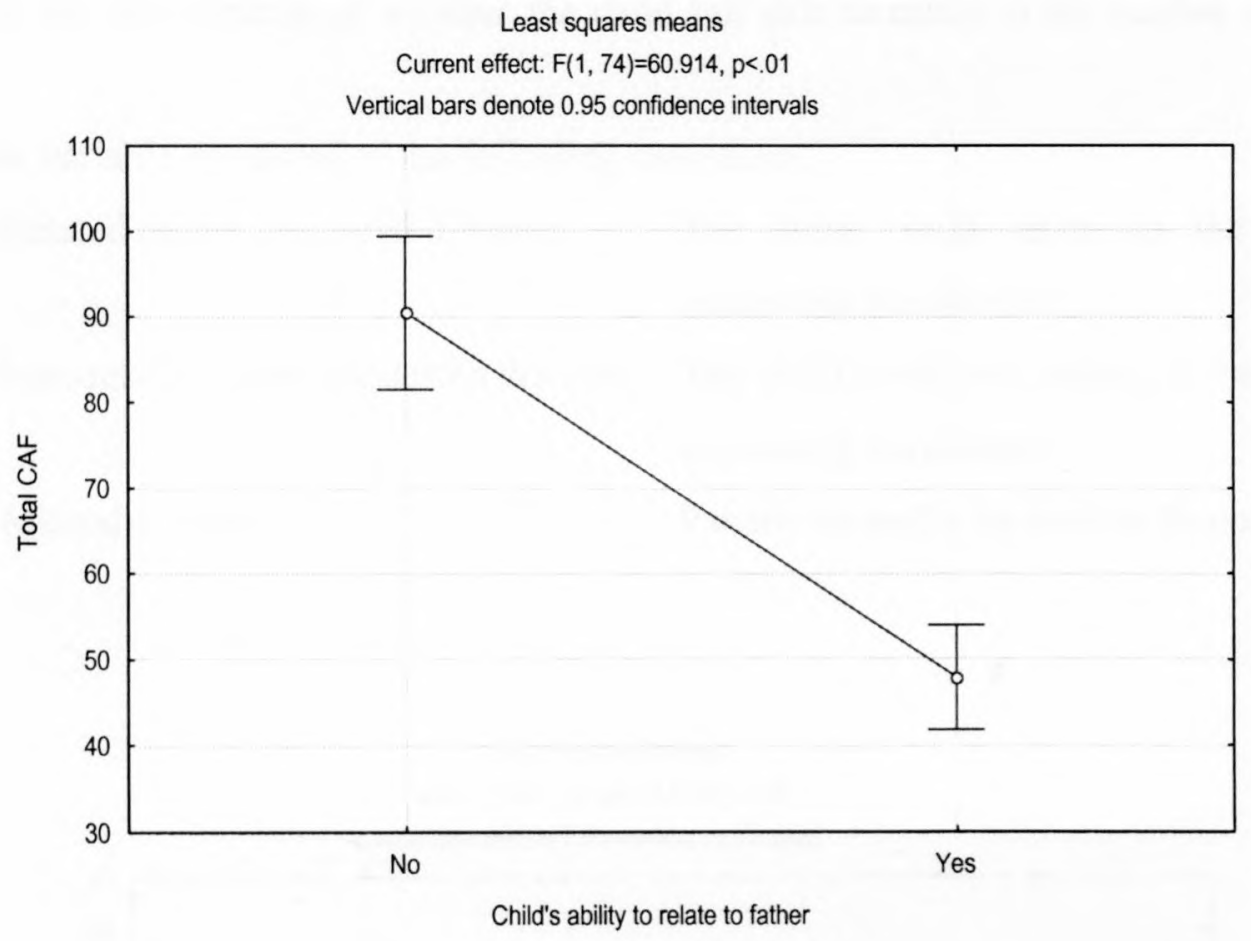

Figure 5.15b. Comparison of father-child relationships between children who are unable to relate to their fathers and children able to relate to their fathers.

As was the case in Figure 5.15a, it is evident from Figure 5.15b that there is a significant difference between the child's attitude to father (CAF) scores of the two groups $(\mathrm{p}<.01)$. It appears, then, that the measures CAM / CAF and ability to relate to mother / father as a behavioural model might in fact be measuring the same construct. The questions pertaining to the child's ability to relate to the mother and father verified the CAM and CAF scales.

In Figure 5.16, attitudes to divorce were compared for children in whose families a parent to whom the child could relate requested the divorce, those where a parent to whom the child could not relate requested the divorce, and those where parents had mutually decided to divorce. To achieve this, a new variable called "requested by good" had to be created. Two variables used in the biographical questionnaire were combined: the variable of whether the divorce had been requested by mother, father or by mutual 
decision; and the variable of whether the child felt able to relate to the mother and / or father.

The new variable consisted of the following categories:

Related parent requested divorce: The child could relate to the parent requesting the divorce

Non-related parent requested divorce: The child could not relate to the parent requesting the divorce

Mutual divorce:

Parents mutually decided to divorce

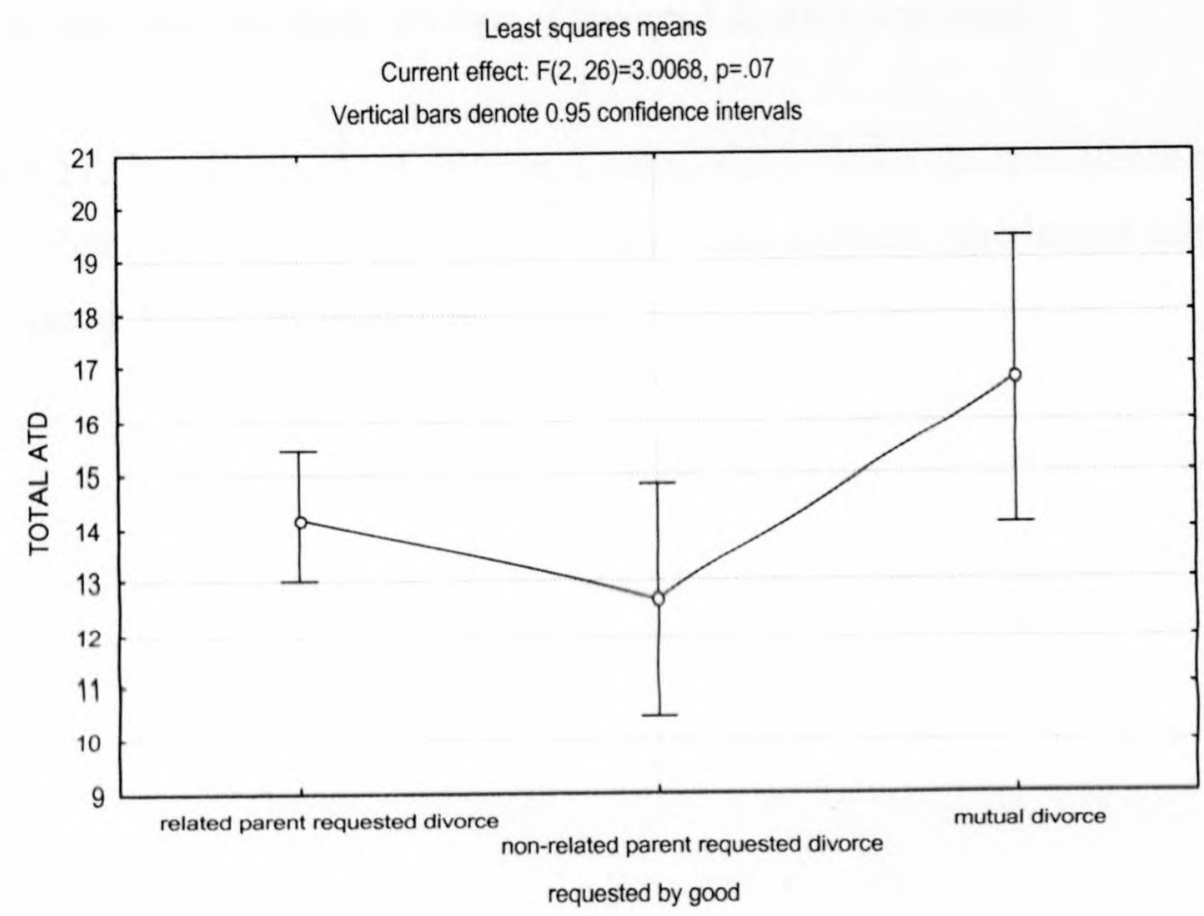

Figure 5.16. Comparison between attitudes to divorce of children, separated according to the nature of their relationships with the parent who had requested the divorce.

It can be seen that the ATD score tends to be higher where the child was able to relate to the parent requesting the divorce $(n=18)$ than where the child had not felt able to relate to that parent $(n=6)$. However, the overlap in the confidence intervals around these two means suggests that this is probably not a significant difference. In cases where divorce was a mutual decision $(n=4)$, there was a tendency for the attitude to divorce (ATD) 
score to be higher $(p=.07)$. These results must be treated with some caution, as only 4 of the cases studied had had mutually requested divorces, while only 6 of them had not felt able to relate to the parent requesting the divorce. The majority of cases found the child able to relate to the parent who had requested the divorce. Cases where the child had been too young to know who requested the divorce were, of necessity, excluded from this analysis.

\subsection{ANALYSES INVESTIGATING LEARNING THEORY}

In the six figures that follow, adjustment of parents following their divorce, and the influence this might have on children's adjustment (LOQ scores) were investigated. For this reason, only the data from children of divorced families was used.

In Figure 5.17, the adjustment of children is compared between children whose mothers had no problems adjusting to divorce, and those whose mothers experienced adjustment problems (according to the children). 


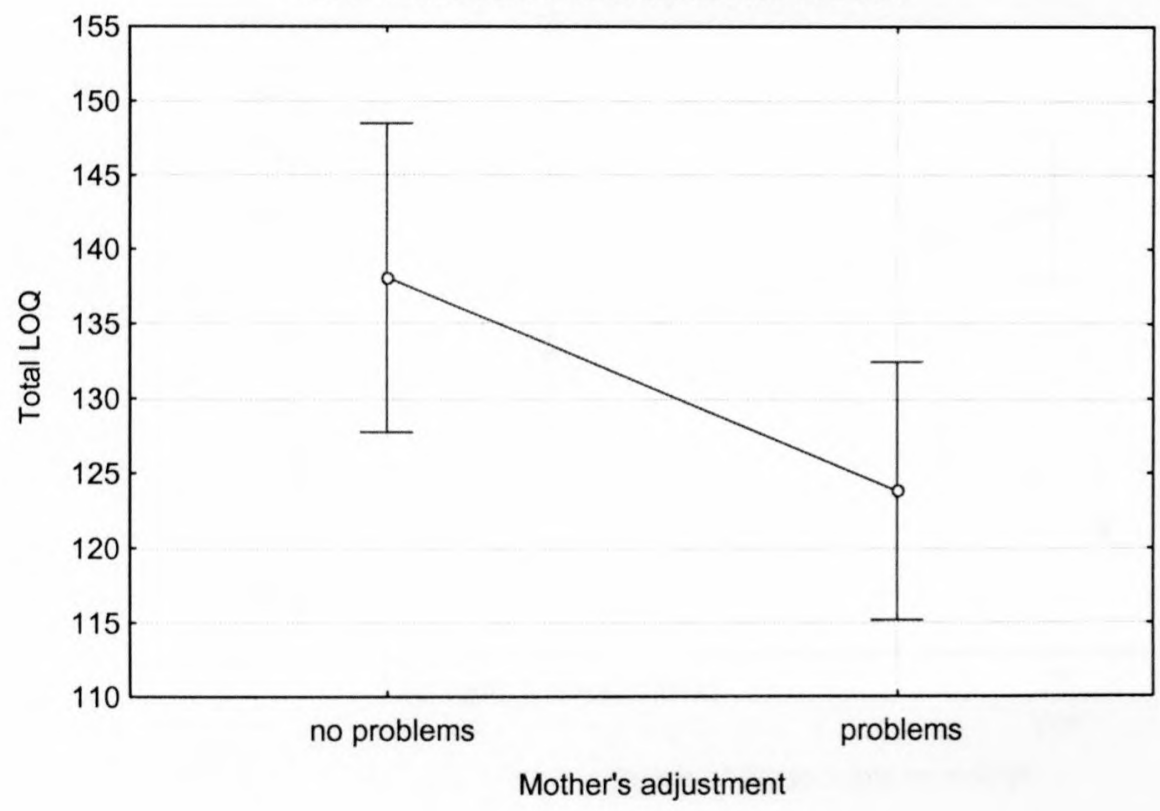

Figure 5.17. A comparison of the adjustment (LOQ) of children whose mothers had adjustment problems $(n=24)$ and those whose mothers did not $(n=18)$.

The question in the biographical questionnaire allowed for three options discussing the mother's adjustment to divorce: well adjusted; some problems; and severe/many problems. In the scoring of the questionnaires, this was made into a dichotomy: the adjustment (LOQ) scores of participants whose mothers had no adjustment problems were compared to the LOQ scores of participants whose mothers experienced adjustment problems. It was found that the LOQ scores of those children whose parents had not experienced adjustment problems had LOQ scores that tended to be higher than those whose parents had experienced adjustment problems $(\mathrm{p}=.04)$.

In Figure 5.18, the adjustment of children whose mothers had not experienced adjustment problems was investigated more closely. Respondents who felt able to relate to their mothers were compared to those who did not feel able to relate to their mothers. 


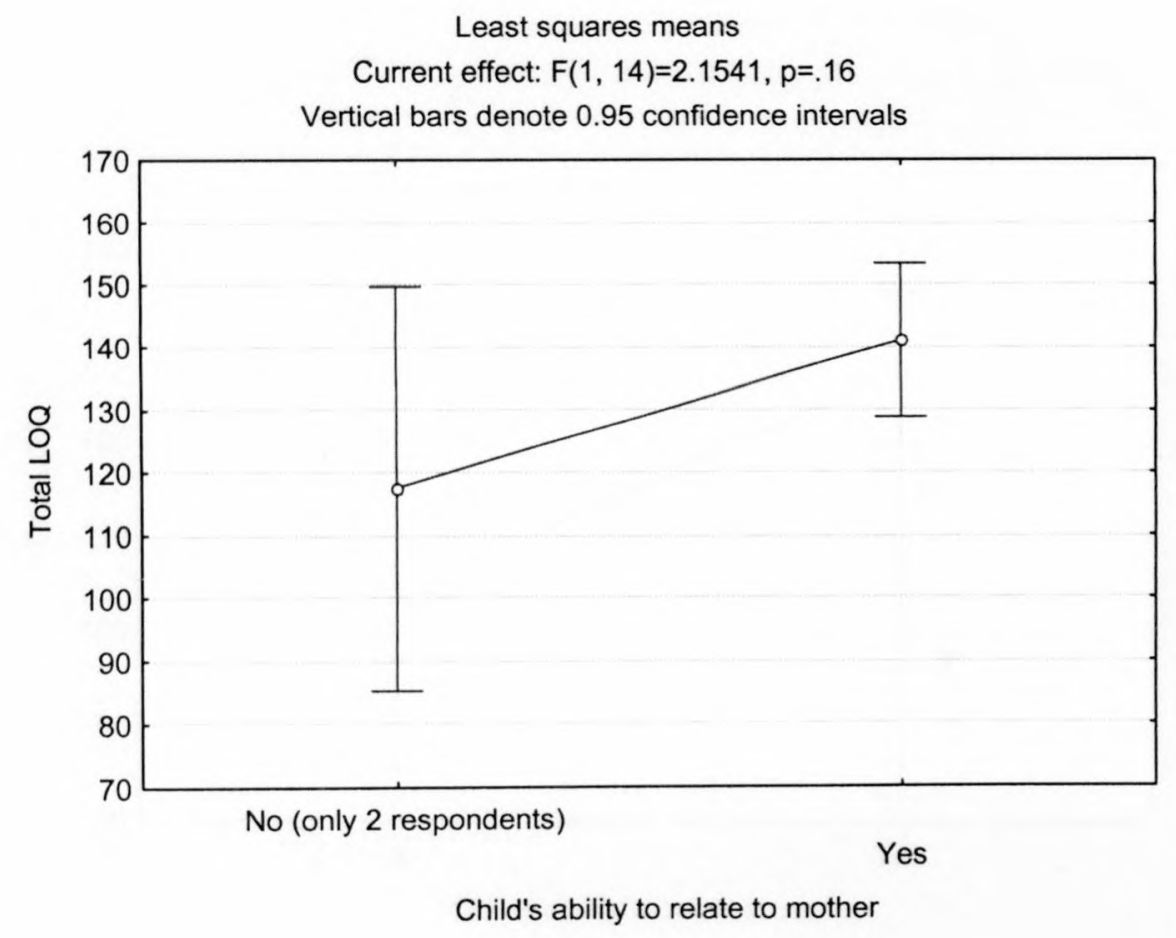

Figure 5.18. A comparison between adjustment of children with well-adjusted mothers who are able to relate to their mothers $(n=16)$, and those unable to relate to their mothers $(\mathrm{n}=2)$.

According to Figure 5.18, the difference in LOQ scores between these groups was not statistically significant, although those who felt they could relate to their mothers tended to have higher LOQ scores $(p=.16)$. Unfortunately there were only 2 respondents in the "no" group.

In Figure 5.19, the adjustment of children whose mothers had experienced adjustment problems was scrutinized more closely. Respondents who felt able to relate to their mothers were compared to those who did not feel able to relate to their mothers. 


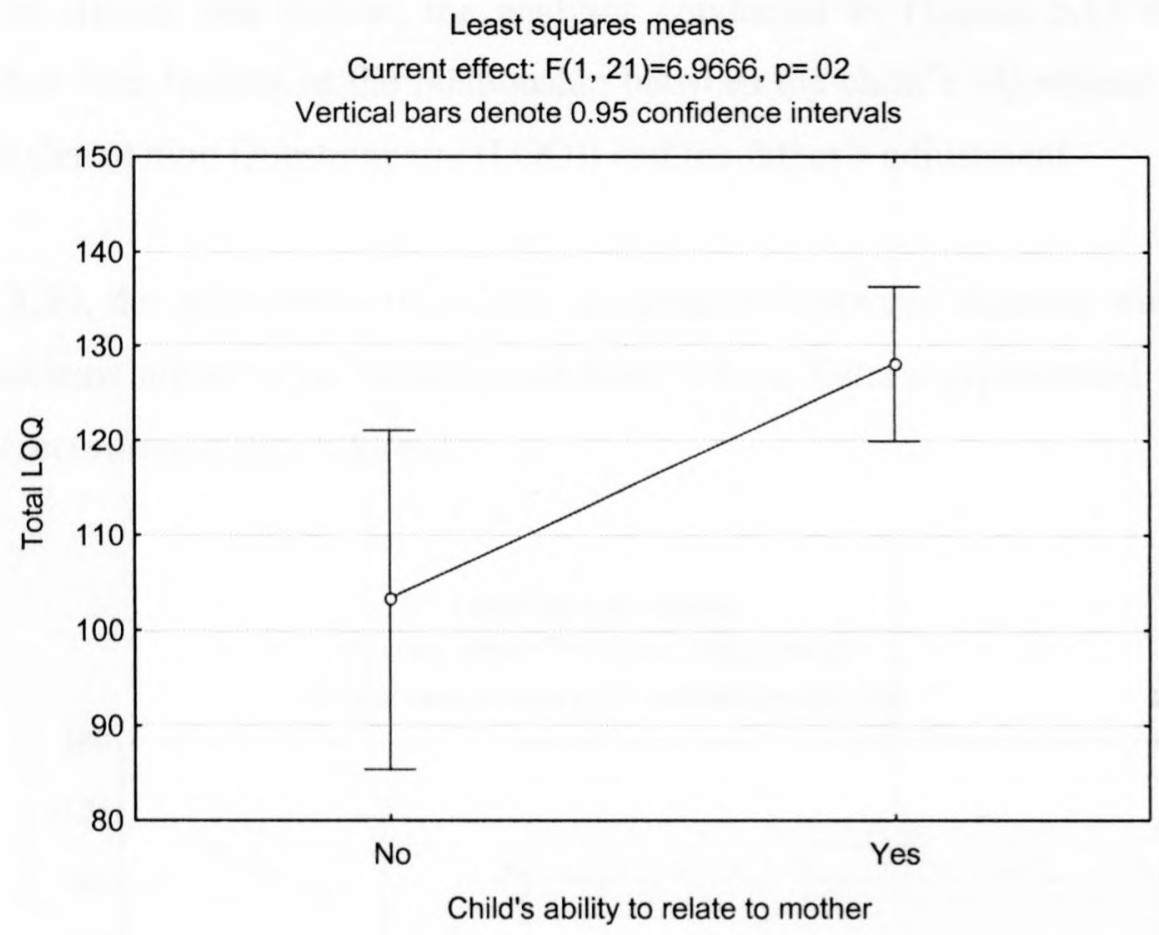

Figure 5.19. A comparison between adjustment of children (with poorly-adjusted mothers) able to relate to their mothers $(n=20)$, and those unable to relate to their mothers $(n=4)$.

According to Figure 5.19, the difference in adjustment (LOQ scores) was indeed significant $(\mathrm{p}=.02)$, again with those who felt that they could relate to their mothers having higher LOQ scores than did those who did not feel able to relate to their mothers. Here, however, there were only 4 respondents who did not feel able to relate to their mothers. A Mann-Whitney U-test was done on this data because of the small sample size. Again, at a $5 \%$ probability level, it was found that this difference was significant ( $\mathrm{p}$ $=.02$ ), showing a distinct tendency for better adjustment in those who feel able to relate to their mothers. 
In the three figures that follow, the analyses conducted in Figures 5.17 to 5.19 are repeated, this time looking at the relationship between the child's adjustment (measured on the Life Orientation Questionnaire (LOQ)) and the father's adjustment.

In Figure 5.20, the adjustment of children is compared between children whose fathers had no problems adjusting to divorce, and those whose fathers experienced adjustment problems (according to the children).

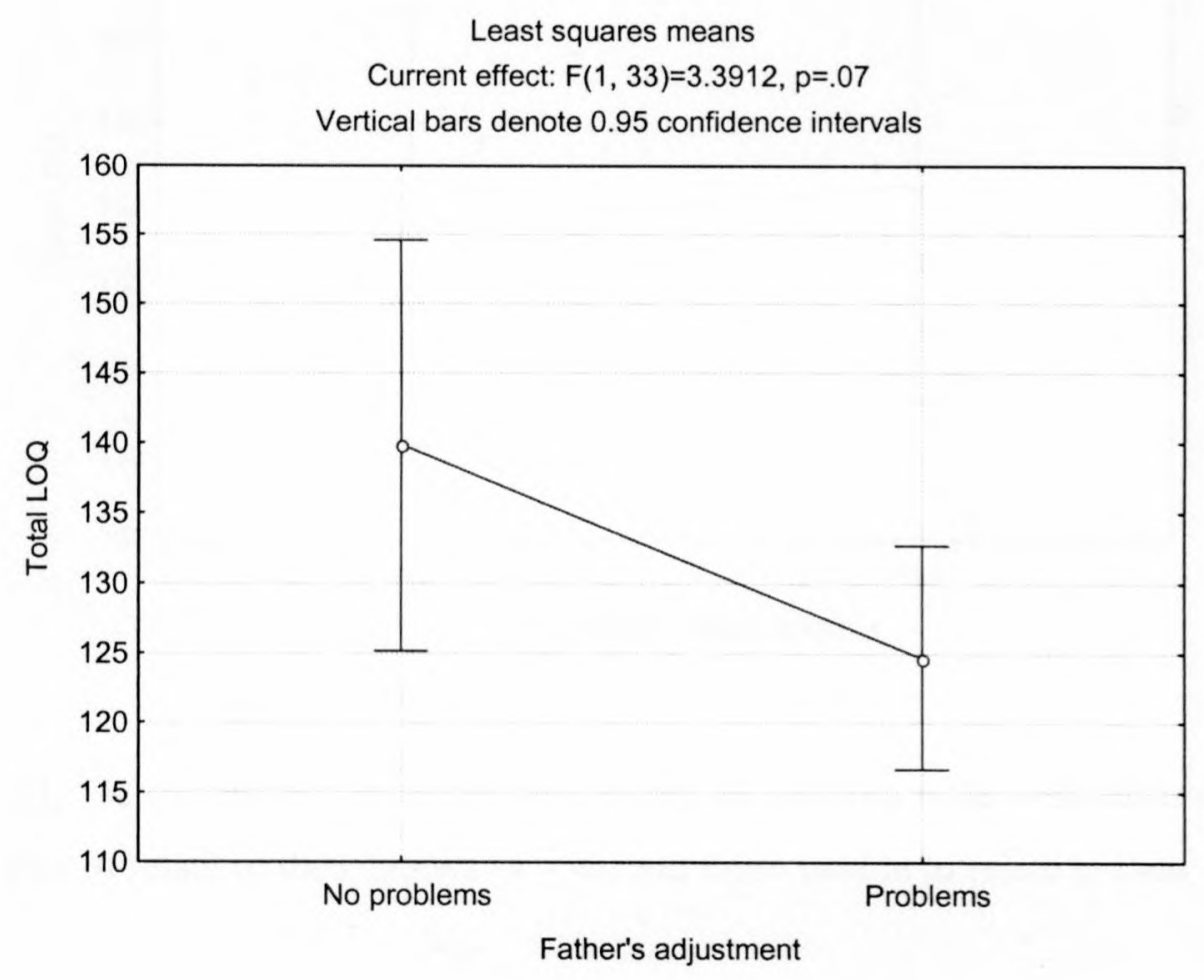

Figure 5.20. A comparison of the adjustment (LOQ) of children whose fathers had adjustment problems $(n=27)$ and those whose fathers did not $(n=8)$.

It can be seen that where the fathers did not have adjustment problems, the children's adjustment scores (LOQ) tended to be higher than where the fathers had adjustment problems $(\mathrm{p}=.07)$, although this trend was not strictly significant. A Mann-Whitney Utest gave a p-value of .10, which supports the ANOVA result. 
In Figure 5.21, the adjustment of children whose fathers had not experienced adjustment problems was analyzed more closely. Respondents who felt able to relate to their fathers were compared to those who did not feel able to relate to their fathers.

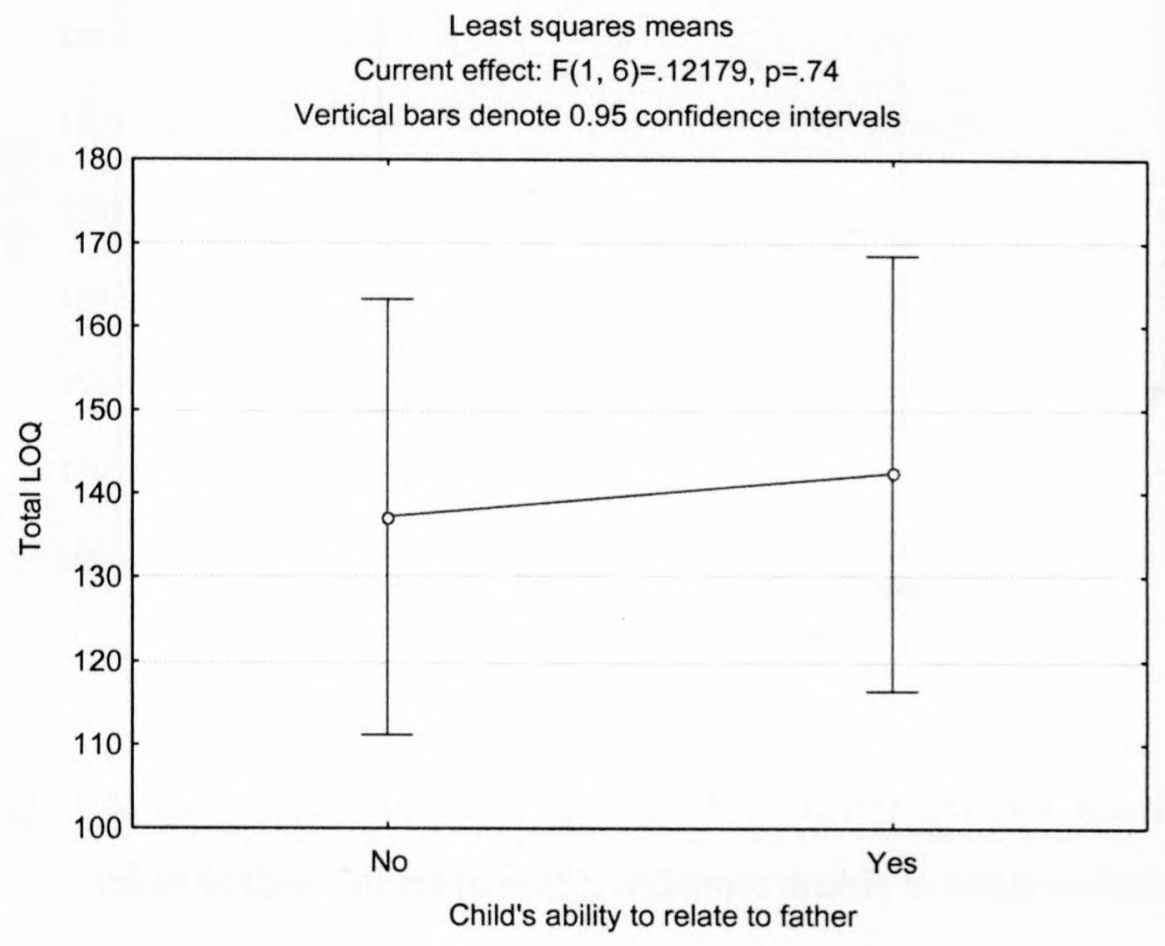

Figure 5.21. A comparison between adjustment of children with well-adjusted fathers who are able to relate to their fathers $(n=4)$, and those unable to relate to their fathers (n $=4)$.

There was very little difference between the means of the two groups seen in Figure 5.21 $(\mathrm{p}=.74)$.

In Figure 5.22, the adjustment of children whose fathers had experienced adjustment problems was analyzed more closely. Respondents who felt able to relate to their fathers were compared to those who did not feel able to relate to their fathers. 


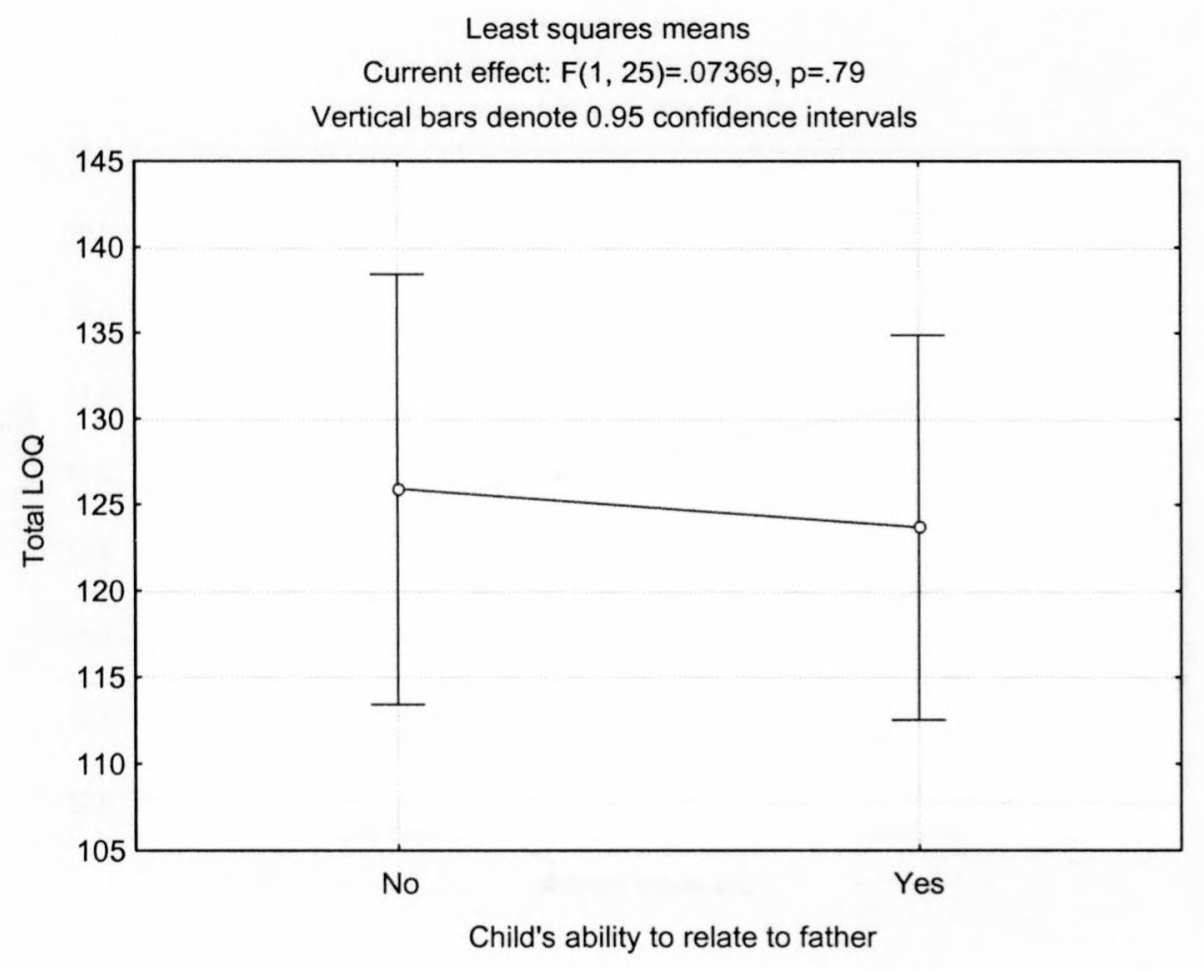

Figure 5.22. A comparison between adjustment of children (with poorly-adjusted fathers) able to relate to their fathers $(n=15)$, and those unable to relate to their fathers ( $n$ $=12$ ).

It was again found that there was very little difference between the adjustment of those children who felt able to relate to their fathers as role models and those who did not $(p=$ .79).

In Figure 5.23a, children's attitudes to divorce were compared where the mother experienced no adjustment problems, to where the mother had experienced adjustment problems. 


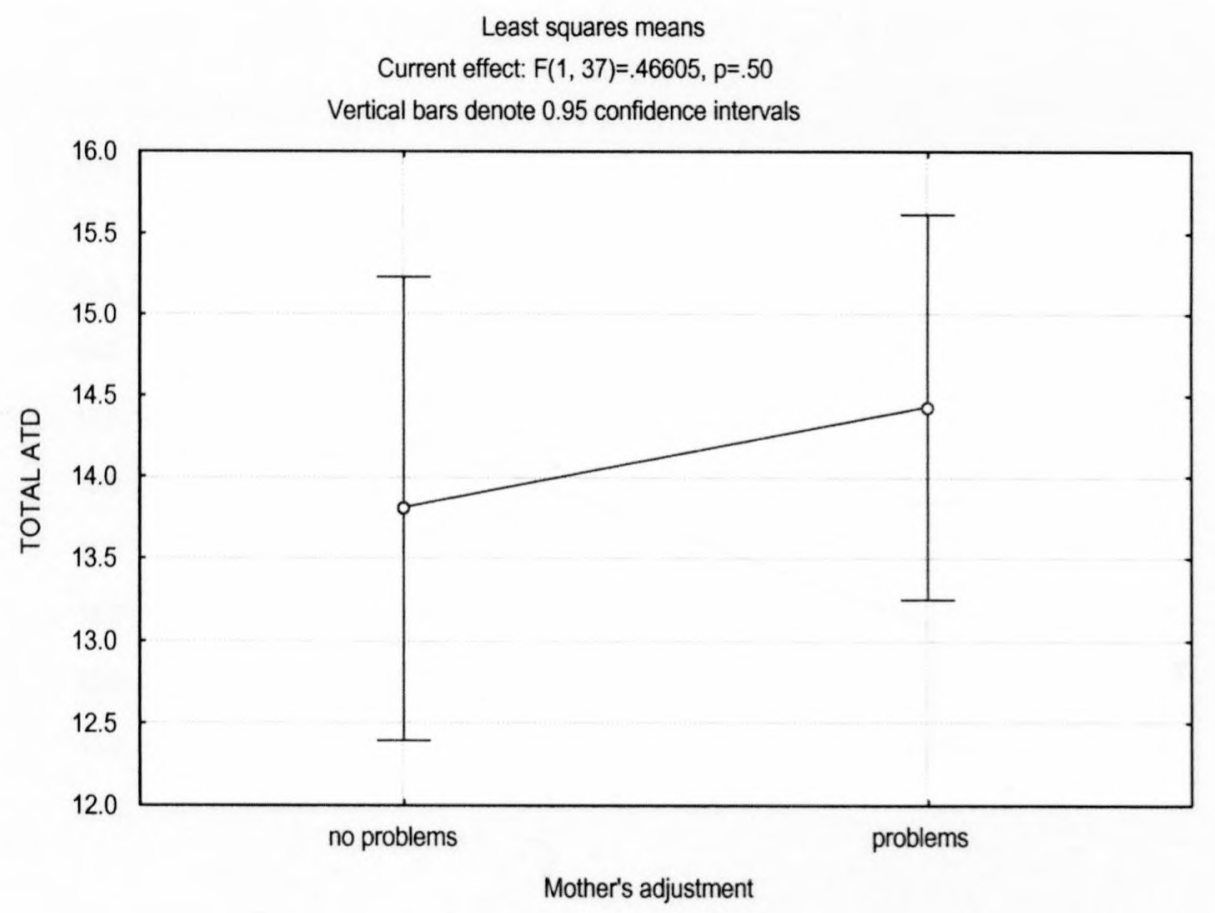

Figure 5.23a. A comparison between attitudes to divorce of children whose mothers experienced adjustment problems $(n=24)$ and those whose mothers did not $(n=18)$.

No significant difference was found between the attitude to divorce (ATD) scores of children whose mothers were well adjusted, and those whose mothers experienced adjustment problems. Here ATD scores were slightly higher where the mothers had experienced adjustment problems $(\mathrm{p}=.5)$.

In Figure 5.23b, children's attitudes to divorce were compared where the father experienced no adjustment problems, to where the father had experienced adjustment problems. 


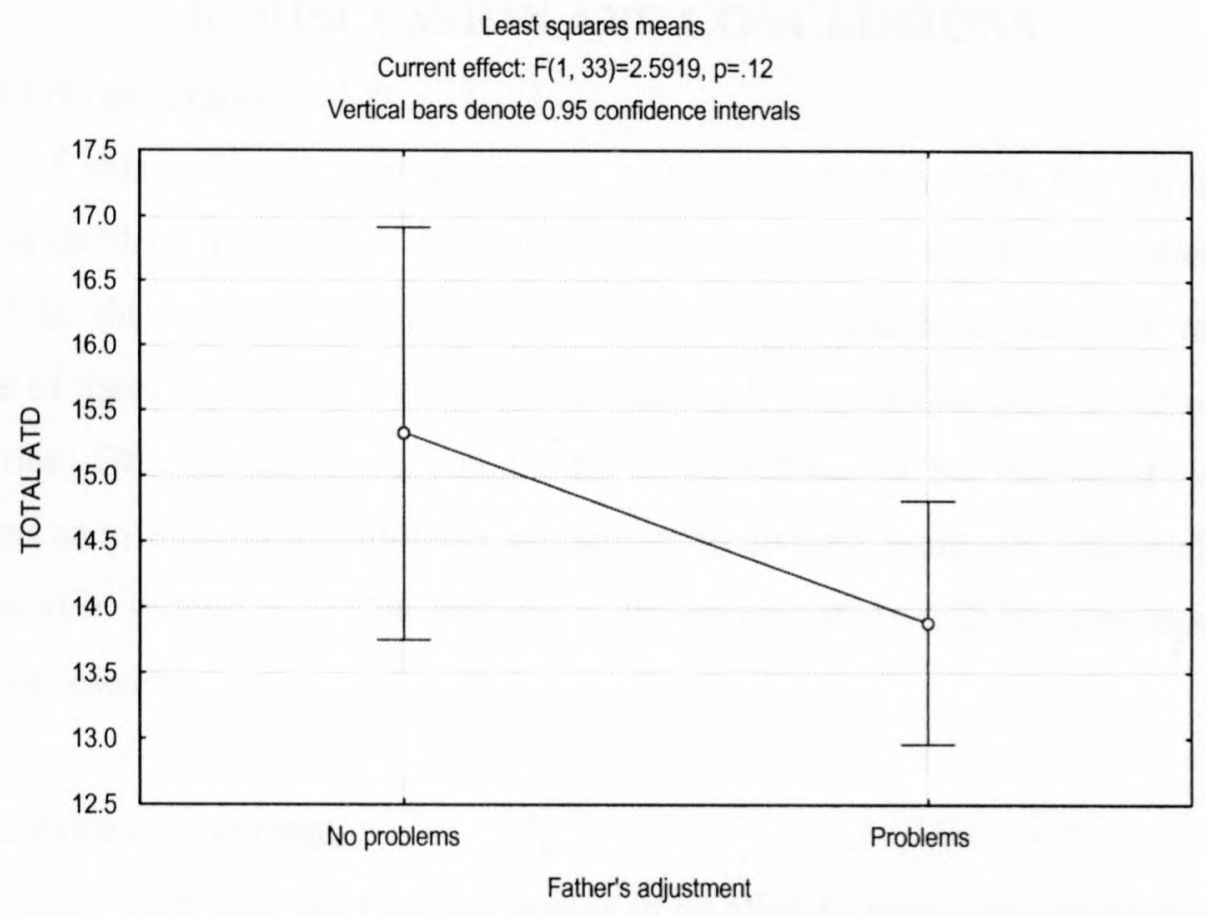

Figure 5.23b. A comparison between attitudes to divorce of children whose fathers experienced adjustment problems $(n=27)$ and those whose fathers did not $(n=8)$.

In Figure 5.23b, there is a (non-significant) tendency $(\mathrm{p}=.12)$ for the attitude to divorce (ATD) scores of children whose fathers were well adjusted to be higher than those whose fathers experienced adjustment problems. Interestingly, where mothers' adjustment was used (Figure 5.23a), it was found that ATD scores were slightly higher where the mother had experienced adjustment problems. However, where fathers' adjustment was studied (Figure 5.23b) fathers without adjustment problems tended to have children with higher ATD scores than did fathers with adjustment problems. However, as stated before, neither of these differences was significant. 


\section{DISCUSSION AND CONCLUSIONS}

\subsection{INTRODUCTION}

The aim of this study was to determine which factors influence the adjustment of adolescent children of divorce. Two theories (schema theory and learning theory) were discussed in this respect. The results obtained from statistical analyses to test the relevance of these theories to the aim of the study will now be discussed in terms of these two theories. Other factors not accounted for by these theories, but discussed by previous researchers as influential in children's adjustment to divorce, were also analyzed, and will be discussed in section 6.2. The findings of the current study will be compared to those of previous research.

\subsection{General ANALyses}

While children from married families appear to be slightly better adjusted (seen by their slightly higher adjustment (LOQ) scores) than are children from divorced families (see Figure 5.1), this difference was not statistically significant. This finding was interesting, as previous research showed some disagreement about the extent to which divorce impacts children's adjustment negatively. Some writers have pointed to the numerous problems that may arise for children of divorced families, including difficulty breaking away from families, and feelings of powerlessness (Barker, Brinkman \& Deardorff, 1995); heterosexual adjustment problems (Frost \& Pakiz, 1990) and feelings of extreme vulnerability (Swartzman-Schatman \& Schinke, 1993). Other writers do not believe this to be the case. Booth and Edwards (1989), for example, suggest that staying in an unhappy married family is more detrimental to the child's adjustment than is divorce. The findings of the current study support the latter conclusion. However, it must be noted that this was a convenience sample, and that an educated group was used to control for educational differences between married and divorced groups. It is possible that the similar adjustment existing between children from married and divorced families in this group is a result of this being a particularly well adjusted sample (adolescents who have managed to work through any issues they may have had following the divorce, and who are studying at tertiary level). It is also a possibility that a university sample represents a particularly intelligent subset of the population of adolescents, and that more intelligent people are better able to maintain a positive outlook in the face of difficulty. 
Although it must not be forgotten that, while the Life Orientation Questionnaire (LOQ) is considered a valid measure of adjustment, it does tap a very specific aspect of adjustment. It measures the individual's ability to maintain his / her belief in the comprehensibility, manageability and meaningfulness of his / her life and circumstances. Perhaps more intellectually minded people are, on the whole, more likely to hold such beliefs. Perhaps, then, it is these beliefs, rather than the practice of good adjustment that are being assessed. While such possibilities must by no means be neglected, the Life Orientation Questionnaire had been found to be a valid measure of adjustment.

Adolescents from divorced and married families were also compared, considering their attitudes to divorce (see Figure 5.2). Again, previous research was not consistent in the predictions made on this issue. Amato and Booth (1991) found that children who had experienced divorce tended to be more accepting of divorce than those who had not. Schwartz (1992), on the other hand, suggests that adolescent children of divorce might be less accepting of divorce. In the current study, although the trend was only bordering on being significant, children from divorced families tended to be more accepting of divorce (having higher Attitude to Divorce (ATD) scores) than were children from married families. Although a $5 \%$ probability is usually used as a cut off point in psychological studies (Howell, 1995), the researcher believes that this trend (at 11\% probability) is worth mentioning. If it were possible to conclude that these groups are indeed significantly different on this measure, this might lend some support to schema theory. This will be discussed in more detail in section 6.4 .

Numerous writers have discussed the importance of a good parent-child relationship as a buffer for problems that children from divorced families might otherwise experience (Amato, 1996; Amato \& Keith, 1991; Grych \& Fincham, 1992; Kline et al., 1991; Tschann et al., 1989). The influence of changes in the parent-child relationship following divorce on the child's adjustment and attitude to divorce was therefore analyzed in the current study (see Figures 5.3 and 5.4). The only significant finding here was where children's adjustment (measured on the Life Orientation Questionnaire) was compared depending on how the child's relationship with his / her mother had changed following 
divorce (see Figure 5.3a). It was found that children whose relationships with their mothers had not changed significantly following the divorce were able to report significantly better adjustment (higher LOQ scores) than children whose relationships with their mothers had changed. It was particularly interesting that, while those whose relationships with their mothers had improved had somewhat higher LOQ scores than those whose relationships had deteriorated, this trend was not nearly as pronounced as the superiority of the adjustment of the children with stable, or unchanged, relationships. In the current sample, the 9 respondents who said that their relationships with their mothers had not changed had also reported feeling able to relate to their mothers. It was seen (see Figure 5.15a) that being able to relate to one's mother was associated strongly with having low Child's Attitude to Mother (CAM) scores, that is, with having a good relationship with one's mother. It is possible, then, that the reason for this association's being as strong as it is, might be explained in part by the fact that all those who were well adjusted with unchanged relationships with their mothers, had had good relationships with their mothers all along. Perchance, had there been respondents whose mother-child relationships had been unchanged, but negative, the results of this analysis may have been different. Perhaps the benefit of a stable mother-child relationship is only effective when this relationship is a strong, or positive, one. Unfortunately the current data set does not contain any respondents who had an unchanged negative relationship with their mothers, so it is impossible, pending further research, to draw any conclusions on this issue.

Where changes in the relationship with fathers were considered, it is interesting that no significant differences existed in the children's adjustment and attitude to divorce, regardless of whether this relationship had improved, deteriorated, or stayed the same (see Figure 5.4b). Amato and Keith (1991) reported similar findings: according to their research, the relationship between the child and the mother (but not the father) was related to good adjustment in the child.

Common sense would suggest that if a child's relationship with his/her parents improved subsequent to a divorce, that that child might be more accepting of divorce, or view it in a more positive light. However, the current data did not support such an assumption (see 
Figure 5.4). It is, of course, possible that the common sense assumptions are incorrect, and that the child's attitude to divorce is not altered by changes in the relationship with either parent. It is also possible that the questionnaire used to assess the child's attitude to divorce was too overt in its method of questioning, and that a less direct method of questioning might be a better instrument to use in assessing as sensitive an issue as this one. In fact, in various analyses where attitude to divorce was expected to play a role, this was found not to be the case (these other analyses will be discussed during the course of this chapter). It is possible, then, that further research in this area might need to make use of a less overt questioning style. Should such research find similar results to the current research, this would make the findings more conclusive than they are at present.

Pryor (1999) found that where marriages had involved high levels of conflict, children tended to be more accepting of divorce than where conflict levels had been low. It stands to reason that where a child has lived through very unpleasant family circumstances in a marriage, he / she will see divorce as a welcome release from an aversive situation. The current research supported this conclusion (see Figure 5.5a). In this analysis there was no reason to doubt the accuracy of the attitude to divorce (ATD) questionnaire. It is possible, though, that no matter how overt the questioning, a child who had lived through a lot of family conflict would support divorce. Perhaps where a situation is less threatening (such as where a relationship with a parent had improved after divorce), the child would tend, still, not to declare him / herself to be overtly in favour of divorce.

Allison and Furstenberg (1989) looked at the role which changes in the financial position of the family following divorce might play in the child's adjustment and feelings about divorce. The current study did not find support for this proposal: There was no significant difference between the Attitudes to Divorce of those who had and had not experienced financial changes following divorce. Perhaps those respondents whose financial position had changed, had not experienced a sufficiently dramatic change in living standard to influence their perceptions of the divorce. Possibly the use of a university sample has introduced a bias. All these people are able to afford to study full time at a reputable tertiary institution, suggesting that the financial problems they may have experienced were either limited, or have since been surmounted. Alternatively, it is 
possible that financial problems are more disturbing to the parents who have to finance their own and their children's activities, than they are to the dependent adolescents.

\subsection{SCHEMA THEORY}

Schema theory is based on the assumptions that people resist changes to their existing knowledge bases (Howard, 1987; Janoff-Bulman, 1992). If this theory were found to be relevant to the adjustment of children to divorce, it would follow that children of divorce with good relationships with their parents (specifically with the parent who requested the divorce) would be accepting of divorce (see chapter 4). This would be the case because seeing divorce as unacceptable would be problematic to those children's schemata (seeing that parent as a good person). Janoff-Bulman (1992) also writes of the importance of interpretation of trauma in adjustment. It follows, from this, that a positive attitude to divorce would be beneficial to the child's adjustment. Other researchers have found this to be the case (Burns \& Dunlop, 1999).

\subsubsection{Is there a significant correlation between parent-child relationship (CAM / CAF scores) and attitude to divorce (ATD)?}

Because the parent-child relationship was assessed separately for each parent, similar analyses were done for the mother-child relationship and the father-child relationship.

The significant positive relationship between attitude to divorce and child's attitude to mother (CAM) scores in children of married families (see Figure 5.7) appears to support schema theory to some extent. A child who does not have a very positive relationship with his / her married mother (high CAM scores are indicative of problems in the motherchild relationship), tends to be more accepting of divorce than is a child from an intact family who has a good relationship with his / her mother. Schema theory said that children who relate well to their parents might come to accept divorce should their parent, whom they see as a good, loving person, decide to divorce. The converse of this might be that in an intact family, a child who has a good relationship with his / her mother might tend to see that mother's staying in a marriage as yet another positive aspect of hers. Interestingly, in Figure 5.2 it is seen that children from divorced families 
tended (although the relationship only approached significance) to be more accepting of divorce, on the whole, than were married children. This, too, could back up schema theory, as these children who have had to live through their parents' decision to divorce might need to believe that divorce is acceptable in order to maintain their views of their parents' "goodness", while those whose parents have stayed together (possibly in the face of adversity) would be inclined to laud their parents' behaviour as "the right thing to do" and might therefore be less accepting of divorce.

However, the results of the analysis of the correlation between the parent-child relationship and the child's attitude to divorce in children of divorced families (see Figure 5.7) was found to be only very slightly negative (a negative relationship would suggest that children with good relationships with their parents are accepting of divorce) and nonsignificant. This finding is contrary to the predictions of schema theory. According to schema theory, this relationship should be significant, as children who have good relationships with their divorced parents would need to accept divorce in order to assimilate their parents' divorce into their schemata of their parents as good people who do good things.

It becomes evident, however, that children who do not feel able to relate to their mothers tend to exert a strong influence on the data in this study. Where these cases are taken on their own, it is found that correlations are stronger and more positive for both married and divorced families (see Figure 5.8). It would appear, then, that where a child cannot relate to his / her mother (this has been seen in Figure 5.15a to strongly correlate with high child's attitude to mother (CAM) scores - that is, with having a problematic relationship with one's mother), that child will be inclined to be accepting of divorce, where his / her parents are married. This correlation is statistically significant in married families, and is positive, but is not significant in divorced families. Perhaps further analysis of those married families where this strong positive correlation existed between problematic mother-child relationships and child's acceptance of divorce might reveal that these children live in unhappy homes where they blame the mother for the family problems, and believe that they would be better off if their parents were to divorce. As mentioned 
in the results, these two samples each consist of only 6 respondents, so the significance of these findings should perhaps be treated with some caution.

However, it is interesting that it is these 6 respondents, in the married sample, who appear to give significance to the correlation between the mother-child relationship and the child's attitude to divorce: when only those respondents who did feel able to relate to their mothers were considered, the correlation no longer approached significance (see Figure 5.9). It seems, then, that children in married families who have good relationships with their mothers do not, in fact, hold consistently accepting or condemning attitudes to divorce. It would appear that, despite the initial appearance of some support for schema theory in terms of the existence of correlations, this analysis cannot be taken as conclusive evidence in favour of schema theory.

The results found for the correlation between the father-child relationship and the child's attitude to divorce are, on the surface, similar to those found for the mother-child relationship. As was the case with the mother-child relationship, respondents from married families who had good relationships with their fathers were significantly less accepting of divorce than were those who did not have good relationships with their fathers (see Figure 5.10). Where parents are divorced, no significant correlations exist between the father-child relationship and the child's attitude to divorce. Again this lack of a significant correlation does not support schema theory. Where the father-child relationship is problematic (that is, where the child does not feel able to relate to his / her father) a negative correlation bordering on significance exists with attitude to divorce (see Figure 5.11). This means that where the father-child relationship is problematic, these children are more accepting of divorce. However, for those respondents whose relationships with their fathers are more positive (see Figure 5.12), this correlation does not exist. It should also be remembered that, among the respondents unable to relate to their fathers, there was a respondent whose data, although apparently valid, exerted a fairly strong influence on this correlation. Again, although this negative correlation does, in itself, appear to support schema theory, this does not give sufficient grounds to accept this theory. 
It is possible that, should it be found that the attitude to divorce (ATD) questionnaire was indeed too overt a style of questioning, further research using a different measure of attitude to divorce might lend more support to schema theory than has the current research.

\subsubsection{Is there a correlation between attitude to divorce and adjustment?}

In the statistical analysis of the correlation between attitude to divorce and adjustment, adolescents from divorced and married families were considered separately. Although it was interesting that the correlation co-efficient for adolescents from divorced families was positive, while that for adolescents from married families was negative, the lack of significance of either correlation was sufficient to suggest that schema theory can again not be supported (see Figure 5.13).

However, a least square means graph was constructed to illustrate the existence of significantly different groups of scores (see Figure 5.14). It is interesting that, where respondents were less well adjusted (having lower life orientation questionnaire (LOQ) scores) their attitudes to divorce were not significantly different, whether they were from married or divorced families. However, where respondents were better adjusted, it was found that children from divorced families were significantly more accepting of divorce than were children from married families. It makes sense in terms of schema theory that well-adjusted children from divorced families would need to be more accepting of divorce in order to maintain their schemata (Janoff-Bulman, 1992), than well-adjusted children from married families.

\subsubsection{Can adjustment be predicted by attitude to divorce and / or parent-child relationship?}

It was found that the mother-child relationship was a significant predictor of variance in adjustment (see Table 5.1). Where a child has a strong relationship with his / her mother, this child would tend to be better adjusted than a child who does not have a good relationship with his / her mother. This relationship is confirmed by other research 
(Amato, 1996; Amato \& Keith, 1991; Grych \& Fincham, 1992; Kline et al., 1991; Tschann et al., 1989). It seems that a good, lasting relationship with a parent will buffer a child from the negative effects divorce might otherwise have on his / her adjustment.

However, attitude to divorce was not found to contribute significantly to the prediction of variance in adjustment (see Table 5.1). As adolescent adjustment cannot be predicted accurately from attitude to divorce, it would seem that schema theory could not be supported by this data.

Because schema theory is based on the assumption that schemata are difficult to change (Janoff-Bulman, 1992), it would only be those children who felt able to relate to the parent who had requested the divorce (and therefore saw that parent as a good person) who would be accepting of divorce. The results of the analysis of attitudes to divorce of children who could relate to the parent requesting the divorce, those who could not, and those whose parents had divorced by mutual consent (see Figure 5.16) were only bordering on significance. Furthermore, the group with the most distinctly accepting attitudes to divorce were those whose parents had divorced by mutual consent. However, in only 6 cases had the divorce been requested by a parent to whom the child could not relate, suggesting that further research may be needed to draw proper conclusions on this issue. Perhaps it is cognitively easier for a child to assimilate the divorce as a good thing if both of his / her parents believed it to be the best option. However, as only 4 cases existed where divorce was a mutual decision, this, too, would have to be researched further to be conclusive.

\subsection{LEARNING THEORY}

Learning theory predicts that a child will model the behaviour of a parent (in this study, this would refer to the adjustment behaviour of the parent), and further, that such modelling will only take place where the child feels able to relate to the model (the parent) (Baron \& Byrne, 1997). If learning theory is found to provide an adequate explanation of variance in children's adjustment to divorce, the results of analyses should show that where a parent is well adjusted, the child would exhibit better adjustment than where a parent has adjustment problems. It is believed that this emulation of a parent's 
adjustment behaviour will take place more where the child feels able to relate to the parent concerned.

\subsubsection{Adjustment of a child with a well-adjusted parent}

The results showed that the adjustment of children whose mothers had not experienced adjustment problems (measured on the life orientation questionnaire (LOQ)) was significantly better than that of children whose parents had experienced adjustment problems (see Figure 5.17). It appears, then, that learning theory may well provide an explanation of at least some of the variance in adjustment of adolescent children. It appears that well-adjusted mothers have well-adjusted children. According to learning theory this is because well-adjusted mothers would model good coping strategies to their children, resulting in their children's emulation of their good adjustment. This finding confirms that of research done by Linker et al. (1999).

Where the father's adjustment was considered, a similar relationship existed (see Figure 5.20). Where the father did not have adjustment problems, the child tended to have a higher adjustment (LOQ) score, indicating better adjustment, than when the father experienced adjustment problems. This difference was not statistically significant, but it was a distinct trend, bordering on significance, lending further support to learning theory.

It is uncertain why the mother's adjustment appears to have a stronger link to the child's adjustment than does the father's adjustment. Perhaps, as suggested by Kline et al. (1991), this is because the child's relationship with the father is of lesser importance than the relationship with the mother. It is also possible that this is the case because a number of children in this study see more of their mothers than their fathers. Of the 39 respondents studied, 27 were brought up primarily by their mothers, while only 4 were brought up primarily by their fathers. The remaining 8 were brought up by both parents. This would seem to lend support to the proposal that it is because of the more frequent contact these children had with their mothers, in general, that the mother would be more likely to be the model followed, simply because of her being available. 


\subsubsection{The impact on adjustment of an ability to relate to the parent}

Linker et al. (1999), in their studies of the modelling of adaptive behaviour, found that this transfer of good adjustment only took place where a good parent-child relationship existed. While there was a tendency for those able to relate to their mothers to be better adjusted (having higher adjustment (LOQ) scores) than those unable to relate to their mothers, this trend was not statistically significant (see Figure 5.18). It is possible that the lack of significance could be ascribed to the very small sample size (only 2 respondents with well-adjusted mothers felt unable to relate to their mothers).

Where a similar analysis was conducted using respondents whose mothers had experienced adjustment problems, results were significant (see Figure 5.19). Here, those able to relate to their mothers had significantly higher adjustment (LOQ) scores (indicative of better adjustment) than those with problems relating to their mothers. These results give strong support to learning theory, and to the research of Linker et al. (1999). It is clear that in both groups of mothers, trends existed whereby it could be seen that children who could relate to their mothers had higher adjustment scores than children not able to relate to their mothers. It seems that, not only does mother's adjustment influence child's adjustment, but also that this is the case to a greater extent where the child is able to relate to the mother. Unfortunately, given the fairly small sample sizes for those unable to relate to their mothers, further research would again be necessary to prove this conclusively.

The child's ability to relate to the father, however, did not exert an appreciable effect on the child's adjustment. Whether the father had or had not experienced adjustment problems, the child's adjustment was similar with or without an ability to relate to the father (see Figure 5.21). Again, given that the current sample had, for the most part, been brought up by their mothers, it is not surprising that the ability to relate to the father (and even to model his adjustment) would be less influential in the child's adjustment than the ability to relate to the mother (the primary role model). 


\subsection{CONCLUSIONS}

In the various analyses, there were some significant findings, and others that merely represented trends in the data that may or may not be explained by random variations. At this point, these findings will be looked at as a whole, and attempts will be made to draw conclusions from them.

Much of the research on divorce has suggested that divorce is problematic for the adjustment of the children concerned (Dankowski, 2001; Frost \& Pakiz, 1990; Swartzman-Schatman \& Schinke, 1993). While such a trend was found, this was not significant, and for this reason the current study cannot support this view. It must, however, be reiterated that the current study does represent a very specific group (educated students at a fairly affluent university). These conclusions should then be considered with caution where adolescents in general are concerned, as this sample may be particularly well adjusted on the whole.

It would appear that a stable, positive relationship between mother and child is strongly related to the good adjustment in the child. This particular sub-group in the study was, however, a small one, and further research on this issue is recommended in order to ascertain whether this is indeed the case. It must be noted here that, where the mother was concerned, all respondents having unchanged relationships with their mothers also had positive relationships with them. For fathers, this was not the case: of those with unchanged relationships, approximately half were problematic (see Figure 5.3). Further research must then seek cases where relationships with mothers are problematic both before and after divorce. Perhaps the significance of the role of stability in the motherchild relationship would decrease where such cases were included.

An interesting phenomenon is that the role of the father in the adjustment of the current sample appears to be relatively unimportant. This supported research by Kline et al. (1991). While stable relationships with mothers seemed to positively impact the adjustment of the child, no such effect was seen where the relationship with the father was considered. Furthermore, where correlations between the parents' adjustment and that of the child were analysed, the trend for the well-adjusted fathers to have well- 
adjusted children was not significant. The ability to relate to the father did not exert a significant influence on the child's adjustment either. The mother's adjustment, as will be discussed in more detail, had a fairly significant effect on the child's adjustment. As will be discussed again later, inspection of the data revealed that only 4 of the respondents from divorced families were brought up primarily by their fathers. Perhaps this could explain the relative unimportance of the father's role in this sample.

It was found that problematic pre-divorce circumstances in the home were positively related to attitudes to divorce. Where these circumstances had involved a lot of conflict and unpleasantness, children were significantly more accepting of divorce than where their home circumstances had been fairly friendly.

However, contrary to previous research (Allison \& Furstenberg, 1989), changes in the family's financial position did not appear to have any effect on whether or not the child was accepting of divorce. Again, it was proposed that this might be due to the nature of the sample used. This sample appears to be fairly affluent, suggesting that difficulties that might have been experienced with finances following the divorce have since been surmounted.

A fair number of the analyses conducted found no significant relationship between attitude to divorce and either adjustment or parent-child relationships. In some cases, this was quite contrary to expectations. While it is quite possible that the results found represent a marked lack of influence of the attitude to divorce on the variables concerned, other possibilities should not be excluded. The attitude to divorce (ATD) questionnaire used in the current study, as well as in previous research (Amato \& Rogers, 1999; Booth \& Edwards, 1989), used a very overt method of questioning. While this questionnaire was found to be both reliable and valid, it is possible that, for the purposes of the current study, a less direct method of questioning might have yielded different results. While it is beyond the scope of the current study to investigate this possibility, it is proposed that further research in this field use a less direct questioning method to analyse the attitudes to divorce held by respondents. It would be interesting to see whether this would change the results appreciably. 


\subsubsection{Schema theory}

While interesting trends were observed, too many of the findings were not significant. It can therefore not be concluded that schema theory offers an adequate explanation for the variance observed in adjustment, attitude to divorce and parent-child relationships. As predicted by previous research the parent-child relationship was a significant predictor of the child's adjustment. Schema theory, however, proposed that this link would be mediated by the child's attitude to divorce. In the analyses conducted it was found that attitude to divorce did not predict adjustment significantly, nor did the parent-child relationship predict attitude to divorce significantly. For these reasons, attitude to divorce cannot be considered a mediating variable.

Again, the observations concerning the overt attitude to divorce questionnaire used in this study must be brought to the fore. It is suggested that before discarding schema theory entirely as an explanation for the link between the parent-child relationship and the child's adjustment, further research should be conducted. This research should conduct similar analyses to those done in this project, but should use a more subtle method of evaluating the child's attitude to divorce. It is possible that this subject is still considered a fairly taboo one by adolescents. Perhaps declaring oneself openly in acceptance of divorce in the circumstances outlined in the ATD questionnaire is not considered acceptable by respondents, albeit anonymous ones.

\subsubsection{Learning theory}

This theory appears to provide the most adequate explanation of the findings in the current research. Not only was a very clear link found between the mother's adjustment and that of her adolescent child, but this link was also found to be significantly stronger where the child had a good relationship with the mother. Learning theory predicts that a child will model the behaviour of a parent (as is seen here in the apparent modelling of the mother's adjustment behaviour), and further, that such modelling will only take place 
where the child feels able to relate to the model (as is seen here where the link is stronger when the child can relate to the mother).

As was discussed previously, the father did not seem to exert as strong an influence on his child's adjustment. While this, on the surface, may appear to contradict learning theory, it was found that the majority of respondents were brought up primarily by their mothers. Therefore the finding that the father had a lesser effect on the adjustment of his children makes sense as interpreted by learning theory, as the child has far less contact with the father, and is therefore less likely to see the father as his / her model. As the current sample only had 4 cases where it was the father who had been responsible for the upbringing of the child, it is not really possible to see whether the father's adjustment would have impacted the child's adjustment more in these cases. Further research should possibly pay more attention to families in which the father was the primary caregiver, in order to see whether this would be the case.

It can be concluded, then, in the absence of further research on schema theory, that learning theory appears to offer a far more adequate explanation of the variance in children's adjustment to their parents' divorce than does schema theory. Children, even in adolescence, appear to emulate the adjustment behaviour modelled to them by the parent with whom they spend most of their time.

In conclusion, this study has confirmed the importance of a good relationship between parents and their adolescent children in helping those children to adjust to divorce. It has also pointed to the strong influence that parents' adjustment has on that of their children. It is believed that this knowledge can be used by parents going through a divorce. Perhaps an awareness of the importance of these two factors would help parents to focus on these issues with their children. A parent who is battling with adjusting to divorce him / herself might be encouraged that if he / she can maintain a positive relationship with his / her child, this could be of great help to that child. Parents with problematic marriages would do well to note that it is a consistently positive relationship both before and after divorce that has the most positive influence on the child's adjustment. Such 
parents might be able to build positive relationships with their children before divorce becomes an issue.

The concept of modeling positive adjustment is perhaps less easy to apply. However, the knowledge that their own adjustment can have a marked impact on that of their children might provide a purpose to those struggling with divorce. Being able to help one's child in this manner might give parents sufficient incentive to behave in as well-adjusted a fashion as possible.

But beyond informing parents, this research can be used by those working with couples who have divorced, or who are considering divorce. These people can design programmes for the families concerned where relationships between parents and children become a focal point. Further, therapists can work with parents to improve their ability to adjust to divorce, not only for their own sake, but also for the sake of their children. 


\section{REFERENCE LIST}

Allison, P.D., \& Furstenberg, F.F., (1989). How marital dissolution affects children: variations by age and sex. Developmental Psychology 25(4), 540 - 549 .

Amato, P.R. (1996). Explaining the intergenerational transmission of divorce. Journal of Marriage and the Family 58, 628 - 640.

Amato, P.R., \& Booth, A. (1991). The consequences of divorce for attitudes toward divorce and gender roles. Journal of family issues 12 (3), 306 - 322.

Amato, P.R., \& Keith, B. (1991)a. Parental divorce and the well-being of children: a meta-analysis. Psychological Bulletin 110(1), 26 - 46.

Amato, P.R., \& Keith, B., (1991)b. Parental divorce and adult well-being: a metaanalysis. Journal of Marriage and the Family 53, 43 - 58.

Amato, P.R., \& Rogers, S.J. (1999). Do attitudes toward divorce affect marital quality? Journal of Family Issues 20(1), $69-86$.

Antonovsky, A. (1979). Health, Stress and Coping. San Francisco: Jossey-Bass.

Antonovsky, A. (1991) Structural sources of Salutogenic Strengths. In C.L. Cooper \& R. Payne (Eds.) Personality and stress: Individual differences in the stress process. England: John Wiley \& Sons.

Antonovsky, H., \& Sagy, S. (1986). The development of a sense of coherence and its impact on responses to stress situations. The Journal of Social Psychology 12(2), 213 $-225$

Barker, J., Brinkman, L., \& Deardorff, M. (1995). Computer intervention for adolescent children of divorce. Journal of Divorce and Remarriage 23(3/4), 197 - 213. 
Baron, R.A., \& Byrne, D., (1997). Social Psychology. Massachussetts: Allyn and Bacon.

Block, J., Block, J., \& Gjerde, P.F., (1988). Parental functioning and the home environment in families of divorce: prospective and concurrent analyses. Journal of the American Academy of Child and adolescent Psychiatry 27(2), 207 - 213.

Booth, A., \& Edwards, J.N. (1989). Transmission of marital and family quality over the generations: the effect of parental divorce and unhappiness. Journal of Divorce $13,41-57$

Brown, J.H., Portes, P.R., \& Christensen, D.N. (1989). Understanding divorce stress on children: implications for research and practice. The American Journal of Family Therapy 17(4), 315 - 325.

Burns, A., \& Dunlop, R. (1999). "How did you feel about it?” Children's feelings about their parents' divorce at the time and 3 and 10 years later. Journal of divorce and remarriage $31(3 / 4), 19-35$.

Carstens, J.A., \& Spangenberg, J.J. (1997). Major Depression: a breakdown in sense of coherence? Psychological Reports 80, 1211 - 1220.

Dankowski, M.E. (2001). Pulling on the heart strings: an emotionally focused approach to family life cycle transitions. Journal of Marriage and Family Therapy 27(2), $177-187$.

Davies, P.T., \& Cummings, E.M. (1994). Marital conflict and child adjustment: an emotional security hypothesis. Psychological Bulletin 116(3), $387-411$.

Fincham, F.D. (1994). Understanding the association between marital conflict and child adjustment: overview. Journal of Family Psychology 8(2), 123 - 127. 
Flannery, R.B., \& Flannery, G.J. (1990). Sense of coherence, life stress and psychological distress: a prospective methodological inquiry. Journal of Clinical Psychology 46(4), $415-420$.

Forehand, R., Weirson, M., Thomas, A.M., Fauber, R., Armistead, L., Kemptom, T., \& Long, N. (1991). A short-term longitudinal examination of young adolescent functioning following divorce: the role of family factors. Journal of abnormal child psychology 19(1), $97-111$.

Franklin, K.M., Janoff-Bulman, R., \& Roberts, J.E. (1990). Long-term impact of parental divorce on optimism and trust: changes in general assumptions or narrow beliefs? Journal of personality and social psychology 59(4), 743 - 755.

Frenz, A.W., Carey, M.P., \& Jorgensen, R.S. (1993). Psychometric evaluation of Antonovsky's sense of coherence scale. Psychological Assessment 5(2), 145 - 153.

Frost, A.K., \& Pakiz, B. (1990). The effects of marital disruption on adolescents: time as a dynamic. American Journal of Orthopsychiatry 60, 544 - 555.

Glenn, N.D., \& Kramer, K.B. (1985). The psychological well-being of adult children of divorce. Journal of Marriage and the Family 47, 905 - 912.

Grotevant, H.D., \& Carlson, C.I. (1989). Family Assessment: A guide to methods and measures. New York: The Guilford Press.

Grych, J.H., \& Fincham, F.D. (1992). Interventions for children of divorce: toward greater integration of research and action. Psychological Bulletin 111(3), 434-454.

Harrist, A.W., \& Ainslie, R.C. (1998). Marital discord and child behaviour problems: parent-child relationship quality and child interpersonal awareness as mediators. Journal of Family Issues 19(2), 140 - 163. 
Howard, R.W. (1987). Concepts and Schemata. London: Cassell Educational.

Howell, D.C. (1995). Fundamental Statistics for the Behavioural Sciences $\left(3^{\text {rd }}\right.$ edition). USA: International Thomson Publishing.

Hudson, W.W. (1982). The Clinical Measurement Package. Illinois: Dorsey Press.

Janoff-Bulman, R. (1992). Shattered Assumptions. New York: Free Press.

Kalter, N. (1990). Growing up with divorce. New York: Free Press.

Kalter, N., \& Rembar, J. (1981). The significance of a child's age at the time of parental divorce. American Journal of Orthopsychiatry 51(1), 85 - 100.

Kline, M., Johnston, J.R., \& Tschann, JM. (1991). The long shadow of marital conflict: a model of children's postdivorce adjustment. Journal of Marriage and the Family 53, 297 - 309.

Lengua, L.J., Wolchik, S.A., \& Braver, S.L. (1995). Understanding children's divorce adjustment from an ecological perspective. Journal of Divorce and Remarriage $22(3 / 4), 25-52$.

Linker, J.S., Stolberg, A.L., \& Green, R.G. (1999). Family communication as a mediator of child adjustment to divorce. Journal of Divorce and Remarriage 30(1/2), 83 $-97$.

Louw, D.A. (1991). Human Development. Pretoria: Kagiso.

Mouton, J., \& Marais, HC. (1990). Basic concepts in the methodology of the social sciences. Pretoria: HSRC Publishers. 
Petersen, J.L., \& Zill, N. (1986). Marital disruption, parent-child relationships and behaviour problems in children. Journal of marriage and the Family 48, 295 - 307.

Petrie, K., \& Brook, R. (1992). Sense of coherence, self-esteem, depression and hopelessness as correlates of reattempting suicide. British Journal of Clinical Psychology 31, $293-300$.

Portes, P.R., Lehman, A.J., \& Brown, J.H. (1999). The child adjustment inventory: assessing transition in child divorce adjustment. Journal of Divorce and Remarriage $30(1 / 2), 37-45$.

Pryor, J. (1999). Waiting until they leave home: the experiences of young adults whose parents separate. Journal of Divorce and Remarriage 32(1/2), $47-61$.

Schwartz, L.L. (1992). Children's perceptions of divorce. The American Journal of Family Therapy 20(4), $324-332$.

Simons, R.L., Whitbeck, L.B., Beaman, J., \& Conger, R.D. (1994). The impact of mothers' parenting, involvement by nonresidential fathers, and parental conflict on the adjustment of adolescent children. Journal of Marriage and the Family 56, 628 - 640.

StatSoft, Inc. (2003). STATISTICA (data analysis software system), version 6. www.statsoft.com.

Stolberg, A.L., Complair, C., Currier, K., \& Wells, M.J. (1987). Individual, familial and environmental determinants of children's post-divorce adjustment and maladjustment. Journal of Divorce 11(1), $51-70$.

Swartzman-Schatman, B., \& Schinke, S.P. (1993). The effect of mid-life divorce on late adolescent and young adult children. Journal of Divorce and Remarriage 19 (1/2), $209-218$. 
Tschann, J.M., Johnston, J.R., Kline, M., \& Wallerstein, J.S. (1989). Family process and children's functioning during divorce. Journal of Marriage and the Family $51,431-444$. 


\section{APPENDIX 1: QUESTIONNAIRES}

THIS QUESTIONNAIRE AIMS TO SEE HOW YOU FEEL ABOUT DIVORCE.

IT IS NOT A TEST, SO THERE ARE NO RIGHT OR WRONG ANSWERS.

PLEASE CIRCLE THE APPROPRIATE NUMBER NEXT TO EACH QUESTION.

\begin{tabular}{l}
\cline { 2 - 6 } \\
\cline { 2 - 6 }
\end{tabular}


BIOGRAPHICAL INFORMATION

- PLEASE NOTE THAT FOR THE PURPOSES OF THIS QUESTIONNAIRE, "MOTHER" REFERS TO YOUR BIOLOGICAL MOTHER; AND "FATHER" TO YOUR BIOLOGICAL FATHER.

- SECTION B REFERS ONLY TO DIVORCED FAMILIES - IF YOUR BIOLOGICAL PARENTS ARE STILL MARRIED, PLEASE LEAVE THESE OUT.

- WHERE APPLICABLE, PLEASE PUT A CROSS (X) IN THE APPROPRIATE BOX

- YOUR COOPERATION IS GREATLY APPRECIATED! THANK YOU!

SECTION A

1. Your age:

2. Your sex:
$\square$ male
$\square$ female

3. Your religion: $\square$ Christian

$\square$ Muslim $\square$ Hindu

Jewish

$\square$ Atheist $\quad \square$ Other (specify

4. Yỏur current living arrangement:
$\square$ university residence
$\square$ flat / house with friend(s)
$\square$ alone in a flat / house / room
$\square$ with parent(s)

5. Your parents' marital status:
$\square$ married
$\square$ divorced (both parents single)
$\square$ mother remarried
$\square$ father remarried
$\square$ mother deceased
$\square$ father deceased

6. In the past year, how often have you seen / spoken to your mother?

$\square$ daily $\square$ few times a week $\quad \square$ weekly $\quad \square$ monthly $\quad \square$ few times a year $\quad \square$ never

7. In the past year, how often have you seen / spoken to your father?

$\square$ daily $\square$ few times a week $\quad \square$ weekly $\quad \square$ monthly $\quad \square$ few times a year $\quad \square$ never

8. Which of your parents was mainly responsible for your upbringing?
$\square$ mother
$\square$ father
$\square$ both

9. Do you feel that you can relate to your mother?
$\square$ yes
$\square$ no

10. Do you feel that you can relate to your father?
$\square$ yes
$\square$ no

11. Did your home situation play a role in your decision on where to study?

If yes, please briefly explain

\section{SECTION B (only answer if your parents are divorced)}

12. How old were you when your parents divorced?

13. Which parent requested the divorce?

$\square$ mother

$\square$ father

$\square$ mutual decision

$\square$ I am not sure 
14. At the time of the divorce, did you experience it as
$\square$ expected
$\square$ unexpected

15. What were your living arrangements after the divorce?

$\square$ lived only with mother $\square$ lived mainly with mother but saw father frequently

$\square$ lived only with father $\square$ lived mainly with father but saw mother frequently

$\square$ lived with family / friends

16. If your parents have been divorced for more than a year
a. How often did you see / speak to your mother after the divorce?
$\square$ daily $\square$ few times a week $\quad \square$ weekly $\quad \square$ monthly $\quad \square$ few times a year
$\square$ never
b. How often did you see / speak to your father after the divorce?
$\square$ daily $\square$ few times a week $\square$ weekly $\quad \square$ monthly $\square$ few times a year
$\square$ never

17. Following the divorce, did you experience a decline / drop in your financial situation (eg. move to a smaller house / worse neighbourhood; less money available)?
$\square$ yes
$\square$ no

18. What were the circumstances preceding the divorce?

$\square$ much fighting between parents; unpleasant $\quad \square$ fairly friendly; cooperative

$\square$ no contact between parents

19. What were the circumstances following the divorce?

$\square$ much fighting between parents; unpleasant $\quad \square$ fairly friendly; cooperative

$\square$ no contact between parents

20. How would you describe your mother's adjustment following the divorce?
$\square$ well-adjusted
$\square$ some problems
$\square$ severe / many problems

21. How would you describe your father's adjustment following the divorce?
$\square$ well-adjusted
$\square$ some problems
$\square$ severe / many problems

22. How did your relationship with your mother change after the divorce?
$\square$ improved
$\square$ deteriorated
$\square$ stayed the same

23. How did your relationship with your father change after the divorce?
$\square$ improved
$\square$ deteriorated
stayed the same 


\section{CHILD'S ATTITUDE TOWARD FATHER}

This questionnaire is designed to measure the degree of contentment you have in your relationship with your father. It is not a test, so there are no right or wrong answers. Answer each item as carefully and as accurately as you can by circling the relevant number next to each statement.

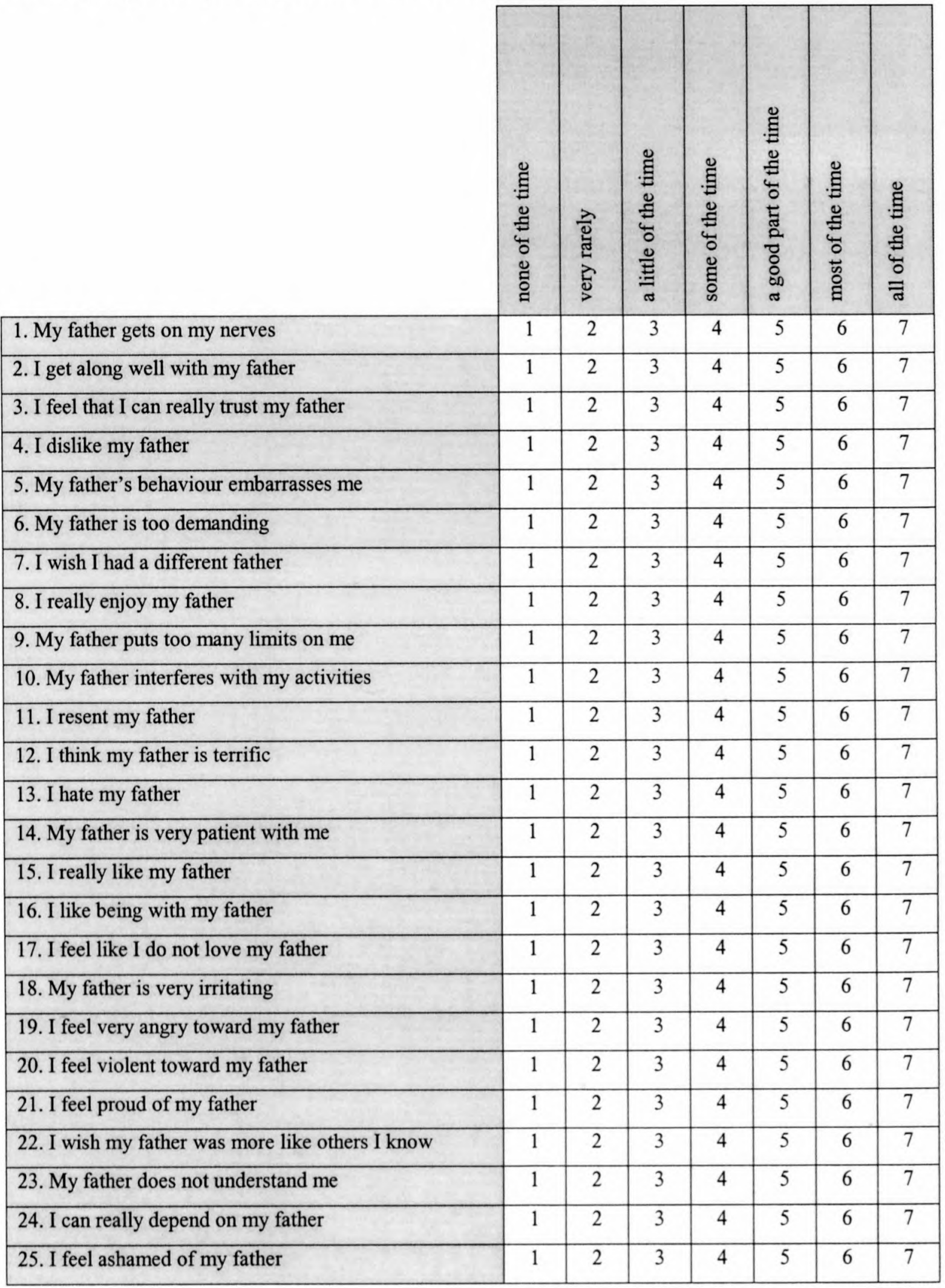




\section{CHILD'S ATTITUDE TOWARD MOTHER}

This questionnaire is designed to measure the degree of contentment you have in your relationship with your mother. It is not a test, so there are no right or wrong answers. Answer each item as carefully and as accurately as you can by circling the relevant number next to each statement.

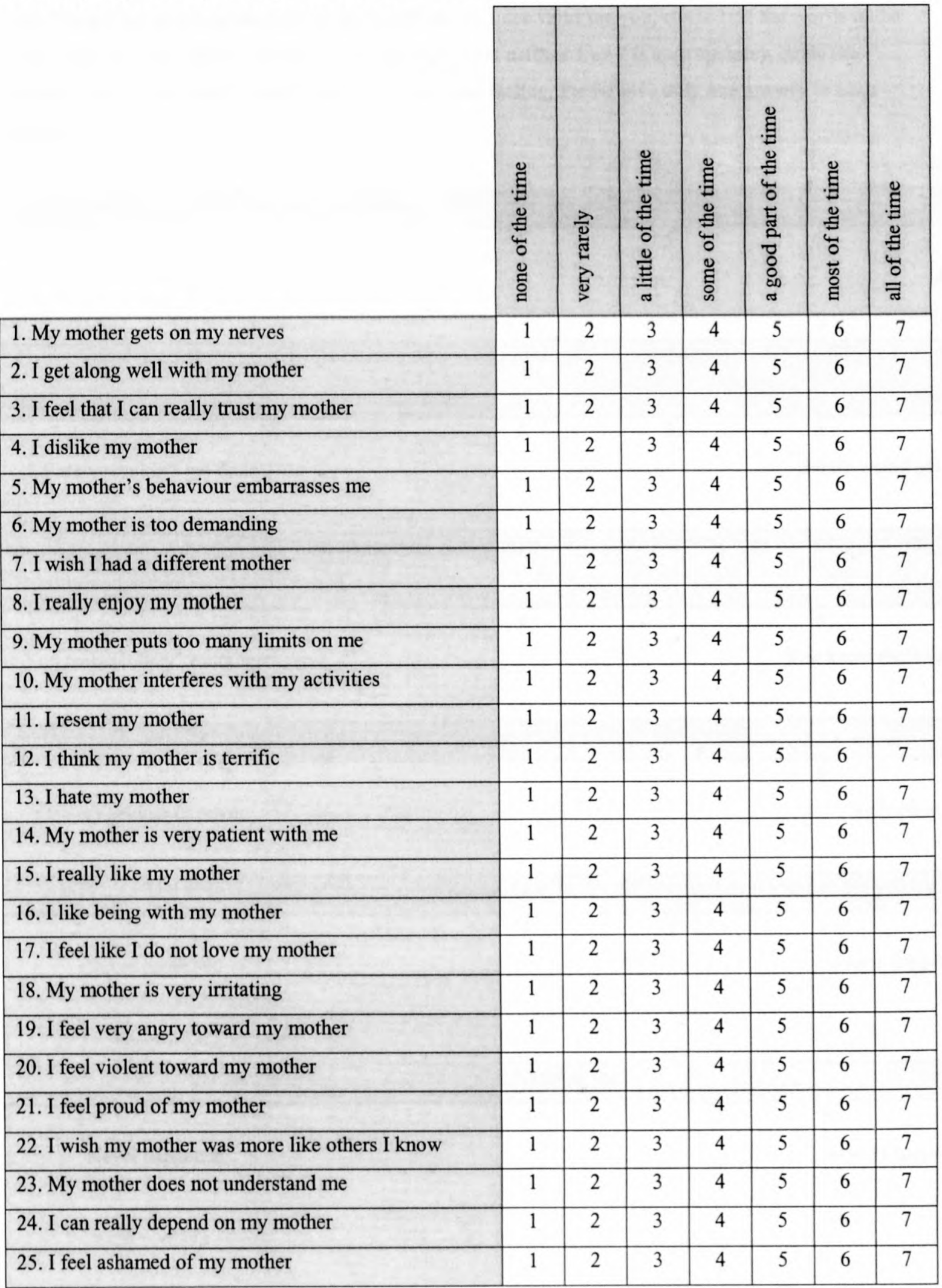




\section{ORIENTATION TO LIFE QUESTIONNAIRE}

The questionnaire contains a series of questions relating to various aspects of our lives. Each question has seven possible answers. Please circle the number which expresses your answer, with numbers 1 and 7 being the extreme answers. If the words under 1 are right for you, circle 1; if the words under 7 are right for you, circle 7 . If you feel differently (that neither 1 or 7 is appropriate), circle the number (between 1 and 7) which best expresses your feeling. Please give only one answer to each question.

1. When you talk to people, do you have the feeling that they don't understand you? 2

3

4

5

6 7

Never

Always

2. In the past, when you had to do something which depended upon co-operation with others, did you have the feeling that it:

1

2

3

4

6

7

Surely wouldn't get done

Surely would get done

3. Think of all the people with whom you come into contact daily, aside from the ones to whom you feel the closest. How well do you know most of them?

1

2 3 4 5 7

You feel that they're strangers

You know them very well

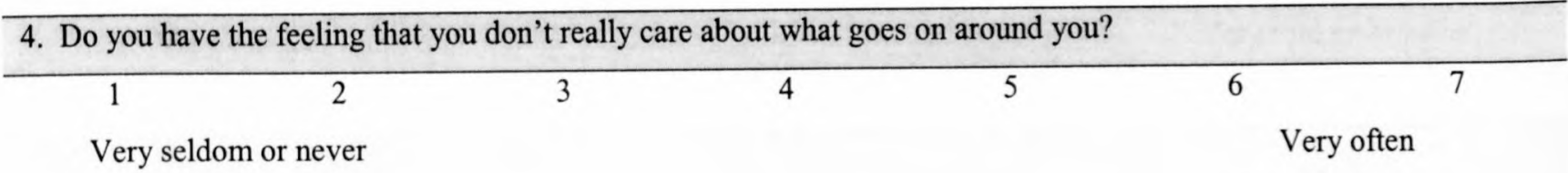

5. Has it happened in the past that you were surprised by the behaviour of people whom you thought you knew well?

$\begin{array}{llllllll}1 & 2 & 3 & 4 & 5 & 6 & 7\end{array}$

Never happened

Always happened

6. Has it happened that people whom you counted on disappointed you?

\begin{tabular}{rrrrr}
\hline 1 & 3 & 4 & 5 & 6 \\
Never happened & & & & Always happened
\end{tabular}




\section{Life is:}

1

2

3

4

5

Completely interesting

Full of routine

\section{Until now your life has had:}

$\begin{array}{lllll}1 & 2 & 3 & 4 & 5\end{array}$

No clear goals or purpose at all

Very clear goals and purpose

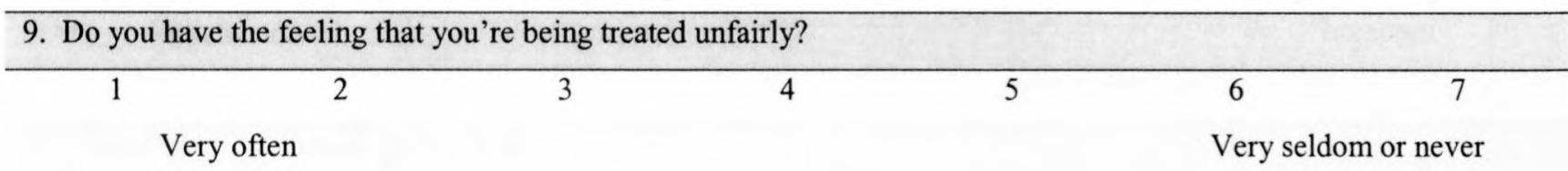

\begin{tabular}{l} 
10. In the past ten years your life has been: \\
\hline 1
\end{tabular}$\quad 3$
2

knowing what will happen next

11. Most of the things you do in future will probably be:

12304

Completely fascinating.

$\begin{array}{llll}4 & 5 & 7\end{array}$

Deadly boring.

12. Do you have the feeling that you are in an unfamiliar situation and don't know what to do?

\begin{tabular}{rrrrrr}
\hline 1 & 2 & 3 & 4 & 5 & 6 \\
Very often. & & & & Very seldom or never.
\end{tabular}

13. What best describes how you see life?

123

One can always find solutions

45

to painful things in life

There is no solution to painful things in life

14. When you think about your life, you very often:

12

Feel how good it is to be alive

34

4

5

6

7

Ask yourself why you exist

at all 
15. When you face a difficult problem, the choice of a solution is:

$\begin{array}{lllll}1 & 2 & 3 & 4 & 5\end{array}$

Always confusing and hard to

Always completely clear find

16. Doing the things you do every day is: 1 2 3 4 7

A source of deep pleasure and satisfaction

A source of pain and boredom

17. Your life in future will probably be:

1

2

3

Full of changes without your

knowing what will happen next

Completely consistent and clear

18. When something unpleasant happened in your past your tendency was: 1 2 3 4 5 7

To "eat yourself up" about it To say "ok, that's that, I have to live with it, and go

on

19. Do you have very mixed-up feelings and ideas?

2

34

4

Very often

6

7

Very seldom or never

20. When you do something that gives you a good feeling:

$\begin{array}{llll}1 & 2 & 3 & 4\end{array}$

45

6 7

It's certain you'll go on feeling

It's certain that something good will happen to spoil that feeling

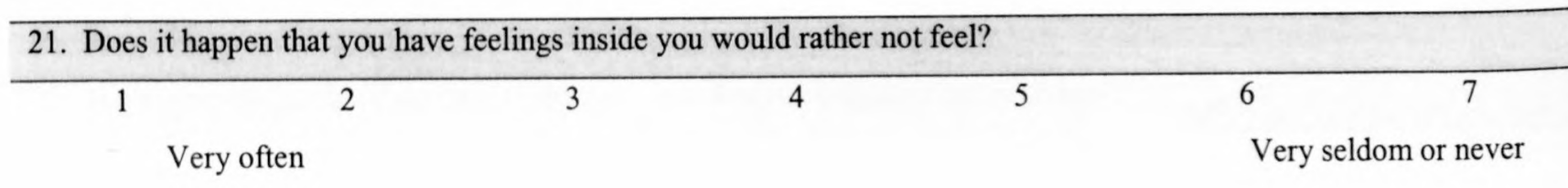


22. You anticipate that your personal life in future will be:

$12 \quad 3 \quad 4$

Totally without purpose and

$4 \quad 5$

7

meaning

Full of meaning and purpose

23. Do you think that there will always be people whom you'll be able to count on in the future?

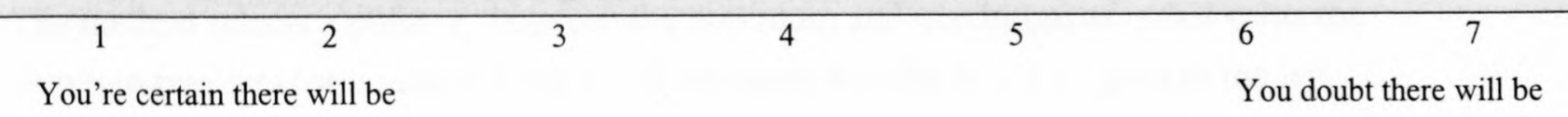

24. Does it happen that you have the feeling that you don't know exactly what's about to happen?

\begin{tabular}{ccccccc}
\hline 1 & 2 & 3 & 4 & 6 & 7 \\
& Very often & & & Very seldom or never
\end{tabular}

25. Many people, even those with strong character, sometimes feel like sad sacks (losers) in certain situations. How often have you felt this way in the past?

\begin{tabular}{llllllll}
\hline 1 & 2 & 3 & 4 & 5 & 6 & 7 \\
& & Never & & & & & Very often
\end{tabular}

26. When something happened, have you generally found that:

1 2 34

You overestimated or

45

$5 \quad 6$

You saw things in the right

underestimated its importance?

proportion?

27. When you think of difficulties you are likely to face in important aspects of your life, you have the feeling that:

$\begin{array}{lllll}1 & 2 & 3 & 4 & 5\end{array}$

7

You will always succeed in

You won't succeed in

overcoming the difficulties overcoming the difficulties

28. How often do you have the feeling that there's little meaning in the things you do in you daily life?
$\begin{array}{llcccc}\text { 28 } \\ \text { Very often }\end{array}$

29. How often do you have feelings that you're not sure you can keep under control?

1

23

4

5 7

Very often

Very seldom or never 


\section{APPENDIX 2: SUMMARY OF REGRESSION TREE METHODOLOGY}

In the case of regression trees the dependent (response) variable $y$ is a continuous variable. (For categorical response variables, a similar technique called classification trees can be used.)

\section{Case 1: One continuous independent variable $(x)$}

The method selects a point $x_{s}$ between the minimum and maximum of $x$ that splits the data into two sets (or nodes in a tree). All the cases for which $x \leq x_{p}$ goes to the left node and all the cases where $x>x_{p}$ goes to the right node.

The point where the split is made is the point that most successfully separates the high response values from the low ones.

The procedure above is then repeated for each of the two nodes. Thus a binary split is made on each node using the criteria mentioned above.

Stopping rules are used to decide when the splitting process should stop. For example a minimum number of cases per node can be specified, and if that minimum number is reached, the node will split no further.

\section{Case 2: One categorical independent variable}

In the case of a categorical independent variable, all combinations of binary splits of the levels of the variable are considered and the combination that most successfully separates the high response values from the low ones are used as splitting criteria. For example if a variable has three levels namely $a, b$ and $c$ then the following combinations of splits will be considered:

$\begin{array}{ll}\text { Left node } & \text { Right node } \\ & b, c \\ a, b & c \\ a, c & b\end{array}$

Case 3: More than one independent variable (combination of continuous and discrete) The procedure described above is applied to each variable independently. Then the variables are compared with one another and the one that provides the best split over all the variables is used as the splitting variable.

\section{Variable importance}

A variable importance factor in terms of its effect on the response variable can be derived once the tree has been built. This variable importance is calculated based on the number of times the variable was used as splitting variable and how well it separated the low values from the high values. 
APPENDIX 3: TABLE OF CODES FOR DATA SET

\begin{tabular}{|c|c|c|c|c|c|c|}
\hline $\begin{array}{l}\text { VARIABLE } \\
\text { NUMBER/NAME }\end{array}$ & 1 & 2 & 3 & 4 & 5 & 6 \\
\hline \multicolumn{7}{|l|}{ AGE } \\
\hline SEX & Male & Female & & & & \\
\hline RELIGION & Christian & Muslim & Hindu & Jewish & Atheist & Other \\
\hline LIVING ARR & $\begin{array}{l}\text { University } \\
\text { Residence }\end{array}$ & $\begin{array}{l}\text { Flat/House } \\
\text { with friends }\end{array}$ & $\begin{array}{l}\text { Alone in } \\
\text { flat }\end{array}$ & $\begin{array}{l}\text { With } \\
\text { parent(s) }\end{array}$ & & \\
\hline MAR/DIV & Married & Divorced & & & & \\
\hline $\begin{array}{l}\text { SEEN MOM } \\
\text { (INV) }\end{array}$ & Daily & $\begin{array}{l}\text { Few times a } \\
\text { week }\end{array}$ & Weekly & Monthly & $\begin{array}{l}\text { Few } \\
\text { times a } \\
\text { year }\end{array}$ & Never \\
\hline SEEN DAD (INV) & Daily & $\begin{array}{l}\text { Few times a } \\
\text { week }\end{array}$ & $\begin{array}{l}\text { Weekly } \\
\text { monthly }\end{array}$ & Monthly & $\begin{array}{l}\text { Few } \\
\text { times a } \\
\text { year }\end{array}$ & Never \\
\hline UPBRINGING & Mother & Father & Both & & & \\
\hline RELATE MOM & Yes & No & & & & \\
\hline RELATE DAD & Yes & No & & & & \\
\hline HOME ROLE & Yes & No & & & & \\
\hline \multicolumn{7}{|l|}{ AGE DIV } \\
\hline REQUESTED & Mom & Dad & Mutual & $\begin{array}{l}\text { Don't } \\
\text { know }\end{array}$ & & \\
\hline EXPECTED & Expected & Unexpected & $\begin{array}{l}\text { Too } \\
\text { young }\end{array}$ & & & \\
\hline $\begin{array}{l}\text { LIVING POST } \\
\text { DIV }\end{array}$ & $\begin{array}{l}\text { Only } \\
\text { mom }\end{array}$ & Only dad & $\begin{array}{l}\text { Mainly } \\
\text { mom }\end{array}$ & $\begin{array}{l}\text { Mainly } \\
\text { dad }\end{array}$ & $\begin{array}{l}\text { Family/ } \\
\text { friends }\end{array}$ & \\
\hline $\begin{array}{l}\text { POST MOM } \\
\text { (INV) }\end{array}$ & Daily & $\begin{array}{l}\text { Few times a } \\
\text { week }\end{array}$ & Weekly & Monthly & $\begin{array}{l}\text { Few } \\
\text { times a } \\
\text { year }\end{array}$ & Never \\
\hline
\end{tabular}




\begin{tabular}{|c|c|c|c|c|c|c|}
\hline POST DAD (INV) & Daily & $\begin{array}{l}\text { Few times a } \\
\text { week }\end{array}$ & Weekly & Monthly & $\begin{array}{l}\text { Few } \\
\text { times a } \\
\text { year }\end{array}$ & Never \\
\hline FINANCES & Yes & No & & & & \\
\hline CIRCS PRE & Fighting & $\begin{array}{l}\text { Co- } \\
\text { operative }\end{array}$ & $\begin{array}{l}\text { No } \\
\text { contact }\end{array}$ & & & \\
\hline CIRCS POST & Fighting & $\begin{array}{l}\text { Co- } \\
\text { operative }\end{array}$ & $\begin{array}{l}\text { No } \\
\text { contact }\end{array}$ & & & \\
\hline MOM ADJ & $\begin{array}{l}\text { Well- } \\
\text { adjusted }\end{array}$ & $\begin{array}{l}\text { Some } \\
\text { problems }\end{array}$ & $\begin{array}{l}\text { Severe } \\
\text { problems }\end{array}$ & & & \\
\hline DAD ADJ & $\begin{array}{l}\text { Well- } \\
\text { adjusted }\end{array}$ & $\begin{array}{l}\text { Some } \\
\text { problems }\end{array}$ & $\begin{array}{l}\text { Severe } \\
\text { problems }\end{array}$ & & & \\
\hline NEW REL M & Improved & Deteriorated & Same & & & \\
\hline NEW REL D & Improved & Deteriorated & Same & & & \\
\hline
\end{tabular}

